\title{
ANÁLISE NÃO-LINEAR DE PÓRTICOS PLANOS, CONSIDERANDO OS EFEITOS DO CISALHAMENTO NO CÁLCULO DE ESFORÇOS E DESLOCAMENTOS
}

André Luís Lima Velame Branco

\begin{abstract}
Dissertação apresentada à Escola de Engenharia de São Carlos, da Universidade de São Paulo, como parte dos requisitos para obtenção do Título de Mestre em Engenharia de Estruturas.
\end{abstract}

ORIENTADOR: Prof. Dr.Wilson Sérgio Venturini

São Carlos

2002 
A Deus, por mais esta oportunidade. 


\section{AGRADECIMENTOS}

Ao meu professor, orientador e amigo Wilson Sérgio Venturini, por todo o incentivo e apoio para o desenvolvimento deste trabalho.

À Fundação Coordenação de Aperfeiçoamento de Pessoal de Nível Superior (CAPES) pelo financiamento do projeto, através da bolsa de estudo concedida.

Aos professores de graduação da Universidade Federal da Bahia (UFBA), em especial à Tatiana Dumêt Bittencourt e Mônica Cristina Cardoso da Guarda, pelos conselhos e recomendações para inscrição no curso de mestrado da Escola de Engenharia de São Carlos, da Universidade de São Paulo (EESC-USP).

A todos os professores, funcionários e colegas da EESC-USP.

Aos colegas do Departamento de Engenharia de Estruturas da EESC que me ajudaram na complementação do trabalho: Rodrigo de Azevedo Neves, Faustino Sanches, Valério Silva Almeida, Selma Nóbrega.

Aos meus pais, pelo amor, apoio e companheirismo em todos os momentos desta empreitada.

Às minhas irmãs, Patrícia, Adriana e Ana Luiza, pelo amor e "torcida" incondicional.

Aos meus familiares, em especial a Marcelo Velame Branco dos Santos e à Adelena Gonçalves Maia.

Às novas e antigas amizades, que permanecerão sempre comigo, em especial à Vanessa Fragiácomo, Érico Bastos, Jackson Rangel, Pablo Marques, Clayton Moreira de Castro, Fernando Menezes e Gilberto Costa Couto. 
$\underline{\text { RESUMO }}$

CAPÍTULO 1: INTRODUCÃO

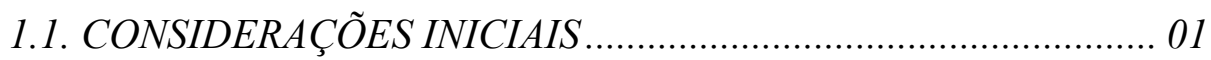

1.2. OBJETIVOS E JUSTIFICATIVAS …………………….............. 02

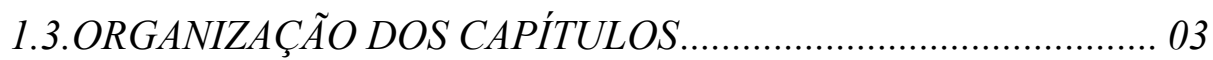

1.4. METODOLOGIA DE PESQUISA E DESENVOLVIMENTO ....... 04

1.5.REVISÃO BIBLIOGRÁFICA........................................................ 05

1.5.1. VIGAS DE TIMOSHENKO ……………………………………………..... 05

1.5.2. MODELO CONSTITUTIVO DE DANO ...................................................

1.5.3. ANÁLISE NÃO-LINEAR GEOMÉTRICA ............................................. 12

CAPÍTULO 2: VIGAS DE TIMOSHENKO............................ 14

2.1. CONSIDERAÇÕES INICIAIS ................................................... 14

2.2. DEDUÇÃO DA MATRIZ DE RIGIDEZ.................................. 15

2.3. ELEMENTO DE PÓRTICO PLANO COM TIMOSHENKO …..... 23 
CAPITULO 3: ANÁLISE NÃO-LINEAR ............................. 26

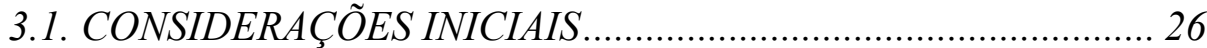

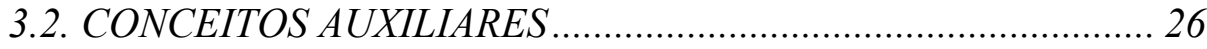

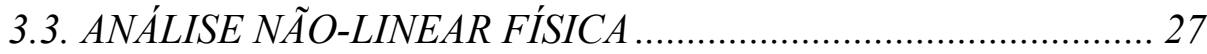

3.3.1. ANÁLISE NÃO-LINEAR FÍSICA NAS ARMADURAS ........................28

3.4. ANÁLISE NÃO-LINEAR GEOMÉTRICA ………………….......... 29

3.5. APLICAÇÃO DA NLG A PÓRTICOS PLANOS ........................... 32

3.5.1. DESCRIÇÃO DO CAMPO DE DESLOCAMENTOS ………………......32

3.5.2. RELAÇÃO DEFORMAÇÃO-DESLOCAMENTO ...................................33

3.5.3. RELAÇÃO ENTRE TENSORES DE TENSÃO E DEFORMAÇÃO......35

3.5.4. MATRIZ DE RIGIDEZ E VETOR DE ESFORÇOS INTERNOS............37

3.5.5. FORMULAÇÃO LAGRANGIANA ATUALIZADA............................... 40

CAPITULO 4: MODELO CONSTITUTIVO DE DANO ....... 42

4.1. CONSIDERAÇÕES INICIAIS................................................... 42

4.2. DESCRIÇÃO DO MODELO DE MAZARS …………………....... 43

4.2.1. ELEMENTO REPRESENTATIVO DE VOLUME ……......................... 44

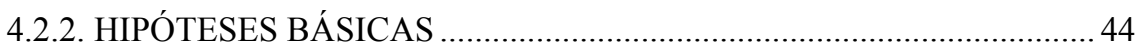

4.2.3. CRITÉRIO DE DANIFICAÇÃO ........................................................... 47

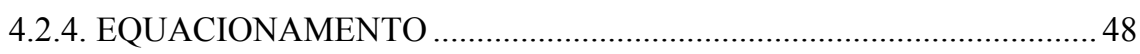

CAPITULO 5: IMPLEMENTACÃO NUMÉRICA ................. 52

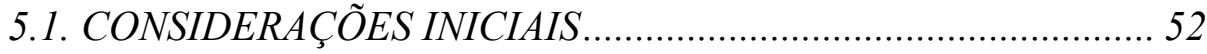

5.2. MECANISMO DE ATUAÇÃO DAS TENSÕES CISALHANTES.. 52

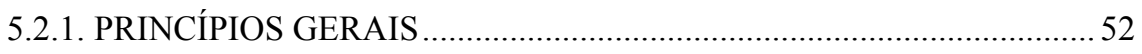

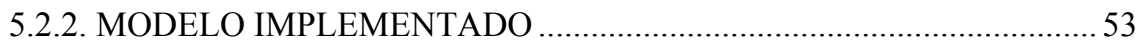

5.3. COMBINAÇÃO DO MODELO DE DANO COM A NLG ........... 54

5.3.1. MATRIZ DE RIGIDEZ E VETOR DE ESFORÇOS INTERNOS.......... 54

5.3.2. PROCESSO DE INTEGRAÇÃO NUMÉRICA ......................................... 57

5.3.3. PROCESSO DE NEWTON-RAPHSON ................................................... 59 


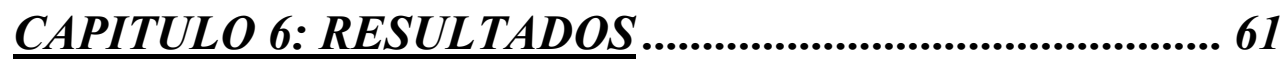

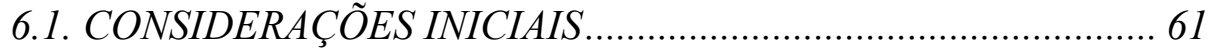

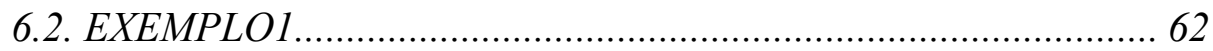

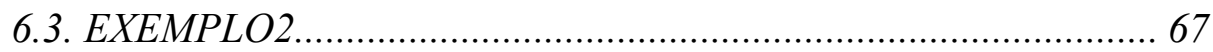

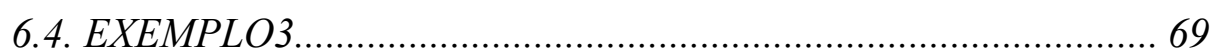

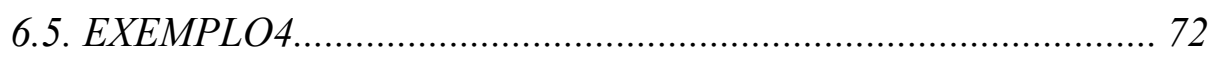

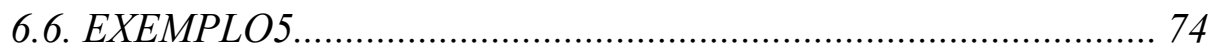

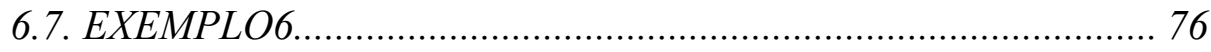

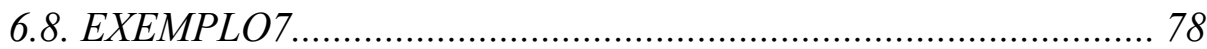

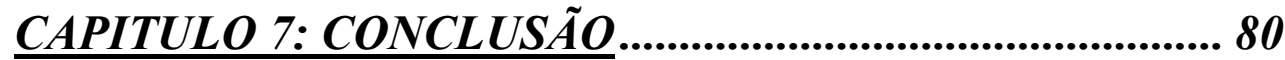

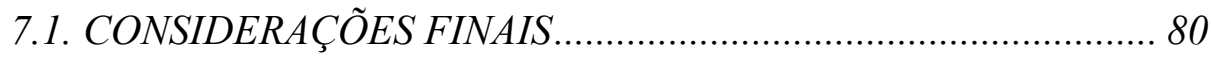

REFERENCIAS BIBLIOGRAFICAS.................................. 82

BIBLIOGRAFIA COMPLEMENTAR ...................................... 86

$\underline{A N E X O} \ldots$ 


\section{LISTA DE FIGURAS}

\section{CAPÍTULO 1:}

Figura (1.01): Efeitos de $1^{\mathrm{a}}$ e $2^{\mathrm{a}}$ ordens

\section{CAPÍTULO 2:}

Figura (2.01): Deformações em vigas considerando os efeitos de cisalhamento.............................14

Figura (2.02): Convenções de sinais do Método dos Elementos Finitos ............................................ 15

Figura (2.03): Configuração do elemento após as deformações, adaptada de NEVES (2000)... 16

Figura (2.04): Elemento de pórtico plano

\section{CAPÍTULO 3:}

Figura (3.01): Modelo elastoplástico com encruamento misto............................................................29

Figura (3.02): Barra rígida c/ carga concentrada transversal .........................................................2 29

Figura (3.03): Barra rígida c/ cargas concentradas transversal e longitudinal..............................30

Figura (3.04): Bifurcação do equilíbrio...........................................................................................30

Figura (3.05): Ponto limite ...................................................................................................................31

Figura (3.06): Deslocamento de pontos da barra …….......................................................................33

Figura (3.07): Deformação de uma fibra genérica - adaptada de Silva (1995)...............................35

Figura (3.08): Elemento de pórtico plano c/ Timoshenko nos sistemas global e local ..................37

\section{CAPÍTULO 4:}

Figura (4.01): Mecânica da fratura e mecânica do dano...........................................................................42

Figura (4.02): Elemento representativo de volume ..........................................................................44

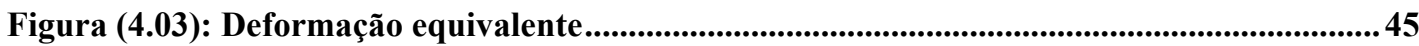

Figura (4.04): Diagramas do concreto à tração uniaxial ..................................................................4

Figura (4.05): Comportamento unilateral do concreto...................................................................48

Figura (4.06): Representação das variáveis de dano em função de $\tilde{\varepsilon}$...............................................49

Figura (4.07): Diagramas teóricos para o concreto...............................................................................49 


\section{CAPÍTULO 5:}

Figura (5.01): Distribuição real de tensões tangenciais ....................................................54

Figura (5.02): Distribuição média de tensões tangenciais ........................................................55

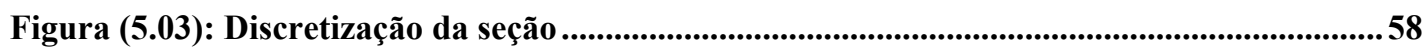

Figura (5.04): Distribuição de tensões................................................................................................58

\section{CAPÍTULO 6:}

Figura (6.01): Viga biapoiada (geometria e carregamento) ................................................62

Figura (6.02): Diagrama de momentos fletores (fig. 6.01) ........................................................62

Figura (6.03): Diagrama de esforços cortantes (fig. 6.01) ......................................................62

Figura (6.04): Viga em balanço (geometria e carregamento).....................................................63

Figura (6.05): Diagrama de momentos fletores (fig. 6.04) .......................................................64

Figura (6.06): Diagrama de esforços cortantes (fig. 6.04) ..............................................................64

Figura (6.07): Viga apoiada-engastada (geometria e carregamento) ..........................................65

Figura (6.08): Diagrama de momentos fletores (fig. 6.07).........................................................65

Figura (6.09): Diagrama de esforços cortantes (fig. 6.07) ......................................................65

Figura (6.10): Viga bi-engastada (geometria e carregamento) ...................................................66

Figura (6.11): Diagrama de momentos fletores (fig. 6.10) .......................................................67

Figura (6.12): Diagrama de esforços cortantes (fig. 6.10) ........................................................6 67

Figura (6.13): Geometria e carregamento da estrutura .............................................................67

Figura (6.14): Deslocamentos adimensionais v/l - Bernoulli.........................................................68

Figura (6.15): Deslocamentos adimensionais v/l - Timoshenko...................................................69

Figura (6.16): Geometria e carregamento da estrutura ..........................................................70

Figura (6.17): Gráfico força $x$ deslocamento horizontal do nó 7- pórtico da figura (6.16) ......... 70

Figura (6.18): Geometria e carregamento da estrutura ............................................................... 72

Figura (6.19): Gráfica força x deslocamento para viga da figura (6.18).....................................74

Figura (6.20): Geometria e carregamento da estrutura .........................................................75

Figura (6.21): Deslocamento horizontal do nó 11 da figura (6.20) ............................................... 75

Figura (6.22): Geometria e carregamento da estrutura ........................................................76

Figura (6.23): Deslocamentos verticais adimensionais - extremidade em balanço...................... 77

Figura (6.24): Geometria e carregamento da estruturada estrutura ............................................ 78

Figura (6.25): Deslocamentos verticais adimensionais - nó 14 ....................................................79

\section{ANEXO}

Figura (A.01): Elemento finito de pórtico plano - sistema global e local......................................A2

Figura (A.02): Viga bi-apoiada (dimensões em cm)...................................................................A4

Figura (A.03): Fluxograma do método de Newthon-Raphson - adaptada de PAULA (2001) ... A6 


\section{LISTA DE TABELAS}

\section{CAPÍTULO 4:}

Tabela (4.01): Particularização para deformação equivalente 46

Tabela (4.02): Particularizações para $\alpha_{T}$ e $\alpha_{C}$ e D

\section{CAPÍTULO 6:}

Tabela (6.01): Deslocamentos e rotações para o caso da figura (6.01) .63

Tabela (6.02): Deslocamentos e rotações para o caso da figura (6.04) ...................................... 64

Tabela (6.03): Deslocamentos e rotações para o caso da figura (6.07) ..........................................65

Tabela (6.04): Deslocamentos e rotações para o caso da figura (6.10) ..........................................66

Tabela (6.05): Deslocamento horizontal do nó 7 da figura (6.16) ........................................... 71

Tabela (6.06): Deslocamento vertical do ponto central da figura (6.18) .................................... 73 


\section{LISTA DE SÍMBOLOS}

\section{GREGOS}

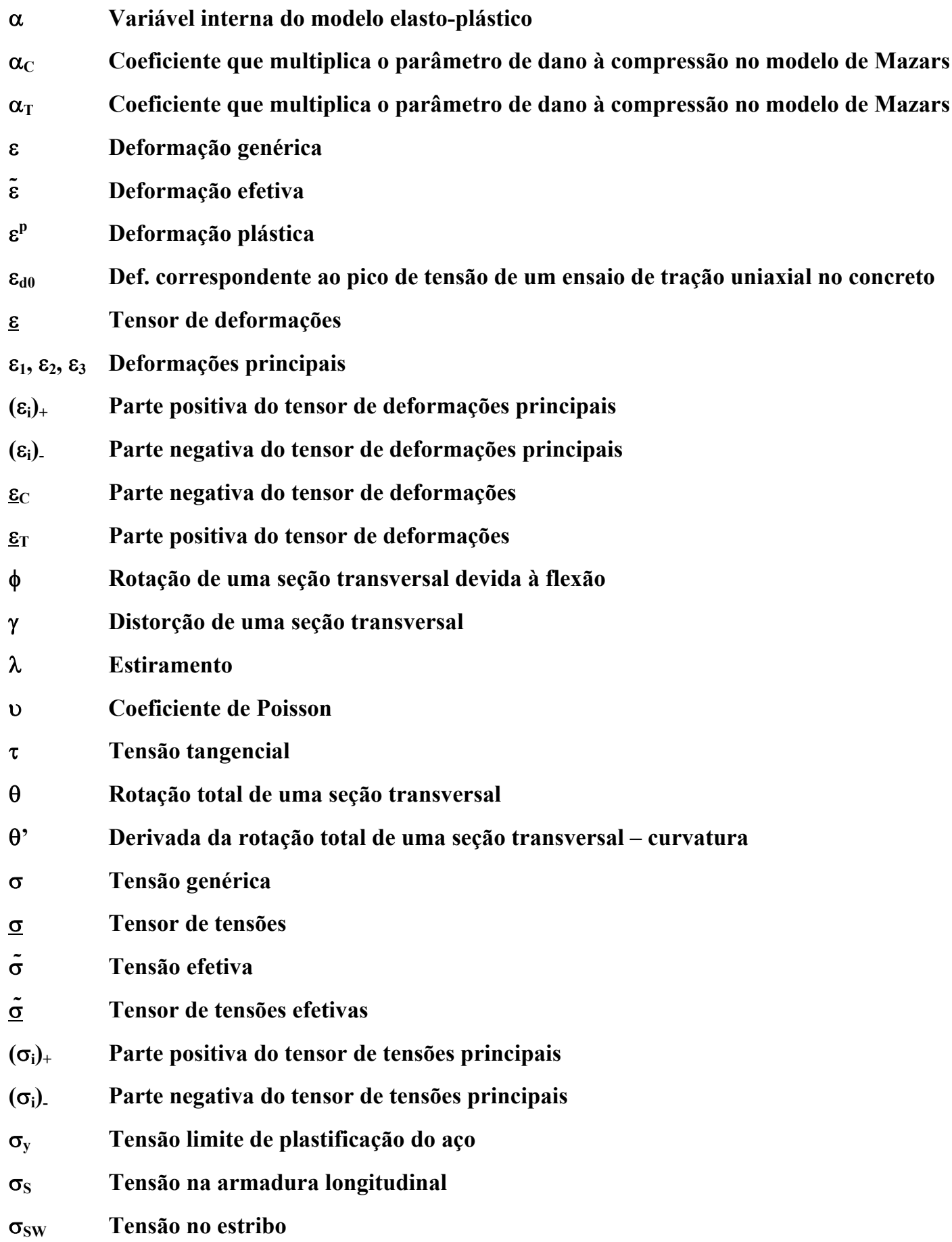




\section{ROMANOS}

1/r Curvatura de uma seção

A Área de uma seção

$A_{C}, B_{C}$ Parâmetros de dano à compressão do modelo de Mazars

$A_{T}, B_{T} \quad$ Parâmetros de dano à tração do modelo de Mazars

b Base da seção transversal de um elemento

B Matriz de incidência

D Variável escalar de dano do modelo de Mazars

D Variação do dano

$D_{\mathrm{C}} \quad$ Variável escalar de dano à compressão do modelo de Mazars

$D_{\mathrm{T}} \quad$ Variável escalar de dano à tração do modelo de Mazars

$\underline{\underline{D}}_{0} \quad$ Tensor elástico linear do material íntegro

E Módulo de elasticidade longitudinal do concreto

$\tilde{\mathbf{E}} \quad$ Módulo de elasticidade longitudinal do concreto danificado

$\mathrm{E}_{\mathrm{S}} \quad$ Módulo de elasticidade longitudinal do aço

$F^{\text {int }} \quad$ Vetor de esforços internos

$\mathrm{F}_{\mathbf{C}}(\tilde{\varepsilon}) \quad$ Função contínua e positiva da deformação equivalente do modelo de Mazars

$\mathrm{F}_{\mathrm{T}}(\tilde{\varepsilon}) \quad$ Função contínua e positiva da deformação equivalente do modelo de Mazars

$F_{C}(\tilde{\varepsilon}) \quad$ Função contínua e positiva da deformação equivalente do modelo de Mazars

g Parâmetro de Gere\&Weaver

G Módulo de elasticidade transversal

G Matriz de incidência (modelo NLG)

h Altura da seção transversal de um elemento

H Módulo de encruamento cinemático

I Momento de inércia de uma seção

$k \quad$ Fator de forma de uma seção

$K \quad$ Módulo de encruamento isótropo

K Matriz de rigidez de um elemento

$K_{T} \quad$ Matriz de rigidez tangente de um elemento

$K_{C} \quad$ Parcela de contribuição do concreto à matriz de rigidez de um elemento

$K_{S} \quad$ Parcela de contribuição da armadura long. à matriz de rigidez de um elemento

L Comprimento de um elemento

M Momento fletor atuante em uma seção

q carga distribuída em um elemento

S Área total de uma superfície

$\underline{S} \quad$ Tensor de tensões de Piolla

S Área resistente efetiva de uma superfície 


$\begin{array}{ll}\mathbf{S}_{\mathbf{0}} & \text { Área danificada de uma superfície } \\ \mathbf{u} & \text { Deslocamento longitudinal de um ponto } \\ \mathbf{U} & \text { Energia de deformação de um elemento } \\ \mathbf{v} & \text { Deslocamento transversal de um ponto } \\ \mathbf{V} & \text { Esforço cortante em uma seção } \\ \mathbf{W} & \text { Trabalho total } \\ \mathbf{W}_{\text {ext }} & \text { Trabalho das cargas externas } \\ \mathbf{W}_{\mathrm{i}} & \text { Pesos dos pontos de Gauss }\end{array}$




\section{RESUMO}

BRANCO, A. L. L. V. (2002). Análise não-linear de pórticos planos, considerando os efeitos do cisalhamento no cálculo de esforços e deslocamentos. São Carlos, 2002. 87 p. Dissertação (Mestrado) - Escola de Engenharia de São Carlos, Universidade de São Carlos.

Segundo modelos teóricos disponíveis na literatura, foi desenvolvido um algoritmo, com a correspondente implementação de um código computacional, baseado no Método dos Elementos Finitos, a ser aplicado a análises não-lineares físicas e geométricas de pórticos planos em concreto armado, nas quais são levadas em consideração as influências da tensão cisalhante e do processo de danificação do concreto associado ao nível de solicitação da estrutura. Levando-se em conta as hipóteses de Timoshenko, comprovou-se a eficiência da formulação proposta e a aproximação via método dos elementos finitos para a análise de estruturas aporticadas e para a determinação da rigidez de barras elásticas ou danificadas; o modelo é caracterizado como uma aproximação mais precisa que o modelo de Bernoulli para análise de vigas e de pórticos planos. Verificou-se que a formulação lagrangiana atualizada gera resultados bastante satisfatórios para a NLG, tanto para vigas como para pórticos planos, como ressaltado pelos exemplos e que o modelo físico proposto, baseado no modelo de dano de Mazars, apesar de muito rigoroso, leva a resultados de boa aplicabilidade prática. A combinação dos modelos de NLF e NLG, juntamente com a influência da distorção, levou a resultados muito bons. No entanto, para uma comprovação mais realista quanto a acuidade da formulação implementada, seria importante a comparação desses resultados a valores experimentais, que não foi possível nesse trabalho.

Palavras-chave: análise não-linear; mecânica do dano; vigas de Timoshenko; pórtico plano de concreto armado. 


\section{ABSTRACT}

BRANCO, A. L. L. V. (2002). Non-linear analysis of reinforced concrete plane frames, considering shear effects to compute internal forces and displacements. São Carlos, 2002. 87 p. Dissertação (Mestrado) - Escola de Engenharia de São Carlos, Universidade de São Carlos.

Following some well-known theoretical models, a numerical algorithm for reinforced concrete frames has been developed and the corresponding computer code implemented. The numerical model was based on the Finite Elements Method and can be applied to geometrical and physical non-linear plane frames analysis. The influences of the shear stresses are taken into account for both, linear and non-linear analyses. In the first case, the stiffness is modified according to Timoshenko's hypothesis. For physical nonlinear analysis, the stiffness is penalized on basis of a well-known damage model for which shear stresses are considered. The geometrical non-linear analysis has been introduced using an updated Lagrangean model. This accurate structural model has proved to be efficient and easily handled for practical purposes, therefore can replace safely similar codes based on Bernoulli's hypothesis. The combination of physical and geometrical non-linearties seems to be very accurate for practical applications, but experimentations maybe required confirming the accuracy of the proposed combined model.

Keywords: non-linear analysis; damage mechanics; Timoshenko's beam; reinforced concrete plane frames. 


\subsection{CONSIDERAÇÕES INICIAIS}

Os elementos estruturais de um edifício estão sujeitos basicamente a ações verticais, peso próprio e sobrecargas, e laterais. Em edifícios altos, as ações laterais devidas, por exemplo, à ação do vento e ao desaprumo, podem gerar deslocamentos que, em combinação com a carga vertical, transformam-se em acréscimo de momentos, conhecidos como efeitos de segunda ordem. Essas estruturas devem, portanto, ser analisadas segundo modelos que levem em conta a posição final de equilíbrio, como mostra a figura (1.01).
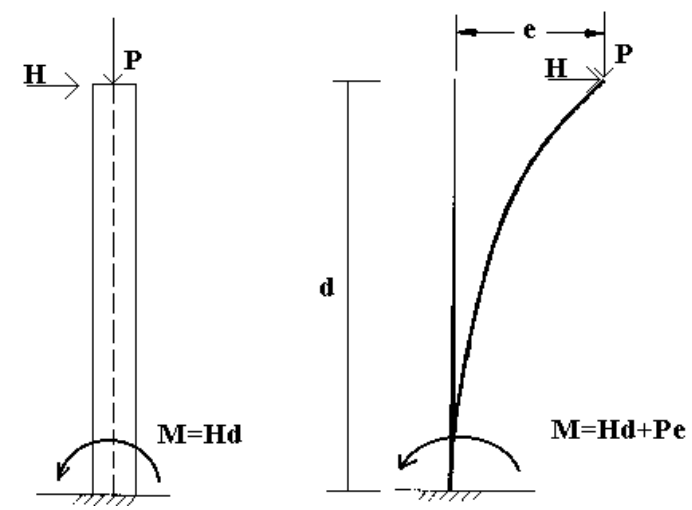

Figura (1.01): Efeitos de $1^{\mathrm{a}}$ e $2^{\mathrm{a}}$ ordens

Dentro deste contexto, surge o conceito de não-linearidade geométrica, no qual o equilíbrio da estrutura é imposto na posição deslocada, com o conseqüente aparecimento de esforços e deslocamentos adicionais, em vigas e pilares.

Outra característica que deve ser observada na avaliação de esforços e deslocamentos na estrutura de edifícios diz respeito ao modelo do comportamento do material, simplificadamente, a definição da curva tensão-deformação. No caso do concreto a 
relação tensão-deformação não é linear, isto é, o módulo de elasticidade $\mathbf{E}$ não é constante. De forma também simplificada, é possível dizer que o valor do momento de inércia $\mathbf{I}$ das seções transversais varia com o nível de solicitação, devido ao desenvolvimento da fissuração.

O fenômeno simplificado acima dá origem ao que se chama não-linearidade física, sempre presente nas estruturas de concreto, que deve ser considerado, por exemplo, na avaliação da estabilidade global de edifícios, como especificado no projeto de revisão da NBR - 6118 (2000).

Como amplamente já verificado por diversos autores, os deslocamentos laterais resultantes de análises estruturais são diretamente afetados pela rigidez dos membros constituintes da estrutura e, por isso, é preciso estimar a rigidez através de processos que considerem a não-linearidade física dos materiais empregados na estrutura.

A análise aproximada de estruturas de edifícios, através de pórticos planos, é uma simplificação bastante interessante do ponto de vista operacional (computacional e análise de resultados), por preservar facilidade de manipulação e entendimento de resultados levandoos ao projeto, sem grandes perdas da modelagem do comportamento da estrutura. Desta maneira, uma análise não-linear física e geométrica de pórticos planos em concreto armado, proposta neste trabalho, pode auxiliar significativamente a análise estrutural de um edifício.

\subsection{OBJETIVOS E JUSTIFICATIVAS}

Este trabalho tem como objetivo principal elaborar um algoritmo, com a correspondente implementação de um código computacional, baseado no Método dos Elementos Finitos, capaz de realizar análises não-lineares físicas e geométricas de pórticos planos em concreto armado, nas quais são levadas em consideração as influências da tensão cisalhante e do processo de danificação do concreto associado ao nível de solicitação da estrutura, segundo modelos teóricos disponíveis na literatura e detalhados nos capítulos seguintes.

Dessa forma, dá uma contribuição à engenharia de estruturas, disseminando a utilização de processos não-lineares - físicos e geométricos - mais sofisticados na análise estrutural, para obter resultados mais precisos e confiáveis do ponto de vista numérico e que, a partir da comparação com resultados experimentais, possam ser utilizados nos meios técnico e acadêmico como base para futuros trabalhos. 


\subsection{ORGANIZAÇÃO DOS CAPÍTULOS}

Ao se aplicar o Método dos Elementos Finitos à análise de determinado tipo de estrutura necessita-se, a priori, escolher o elemento que possua melhor desempenho para o modelo matemático adotado na representação. O Capítulo 2 discute a formulação numérica e as hipóteses básicas que regem o comportamento do elemento de viga de Timoshenko, o qual serve de base para formulação do elemento de pórtico plano implementado. O elemento de viga de Timoshenko utilizado possui dois nós e dois parâmetros nodais por nó, equivalentes à rotação e ao deslocamento transversal do ponto de referência da seção.

$\mathrm{O}$ que diferencia os elementos de viga tradicionais do elemento de viga de Timoshenko é o fato de, em sua formulação, este último levar em consideração o efeito da distorção que aparece em uma seção genérica provocada pela atuação da tensão cisalhante. Dessa forma, o deslocamento transversal engloba a parcela proveniente da flexão, acrescida da parcela proveniente do cisalhamento, sendo seu campo interpolado por um polinômio cúbico, enquanto que para a rotação da seção utiliza-se um polinômio interpolador quadrático independente. Ao se acrescentar a este elemento de viga mais um parâmetro nodal por nó, referente ao deslocamento longitudinal, obtém-se o elemento de pórtico plano com as hipóteses de Timoshenko.

O Capítulo 3 discute os aspectos gerais de uma análise não-linear, distingue dois tipos de não-linearidade e destaca, também, conceitos auxiliares importantes como o Princípio dos Trabalhos Virtuais e os conceitos básicos do Método dos Elementos Finitos.

O comportamento não-linear geométrico é estudado em teoria de $2^{\mathrm{a}}$ ordem e, dependendo das aproximações adotadas, pode gerar problemas de bifurcação do equilíbrio ou problemas de ponto limite. Para ser aplicado a pórticos planos foi adotado um modelo baseado na formulação lagrangiana atualizada, utilizando-se a medida de deformação de Green e a tensão de Piola-Kirchhoff de $2^{\mathrm{a}}$ espécie, em regime de pequenas deformações.

Como o concreto armado é um material composto por dois materiais distintos que trabalham em conjunto, os modelos teóricos adotados para representar a não-linearidade do concreto e da armadura também são distintos. Sob esse aspecto, a não-linearidade física da armadura segue o modelo de encruamento misto, que reduz o módulo de elasticidade das barras de aço a um valor obtido a partir de uma relação que envolve o módulo de elasticidade inicial, o módulo de encruamento cinemático e o módulo de encruamento isótropo, quando o valor da tensão, à qual a armadura está submetida, atinge o patamar de escoamento. 
Quanto ao concreto, os efeitos da sua não-linearidade física são analisados a partir de um modelo constitutivo de dano baseado na teoria do dano escalar proposta por Mazars, de modo que o módulo de elasticidade do concreto seja penalizado por uma variável escalar que varia de acordo com o nível de danificação do concreto na seção, conforme explicitado no

\section{Capítulo 4.}

A utilização desse modelo é justificada por sua eficácia em representar o comportamento não-linear físico do concreto tanto em situações complexas de solicitação, quanto em casos particulares como compressão ou tração uniaxiais, como comprovado por diversos trabalhos, inclusive aqueles realizados na própria EESC-USP.

O Capítulo 5 discute os aspectos relacionados à implementação numérica e destaca a combinação do modelo de dano com a formulação lagrangiana atualizada, para verificação da não-linearidade geométrica. Contempla, ainda, o modelo resistente dos esforços cortantes.

Com o intuito de confirmar a eficácia do modelo proposto, o Capítulo 6 contém exemplos analisados com o algoritmo implementado, cujos resultados são comparados aos: da bibliografia consultada, de programas comerciais e de experimentações realizadas na EESC - USP.

De posse desses resultados, o Capítulo 7 finaliza o trabalho com discussões acerca do modelo implementado e de sua eficiência, além de apresentar possíveis sugestões para incremento do modelo e para serem observadas em futuros trabalhos.

\subsection{METODOLOGIA DE PESQUISA E DESENVOLVIMENTO}

O desenvolvimento deste trabalho, de modo geral, seguiu as etapas mencionadas a seguir, de forma que, inicialmente, foi realizada uma pesquisa bibliográfica sobre os três assuntos básicos: Vigas de Timoshenko, Modelo Constitutivo de Dano e Análise Não-linear Geométrica.

$\mathrm{Na}$ etapa seguinte, foi implementado, em linguagem Fortran, um código computacional capaz de realizar análises não-lineares geométricas, baseada na formulação lagrangiana atualizada, de pórticos planos de concreto armado, em que o elemento estrutural utilizado é o elemento de pórtico plano segundo as hipóteses de Timoshenko e o modelo constitutivo é baseado no modelo de dano proposto por Mazars.

Para melhor adaptar o elemento de pórtico plano às hipóteses de Timoshenko, propôs-se o estudo de mecanismos de resistência ao cisalhamento em vigas de concreto armado, também fundamentado na mecânica do dano. 
Após a finalização das implementações propostas, realizou-se um estudo comparativo entre os resultados obtidos para diversas análises lineares e não-lineares, com e sem as hipóteses de Timoshenko, de modo a confirmar conclusões obtidas em outros trabalhos realizados na EESC-USP.

\subsection{REVISÃO BIBLIOGRÁFICA}

\subsubsection{Vigas de Timoshenko}

Pioneiramente, TIMOSHENKO (1955) iniciou a fundamentação do elemento de viga que considera em sua formulação a distorção provocada pelas tensões cisalhantes. Em TIMOSHENKO\&GERE (1983) e TIMOSHENKO\&GERE (1984) podem ser encontradas discussões importantes sobre a teoria e a formulação das chamadas vigas de Timoshenko.

COWPER (1966) obteve as equações gerais da teoria de vigas a partir da integração das equações da teoria da elasticidade tridimensional, possibilitando nova formulação para que seja obtido o coeficiente de distorção que aparece no cálculo. Essa formulação determina valores numéricos para o coeficiente de distorção para diversos tipos de seções, entre elas: as circulares, as retangulares, as elípticas, as semicirculares e as de paredes finas.

Ao comparar os resultados de seu trabalho com os valores obtidos por outros autores, COWPER concluiu que eles estão bem próximos, exceto quanto aos valores obtidos por TIMOSHENKO. COWPER considerou esse fato muito interessante, uma vez que os diversos autores utilizaram métodos bastante distintos.

Sob outra perspectiva, o propósito do trabalho de NARAYNASWAMI\&ADELMAN (1974) foi demonstrar que a minimização contínua da energia produz o correto comportamento do elemento finito de viga, quando os efeitos do cisalhamento são incluídos, e que os graus de liberdade adicionais não colaboram no tratamento desses efeitos.

Os autores destacaram a importância de se tomar a rotação de flexão como grau de liberdade ao invés da derivada da deflexão e justificam a escolha com base na continuidade apresentada por ela quando se combina dois ou mais elementos, mesmo na presença dos efeitos cisalhantes. Concluíram que o uso do procedimento proposto leva à obtenção correta da matriz de rigidez do elemento de Timoshenko sem necessidade de graus de liberdade 
adicionais e que os resultados obtidos com o elemento utilizado comprovam o acerto na escolha da rotação de flexão como parâmetro nodal.

THOMAS\&ABBAS (1975) apresentaram um modelo de elemento finito com graus de liberdade que satisfazem todas as condições de contorno naturais e essenciais da viga de Timoshenko para análise dinâmica, de modo que as matrizes de rigidez e de massa do elemento são deduzidas a partir das energias de deformação e cinética e assumem polinômios para interpolar o deslocamento total e a rotação.

Propuseram, portanto, um elemento com dois nós e quatro graus de liberdade por nó: deflexão total, rotação total, rotação de flexão e sua derivada. Dessa forma garantiram que esse elemento representa a análise dinâmica da viga de Timoshenko de modo mais preciso e eficiente que os demais modelos de elementos existentes, pois é o único que aplica, corretamente, as condições de contorno do problema. Sendo assim, concluíram que a convergência dos resultados obtidos com o modelo é muito rápida, mesmo para discretizacões pobres.

Em GERE\&WEAVER (1987) encontra-se o modelo de Timoshenko usando a forma exata da elástica, portanto evitando o problema do travamento da solução. Por esse motivo, é um modelo com desempenho melhor que o dos modelos propostos por BATHE (1996), NÓBREGA (1997) e RIGITANO (1998), que utilizaram interpolações lineares tanto para deslocamentos transversais quanto para rotações, o que faz com que o modelo se torne muito rígido para as vigas pouco deformáveis ao cisalhamento, ocorrendo então o travamento.

No intuito de permitir que engenheiros projetistas facilmente possam obter soluções de TIMOSHENKO sem que necessariamente sejam desenvolvidas análises mais complexas de deformações por flexão e cisalhamento, WANG (1995) apresentou as flechas e tensões resultantes de vigas de Timoshenko com carregamentos e condições de contorno quaisquer, associadas às soluções correspondentes na teoria de BERNOULLI.

Para tanto, WANG considerou seis combinações distintas de condições de contorno para uma viga de vão único e para cada um delas determinou os valores dos coeficientes presentes na função interpoladora dos deslocamentos transversais. A partir da análise desses coeficientes propôs relações para obtenção do momento fletor e do esforço cortante e verificou que, para vigas estaticamente determinadas, esses valores não divergem entre as duas teorias, o que não acontece nas vigas estaticamente indeterminadas. Concluiu reafirmando a praticidade desse modelo para projeto e destacou a importância da determinação correta da rigidez à flexão e ao cisalhamento de vigas sanduíche. 
Dentre os trabalhos produzidos na EESC-USP destacam-se os de RIGITANO (1998) e NEVES (2000); este último serviu de referência inicial. Atualmente, SANCHES (2002 - tese em andamento) também desenvolve um trabalho no qual implementa o modelo de Timoshenko tomando rotação total da seção como parâmetro nodal.

NEVES (2000) implementou o modelo de dano de MAZARS (1984) em um código computacional aplicado ao cálculo de deslocamentos e esforços em grelhas de concreto armado, considerando a influência das tensões cisalhantes. Para considerar a influência das tensões cisalhantes, empregou-se, nesse trabalho, a teoria de vigas de Timoshenko na obtenção da matriz de rigidez do elemento de grelha, tomando como base para sua formulação o procedimento proposto por GERE\&WEAVER (1987).

Além disso, revisou o modelo da treliça clássica de Mörsch que serviu como base para a formulação de um modelo de resistência de esforços cortantes em uma seção transversal de concreto armado. Simplificadamente, NEVES considera que as tensões cisalhantes residuais são totalmente absorvidas pela armadura transversal.

Comparou os resultados provenientes de análises elásticas e análises não-lineares, tanto considerando as hipóteses de Bernoulli como as de Timoshenko e concluiu que a análise não-linear com as hipóteses de Timoshenko, além da simplificação adotada para o modelo de resistência de esforços cortantes, leva a resultados mais condizentes com o comportamento real das peças de concreto armado sujeitas à flexão, uma vez que é significativa a influência da distorção no trecho pós-elástico da curva tensão $\mathrm{x}$ deformação de vigas curtas.

\subsubsection{Mecânica do Dano Contínuo}

KACHANOV (1958), pioneiramente, iniciou a fundamentação da teoria do dano contínuo ao introduzir o conceito de dano para descrever o processo de formação de fissuras na ruptura frágil por fluência em metais solicitados uniaxialmente à tração para elevadas temperaturas, com adoção de uma variável interna de dano nas relações constitutivas.

A partir desse trabalho, muitos pesquisadores contribuíram para o desenvolvimento desse campo de pesquisa. Mas os avanços foram pouco significativos devido às dificuldades impostas pelos processos matemáticos adotados no modelo. Apenas recentemente a Mecânica do Dano Contínuo teve sua teoria formalizada segundo a termodinâmica dos processos irreversíveis. 
O trabalho de CABOCHE (1988) revisou alguns aspectos gerais da Mecânica do Dano Contínuo e resumiu suas principais possibilidades. Dentre os importantes aspectos levados em consideração por CABOCHE, pode-se dar destaque primordial à preocupação em definir e mensurar o dano, com descrição do estado danificado da microestrutura através de variáveis mecânicas apropriadas. Ele afirmou ser importante caracterizar, com precisão, o estágio correspondente ao início do processo de fissuração responsável pela fragmentação do elemento contínuo de volume; discutiu as possibilidades de utilização do conceito de vida útil e da observação e quantificação dos defeitos irreversíveis como forma de definição do dano e propôs que essa definição fosse feita a partir de parâmetros físicos e do conceito de tensão efetiva.

Esse estudo abordou outro aspecto, quanto ao comportamento mecânico do material que sofreu dano, analisado com base na termodinâmica dos processos irreversíveis, limitado por hipóteses de pequenas deformações e dano isótropo.

O último aspecto considerado é a formulação das equações que governam a evolução das variáveis de dano analisadas anteriormente, que podem ser utilizadas tanto para melhorar as técnicas da vida útil adotadas nos cálculos de evolução do dano e do processo de formação de fissuras em estruturas de concreto armado, como para melhorar os procedimentos de cálculo relacionados à evolução das fissuras macroscópicas, baseadas nos conceitos da Mecânica da Fratura. Finalmente, CABOCHE concluiu que um dos principais aspectos da Mecânica do Dano Contínuo é levar em conta o efeito conjunto entre processos de dano e comportamento da relação tensão x deformação, além de permitir possibilidades adicionais na análise de aproximações locais para a fratura.

Esse trabalho foi um dos primeiros a fazer essa abordagem e, apesar de limitar-se às hipóteses de pequenas deformações, dano isótropo e encruamento isótropo, mesmo quando conhecidas as formulações para o encruamento cinemático e para a teoria do dano anisótropo -proposta anos antes pelo próprio CABOCHE - teve como principal mérito a analogia com a termodinâmica.

No trabalho de MAZARS \& PIJAUDIER-CABOT (1989) faz-se uma revisão dos diferentes modelos baseados na Mecânica do Dano Contínuo até então formulados, bem como discutem-se a anisotropia induzida, comportamento dúctil e efeitos unilaterais, juntamente com análises numéricas que, segundo a termodinâmica dos processos irreversíveis, descrevendo o processo de ruína e de forma bem precisa o comportamento do concreto.

Nesse trabalho apesar das limitações e hipóteses de cada modelo, os autores obtiveram resultados muito próximos dos experimentais e sugeriram adequação coerente 
entre modelos e casos propostos. Concluíram também que a teoria da Mecânica do Dano Contínuo e o conceito de variável interna possuem a vantagem de promover uma teoria mais ampla e englobam muitos modelos baseados na termodinâmica, e verificaram também que o efeito de anisotropia pode ser útil ao entendimento do comportamento e do processo de colapso de elementos estruturais.

KRAJCINOVIC (1989) revisou os principais modelos utilizados e destacou as relações tensão $\mathrm{x}$ deformação em sólidos sujeitos à danificação causada por diferentes mecanismos de fissuração como concreto, rochas, materiais cerâmicos e certos sólidos frágeis. Nessa revisão, enfatizou que a evolução do dano tem início com a formação de um núcleo de fissuração que, posteriormente, tem sua abertura alargada e termina com a reunião das diversas microzonas danificadas (coalescência), com formação de uma macrozona danificada.

Conclui-se, portanto, que as diferenças entre tais modelos podem ser resumidas na escolha da expressão da energia de deformação e na escolha da representação matemática para a variável do dano. Consequentemente, torna-se necessário introduzir simplificações que, em alguns casos, podem limitar a aplicabilidade desses processos simplificados.

PEREGO (1989) fez a análise numérica do modelo de MAZARS (1984) com auxílio do método dos elementos finitos e concluiu que a utilização da Mecânica do Dano é uma das soluções viáveis para problemas não lineares. Sugere, porém, para futuros trabalhos, que a solução pode ser refinada se forem levados em consideração o comportamento interativo entre concreto e aço, com possível plastificação da armadura.

ÁLVARES (1993) utilizou o modelo de MAZARS (1984) associado à formulação do método dos elementos finitos, e comparou os resultados numéricos com resultados experimentais de vigas de concreto armado ensaiadas nos laboratórios da EESC-USP, o que possibilitou a calibragem dos parâmetros do modelo.

Como alternativa para o dano no material concreto pode ser adotado um modelo elastoplástico ou um modelo de plasticidade com dano. CHEN (1994) fez um amplo estudo sobre modelos elastoplásticos aplicados a concreto. Discutiu, também, o comportamento softening pós-pico do concreto, a partir da descrição de uma formulação baseada na combinação entre a teoria da plasticidade e a mecânica do dano.

CHEN também comentou algoritmos numéricos e desenvolvimento de programas computacionais para esse tipo de modelo e o papel da interface pasta de cimento-agregado no entendimento do comportamento do concreto em nível microscópico. Concluiu sugerindo que o desenvolvimento e a aplicação de modelos específicos combinando os modelos elatoplásticos com o dano deva ser o procedimento mais correto para a modelagem do 
concreto, contudo destaca a necessidade de torna-los práticos e absorvíveis pelo meio técnico.

PAAS et al. (1993) adotaram uma aproximação contínua do dano para descrever o mecanismo de ruptura frágil a partir do estabelecimento de uma relação tensão $\mathrm{x}$ deformação, baseada no conceito de tensão efetiva e deformação equivalente, e de uma equação de evolução do dano associada a um critério de danificação. Analisaram, também, o mecanismo de ruptura por fadiga, cujo critério de danificação diferencia-se do critério de ruptura frágil devido à invariabilidade da superfície de dano e se utiliza desse modelo para gerar modelos aceitáveis de dano cumulativo.

Finalizaram o trabalho com análise do processo de propagação de uma fissura induzida em uma placa com carregamento periódico que obedece leis específicas para a evolução do dano. Sem outras referências, qualificaram os resultados obtidos como promissores e concluíram que o emprego de algoritmos incrementais, para resolver numericamente as equações propostas pelos modelos, reduz significativamente o esforço computacional.

Em resumo, propõem um modelo isótropo de dano aplicado à ruptura de materiais frágeis, cujo processo dissipativo depende da expansão do quadro de fissuração, e faz com que as relações tensão $\mathrm{x}$ deformação sejam penalizadas por um fator referente à danificação, associadas a um critério de evolução do dano.

DIAO (1995) propôs uma teoria de dano com fundamento estatístico para o dano a partir da combinação entre Mecânica do Dano Contínuo, Física do Desequilíbrio Estatístico e Mecânica da Fratura que considera o processo de evolução dos microdefeitos como processo elementar de degradação da estrutura do material, que pode ser caracterizado como evolução da teoria de KACHANOV da qual, no entanto, questiona o significado físico das variáveis de dano.

Ao debater a clareza física e a coerência matemática da definição da variável de dano adotada pela Mecânica do Dano Contínuo, afirma que a formulação precisa ser melhorada para dar, à variável do dano, definição fisicamente aceitável e fornecer nova equação para a evolução do dano que possa ser diretamente relacionada ao micromecanismo de dano da estrutura.

Para tanto, ele apresentou uma equação que, segundo seu ponto de vista, supera essas falhas e concluiu ser sua teoria mais vantajosa, por definir a variável do dano de acordo com um significado físico coerente e considerou que a equação estatística de evolução do dano é mais consistente que a equação cinemática do dano proposta por KACHANOV na descrição do material danificado, uma vez que caracteriza o dano no material em todas as 
etapas de evolução dos microdefeitos. Contudo, DIAO (1995) considera que sua teoria precisa ser desenvolvida para levar em consideração a interação entre microdefeitos.

DRIEMEIER (1995) utilizou implementação numérica baseada na técnica dos elementos finitos para estudar o comportamento de vigas de concreto armado sujeitas a solicitações cíclicas, com modelo de dano que se apresenta como extensão do modelo de MAZARS (1984). Destacou, também, o comportamento microestrutural do concreto sujeito a cargas repetidas.

BURR (1995) ressaltou a importância do entendimento dos mecanismos físicos de propagação do dano e de seu devido correlacionamento com a resposta de testes mecânicos. Verificou que a adoção de uma variável de dano tensorial conduz a melhores resultados em materiais como concreto, cujas propriedades elásticas variam com a direção de análise, devido à sua anisotropia. No entanto, exemplifica o procedimento proposto em compostos cerâmicos com fibras, os quais podem sofrer fissuração na matriz e escorregamento entre a matriz e fibra, com perda de rigidez e deformações inelásticas.

FERNANDES (1998) estudou o modelo do dano aplicado à análise não linear de placas de Kirchhoff acoplado ao método dos elementos de contorno e concluiu que o modelo de MAZARS (1984) é estável, porque há sempre convergência com o refinamento da malha ou com o aumento do número de pontos de Gauss.

BOTTA (1998) desenvolveu um código computacional aplicado ao cálculo de deslocamentos e esforços em grelhas de concreto armado, baseado nos modelos de MAZARS (1984) e de CERVERA et al (1996), na tentativa de, com maior fidelidade, representar o comportamento não-linear físico dessas estruturas. Assim, os modelos são aplicados juntamente com o método dos elementos finitos, substituindo a relação tensão $\mathrm{x}$ deformação pela relação momento x curvatura e considera que, na seção de concreto armado, a armadura está concentrada em uma única camada e possui comportamento elastoplástico com encruamento.

BOTTA constatou, a partir dos exemplos numéricos, que a identificação paramétrica é a principal característica dos modelos de dano; por esse motivo destacou a importância dessa identificação na consistência de um modelo e, por isso, sua formulação não deve exigir processos muito trabalhosos para a correta obtenção desses parâmetros.

PAULA (2001) combinou a análise não-linear física baseada nos modelos de dano de MAZARS e de LA BORDERIE à análise não-linear geométrica em pórticos planos de concreto armado.

A análise não-linear geométrica é aplicada, segundo as formulações lagrangianas total e atualizada e compara os resultados de ambas. Realiza a integração numérica para 
obtenção do vetor de esforços internos e da matriz de rigidez tangente a partir das quadraturas de GAUSS e GAUSS-LOBATTO e do método de integração por estratos.

PAULA chamou a atenção também, para a coerente identificação paramétrica dos modelos propostos e para aspectos importantes que devem ser levados em conta no emprego dos Modelos de Dano Contínuo em análises dinâmicas. Concluiu que o emprego dos dois modelos de dano para a consideração da não-linearidade física em análises estáticas gera resultados bem próximos dos obtidos experimentalmente; por esse motivo a modelagem baseada no dano é considerada muito interessante em situações onde a não-linearidade física produz efeitos significativos. Quanto à não-linearidade geométrica, afirmou que a comparação entre resultados numéricos e respostas analíticas conhecidas comprova a eficiência das descrições lagrangianas.

\subsubsection{Análise Não-Linear Geométrica}

SILVA (1995) apresentou uma contribuição ao estudo da não-linearidade física e geométrica em pórticos de concreto armado utilizando uma formulação baseada na teoria de grandes deslocamentos e grandes deformações. Utilizou a formulação lagrangiana parcialmente atualizada para a obtenção da matriz de rigidez tangente para um sistema de coordenadas corrotacional, solidário ao elemento, considerando apenas os graus de liberdade naturais.

Definiu o campo de deformação do elemento com base nas hipóteses de Bernoulli, utilizou o PTV na formulação do equilíbrio elemental interpolando o campo de deslocamentos a partir de funções aproximadoras, lineares para os deslocamentos axiais e cúbicas para os transversais. Realizou algumas aproximações de ordem geométrica e simplificações no comportamento do elemento para obter um elemento prismático em regime elastoplástico.

Dessa forma, implementou um código computacional para análise não-linear de pórticos planos que utiliza o PTV na obtenção da equação de equilíbrio incremental e o método de Newton-Raphson para solucionar o sistema de equações não-lineares proposto pelo problema.

A partir dos exemplos numéricos analisados com o programa, cujos resultados foram comparados com os presentes na literatura, SILVA concluiu que, para fins de análise de comportamento estrutural, a formulação desenvolvida em seu trabalho e implementada computacionalmente, mostrou-se bastante eficiente, poderosa e versátil. 
Finalmente, sugeriu alguns tópicos, relacionados ao seu trabalho, que podem ser desenvolvidos futuramente, como: inclusão dos efeitos reológicos; inclusão das deformações por cisalhamento e outros não menos importantes.

RODRIGUES (1997) discutiu em seu trabalho a análise dinâmica bidimensional em treliças de aço e pórticos de concreto armado. Em associação, estudou os efeitos da nãolinearidade física dos materiais, segundo os modelos propostos pelo ACI e pelo CEB, e os efeitos da não-linearidade geométrica de tais estruturas.

Como ferramenta básica, utilizou o método dos elementos finitos para discretizar a estrutura e, aplicando o princípio dos trabalhos virtuais, obteve a equação geral do movimento. A integração temporal dessa equação é realizada através de método implícito de integração numérica baseado no processo de Newmark.

Com relação à não-linearidade geométrica, para interpolar o campo de deformações, usou uma função quadrática dos deslocamentos, de forma que, para as treliças planas são, consideradas todas as parcelas enquanto que, nos pórticos planos são desprezadas as parcelas que contêm produtos de ordem superior. Deduziu as matrizes de rigidez secante e tangente, a partir da formulação lagrangiana atualizada, para descrever a posição do equilíbrio do sistema estrutural ao longo do processo de integração numérica.

Apresentou exemplos de treliças e pórticos sujeitos à análises dinâmicas não-lineares que servem de base para verificação da precisão dos programas implementados e para conclusões acerca da validade e precauções envolvidas no uso desse tipo de análise. 


\section{VIGAS DE TIMOSHENKO}

\subsection{CONSIDERAÇÕES INICIAIS}

A teoria de vigas de Timoshenko, a princípio, baseia sua formulação na teoria de Euller-Bernoulli, porém leva em conta o efeito da deformação por esforço cortante. Desta forma, a hipótese que as seções planas permanecem planas após as deformações continua válida, entretanto não sendo mais perpendicular ao eixo deformado.

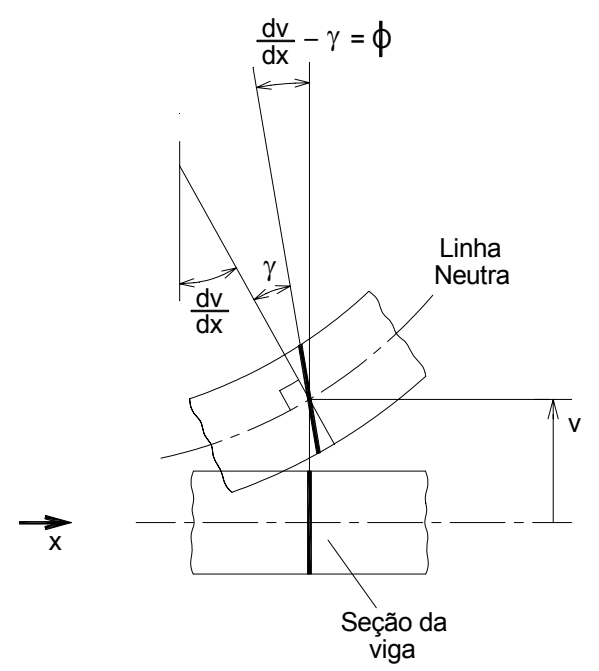

Figura (2.01): Deformações em vigas considerando os efeitos de cisalhamento

Como mostra a figura (2.01), a distorção diferente de zero, agora presente, leva a um acréscimo da curvatura de flexão, o que é muito significativo quando se trata de vigas curtas, vigas com baixo módulo de elasticidade transversal ou quando se necessita determinar a elástica de forma mais precisa. Para isso reduz-se a rigidez da viga segundo um pequeno fator, aumentando-se então os deslocamentos nodais.

Muitos autores propuseram elementos finitos para a viga de Timoshenko, cujas formulações estão baseadas no método dos deslocamentos e em métodos mistos, diferenciando-se apenas na escolha da função de interpolação utilizada para aproximar os deslocamentos transversais e as rotações. Assim, nos modelos mais simples, utilizam-se 
funções lineares para interpolar os deslocamentos e rotações, mas com inconvenientes, quando se trata de vigas pouco deformáveis ao esforço cortante, que podem ser eliminados com uso de funções de interpolação de ordens iguais para os deslocamentos transversais e rotações e um polinômio de ordem inferior para as distorções.

Nesses modelos, o cálculo dos coeficientes de rigidez associados à distorção é realizado por meio de integração reduzida, enquanto que para o cálculo dos demais coeficientes, deve ser utilizada integração precisa. Isso diminui a participação da parcela de esforço cortante na matriz de rigidez e alivia o travamento da solução.

\subsection{DEDUÇÃO DA MATRIZ DE RIGIDEZ}

$\mathrm{Na}$ bibliografia consultada, foram encontradas diversas formulações e procedimentos para dedução da matriz de rigidez do elemento de viga de Timoshenko, mas neste trabalho preferiu-se utilizar a formulação contida em NEVES (2000), baseada em GERE \& WEAVER (1987), por ser uma formulação simples e eficiente. A matriz de rigidez obtida com função de forma exata não traz o sério problema de travamento, observado quando a aproximação é feita a partir de funções aproximadoras mais pobres.

Para garantir a continuidade das funções aproximadoras foram tomados os seguintes parâmetros nodais:

$$
\begin{aligned}
& \mathbf{v}_{1} \text { e } \mathbf{v}_{2} \text { - flechas devidas à flexão e cisalhamento } \\
& \phi_{1} \text { e } \phi_{2} \text { - rotações devidas à flexão }
\end{aligned}
$$

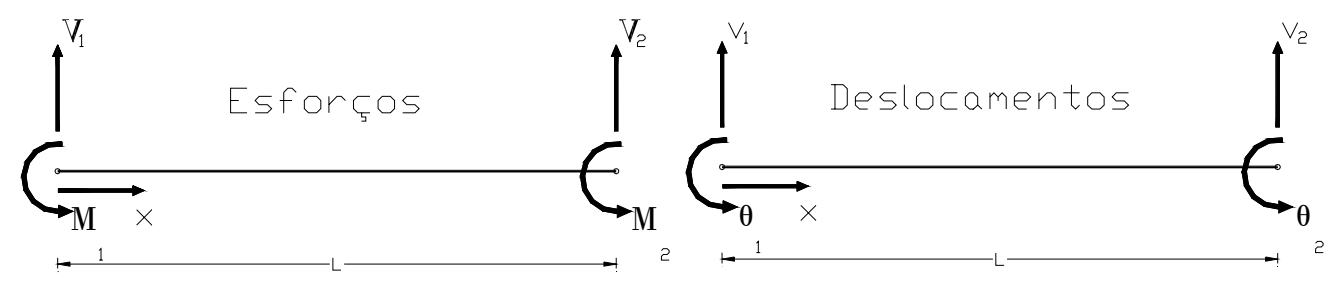

Figura (2.02): Convenções de sinais do Método dos Elementos Finitos

Como essa formulação várias vezes recorre à expressões clássicas da Resistência dos Materiais, faz-se necessário ajuste entre convenções, para os graus de liberdade, utilizadas nas expressões e no Método dos Elementos Finitos. A principio, seria ideal o uso da convenção da Resistência dos Materiais, mas a programação ficaria muito confusa e, por isso 
foi escolhida uma convenção mais prática, figura (2.02), com ajuste de sinais no final do processo.

Observando-se a figura (2.03), pode-se escrever a seguinte relação geométrica, em termos de flecha:

$$
v_{t}=v_{f}+v_{c}
$$

onde:

$\mathrm{v}_{\mathrm{t}}$ : deslocamento transversal total

$\mathrm{v}_{\mathrm{f}}$ : deslocamento transversal devido à flexão

$\mathrm{v}_{\mathrm{c}}$ : deslocamento transversal devido ao cisalhamento

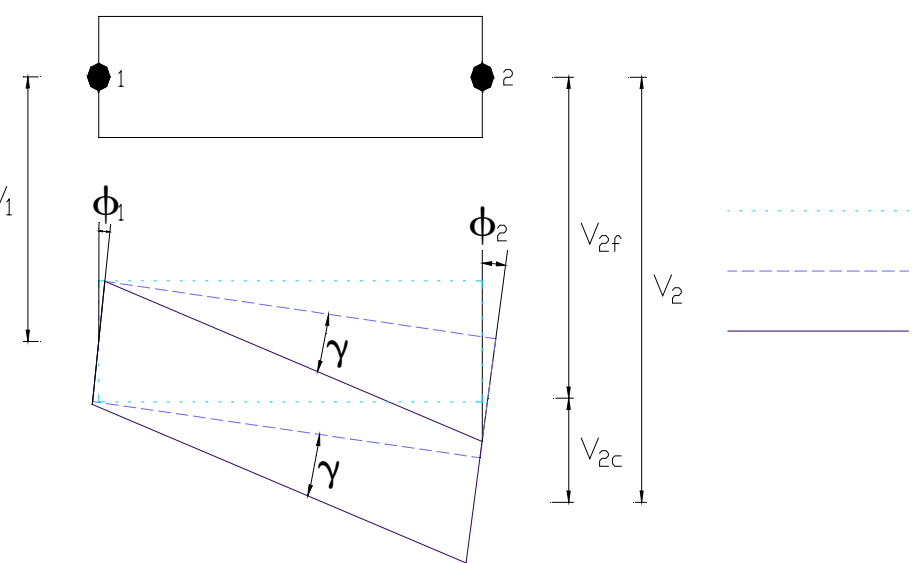

pos. original

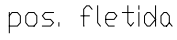

Figura (2.03): Configuração do elemento após as deformações, adaptada de NEVES (2000)

Da mesma forma, a relação é mantida em termos da primeira derivada:

$$
\frac{d}{d x} v_{t}=\frac{d}{d x} v_{f}+\frac{d}{d x} v_{c}
$$

e da segunda:

$$
\frac{d^{2}}{d x^{2}} v_{t}=\frac{d^{2}}{d x^{2}} v_{f}+\frac{d^{2}}{d x^{2}} v_{c}
$$

A equação (2.02a) pode, também, ser escrita da seguinte forma:

$$
\theta=\phi+\gamma
$$


Tomando-se as equações de equilíbrio, provenientes da Resistência dos Materiais, para um elemento isolado, tem-se:

$$
\begin{aligned}
& \frac{d}{d x} V=-q \\
& \frac{d}{d x} M=V
\end{aligned}
$$

onde:

$$
\begin{aligned}
& \mathrm{V} \text { - força cortante } \\
& \mathrm{M} \text { - momento fletor } \\
& \mathrm{q} \text { - carga distribuída no elemento }
\end{aligned}
$$

A Resistência dos Materiais também fornece a seguinte relação para a equação da linha elástica, contendo as parcelas de flexão e de cisalhamento:

$$
v_{t}^{\prime \prime}=-\frac{M}{E I}+\frac{k \cdot V^{\prime}}{G A}
$$

no entanto, em sua formulação, o método dos elementos finitos, converte a carga distribuída ao longo do elemento em um carregamento nodal equivalente, que facilita a automação do processo sem causar perda de precisão dos resultados; admite-se, portanto para a primeira das equações de equilíbrio, que (sem a presença de momentos distribuídos):

$$
\frac{d}{d x} V=0
$$

de forma que a equação (2.05) resulta em:

$$
M=-E I \cdot v_{t}^{\prime \prime}
$$

Recorrendo-se às equações (2.02a) e (2.03), tem-se que a rotação de flexão é dada por:

$$
\phi=\frac{d}{d x} v_{f} \therefore \frac{d}{d x} \phi=v_{f}^{\prime \prime}
$$

e a distorção por:

$$
\gamma=\frac{d}{d x} v_{t}-\phi
$$


Substituindo-se na expressão da linha elástica a equação (2.08a), juntamente com as equações (2.04a), (2.04b) e (2.08b), obtêm-se as seguintes relações constitutivas:

$$
\begin{aligned}
& M=-E I\left(\frac{d}{d x} \phi+\frac{d}{d x} \gamma\right) \\
& V=-E I\left(\frac{d^{2}}{d x^{2}} \phi+\frac{d^{2}}{d x^{2}} \gamma\right) \\
& V=k \cdot G A \cdot \gamma=k \cdot G A \cdot\left(\frac{d}{d x} v_{t}-\phi\right)
\end{aligned}
$$

sendo $k \mathrm{o}$ fator de forma da seção transversal e o seu valor dado por:

- $\frac{1}{1,2} \rightarrow$ seções retangulares

- $\frac{1}{0,9} \rightarrow$ seções circulares

Recorrendo-se, novamente, à equação (2.06) é possível, substituir a força cortante pelo valor obtido com a relação constitutiva (2.09c), de modo que:

$$
\frac{d}{d x} k \cdot G A \cdot\left(\frac{d}{d x} v_{t}-\phi\right)=0
$$

da qual resulta que:

$$
\frac{d}{d x}\left(\frac{d}{d x} v_{t}-\phi\right)=0
$$

logo:

$$
\frac{d^{2}}{d x} v_{c}=\frac{d}{d x} \gamma=0
$$

Tomando-se como base o resultado de (2.11b) pode-se reescrever as equações constitutivas (2.09a) e (2.09b) como:

$$
\begin{aligned}
& M=-E I \frac{d}{d x} \phi \\
& V=-E I \frac{d^{2}}{d x^{2}} \phi
\end{aligned}
$$


Substituindo-se na segunda equação de equilíbrio (2.04b) as expressões obtidas com as relações constitutivas (2.12a) e (2.12c), tem-se:

$$
\frac{d}{d x}\left(-E I \frac{d}{d x} \phi\right)=k \cdot G A \cdot\left(\frac{d}{d x} v_{t}-\phi\right)
$$

que após as devidas simplificações resulta em:

$$
E I \frac{d^{2}}{d x^{2}} \phi+k \cdot G A \cdot\left(\frac{d}{d x} v_{t}-\phi\right)=0
$$

Aplicando-se na equação de equilíbrio (2.04a) a relação constitutiva (2.12b) e a consideração (2.06), tem-se que:

$$
\frac{d^{3}}{d x^{3}} \phi=0
$$

e, portanto, para se ter nula a terceira derivada da rotação, escolhe-se uma função interpoladora para as rotações, dada por:

$$
\phi=c+b \cdot x+a \cdot x^{2}
$$

Substituindo-se na equação (2.13b) os valores dados por (2.15) e (2.08b), tem-se:

$$
\begin{aligned}
& E I \frac{d^{2}}{d x^{2}}\left(c+b \cdot x+a \cdot x^{2}\right)+k \cdot G A \cdot(\gamma)=0 \\
& E I(2 a)+k \cdot G A \cdot(\gamma)=0
\end{aligned}
$$

resultando numa expressão para a distorção em função dos parâmetros gerais e das características geométricas e físicas da seção, dada por:

$$
\gamma=-\frac{2 a \cdot E I}{k \cdot G A}
$$

Obtida a distorção dada por (2.17) e substituindo-a, juntamente com a função de interpolação (2.15), na equação (2.08b), obtém-se para a primeira derivada do deslocamento transversal total a expressão:

$$
\frac{d}{d x} v_{t}=c+b x+a x^{2}-\frac{2 a \cdot E I}{k \cdot G A}
$$


que ao ser integrada e devidamente simplificada resulta na expressão do deslocamento transversal total, dada por:

$$
v_{t}=d+c x+\frac{b x^{2}}{2}+a\left(\frac{1}{3} x^{3}-\frac{2 \cdot E I}{k \cdot G A} x\right)
$$

Convenientemente pode-se definir a seguinte constante para a viga de Timoshenko:

$$
g=\frac{6 \cdot E I}{k \cdot G A \cdot L^{2}}
$$

assim, pode-se reescrever a expressão (2.19) da seguinte forma:

$$
v_{t}=d+c x+\frac{b x^{2}}{2}+\frac{a}{3}\left(x^{3}-g \cdot L^{2} x\right)
$$

A expressão (2.21) representa o polinômio aproximador dos deslocamentos (contendo as parcelas de flexão e cisalhamento), enquanto que a expressão (2.15) representa o polinômio aproximador das rotações (contendo somente a parcela de flexão). Contudo esses polinômios estão expressos em função dos parâmetros generalizados e devem ser reescritos em função dos parâmetros nodais do elemento, com os devidos ajustes de convenções.

Portanto, no contorno do elemento, tem-se:

- $x=0 \rightarrow v=v_{1}, \quad x=0 \rightarrow \phi=\phi_{1}$

- $x=L \rightarrow v=v_{2}, x=L \rightarrow \phi=\phi_{2}$

As relações acima podem ser mais bem compreendidas em termos matriciais, da seguinte forma:

$$
\left[\begin{array}{cccc}
0 & 0 & 0 & 1 \\
0 & 0 & 1 & 0 \\
\frac{1}{3} \mathrm{~L}^{3} \cdot(1-\mathrm{g}) & \frac{1}{2} \mathrm{~L}^{2} & \mathrm{~L} & 1 \\
\mathrm{~L}^{2} & \mathrm{~L} & 1 & 0
\end{array}\right] \times\left(\begin{array}{l}
\mathrm{a} \\
\mathrm{b} \\
\mathrm{c} \\
\mathrm{d}
\end{array}\right)=\left(\begin{array}{c}
\mathrm{v}_{1} \\
\phi_{1} \\
\mathrm{v}_{2} \\
\phi_{2}
\end{array}\right)
$$


Resolvendo-se o sistema (2.22), obtém-se:

$$
\left(\begin{array}{l}
\mathrm{a} \\
\mathrm{b} \\
\mathrm{c} \\
\mathrm{d}
\end{array}\right)=\left[\begin{array}{c}
3 \cdot \frac{\left(2 \cdot \mathrm{v}_{1}+\phi_{1} \cdot \mathrm{L}-2 \cdot \mathrm{v}_{2}+\phi_{2} \cdot \mathrm{L}\right)}{\left[\mathrm{L}^{3} \cdot(2 \cdot \mathrm{g}+1)\right]} \\
-2 \cdot \frac{\left(3 \cdot \mathrm{v}_{1}+\phi_{1} \cdot \mathrm{L} \cdot \mathrm{g}+2 \cdot \phi_{1} \cdot \mathrm{L}-3 \cdot \mathrm{v}_{2}+\phi_{2} \cdot \mathrm{L}-\phi_{2} \cdot \mathrm{L} \cdot \mathrm{g}\right)}{\left[\mathrm{L}^{2} \cdot(2 \cdot \mathrm{g}+1)\right]} \\
\phi_{1} \\
\mathrm{v}_{1}
\end{array}\right]
$$

A rotação total e sua primeira derivada, em função dos parâmetros generalizados, são dadas por:

$$
\begin{aligned}
& \theta=-\frac{1}{3} g L^{2} a+c+b x+a x^{2} \\
& \theta^{\prime}=b+2 a x
\end{aligned}
$$

e nos parâmetros nodais é dado por:

$$
\theta^{\prime}=\frac{2}{L^{2}} \cdot \frac{\left(3 v_{1}+2 \phi_{1} L+\phi_{1} L g-3 v_{2}+\phi_{2} L-\phi_{2} L g\right)}{(1+2 g)}-\frac{6 x}{L^{3}} \cdot \frac{\left(2 v_{1}+\phi_{1} L-2 v_{2}+\phi_{2} L\right)}{(1+2 g)}
$$

A primeira derivada da rotação total representa a curvatura $1 / r$ da seção ao longo do elemento. Para isso, são substituídos na equação (2.24b) os pontos $\mathrm{x}=0$ e $\mathrm{x}=\mathrm{L}$, de forma que:

$\operatorname{Em} x=0$

$$
\frac{1}{r}=\left[\frac{6}{L^{2} \cdot(1+2 g)}\right] \cdot v_{1}+\left[\frac{4 \cdot\left(1+\frac{g}{2}\right)}{L^{2} .(1+2 g)}\right] \cdot \phi_{1}-\left[\frac{6}{L^{2} \cdot(1+2 g)}\right] \cdot v_{2}+\left[\frac{2 \cdot(1-g)}{L^{2} \cdot(1+2 g)}\right] \cdot \phi_{2}
$$

$\mathrm{Em} x=\mathrm{L}:$

$$
\frac{1}{r}=\left[\frac{6}{L^{2} .(1+2 g)}\right] \cdot v_{1}-\left[\frac{2 .(1-g)}{L^{2} .(1+2 g)}\right] \cdot \phi_{1}+\left[\frac{6}{L^{2} .(1+2 g)}\right] \cdot v_{2}-\left[\frac{4 \cdot\left(1+\frac{g}{2}\right)}{L^{2} .(1+2 g)}\right] \cdot \phi_{2}
$$


sendo assim, as equações (2.25a) e (2.25b) podem ser organizadas matricialmente determinando o vetor das curvaturas nas extremidades dos elementos, como segue:

$$
\left(\begin{array}{c}
\frac{1}{\mathrm{r}_{0}} \\
\frac{1}{\mathrm{r}_{\mathrm{L}}}
\end{array}\right)=\frac{1}{1+2 \mathrm{~g}} \cdot\left[\begin{array}{cccc}
\frac{6}{\mathrm{~L}^{2}} & \frac{4}{\mathrm{~L}} \cdot\left(1+\frac{\mathrm{g}}{2}\right) & \frac{-6}{\mathrm{~L}^{2}} & \frac{2}{\mathrm{~L}} \cdot(1-\mathrm{g}) \\
\frac{-6}{\mathrm{~L}^{2}} & \frac{-2}{\mathrm{~L}} \cdot(1-\mathrm{g}) & \frac{6}{\mathrm{~L}^{2}} & \frac{-4}{\mathrm{~L}} \cdot\left(1+\frac{\mathrm{g}}{2}\right)
\end{array}\right] \times\left(\begin{array}{c}
\mathrm{v}_{1} \\
\phi_{1} \\
\mathrm{v}_{2} \\
\phi_{2}
\end{array}\right)
$$

A distorção da seção transversal em função dos parâmetros nodais é obtida a partir da substituição da expressão (2.23) em (2.17), que devidamente simplificada fica:

$$
\gamma=\left(-2 v_{1}+2 v_{2}-L \phi_{1}-L \phi_{2}\right) \cdot \frac{g}{L \cdot(1+2 g)}
$$

$\mathrm{Na}$ literatura existem diversos processos consagrados para se obter a matriz de rigidez de um elemento; contudo o método dos elementos finitos recorre ao procedimento de minimizar o funcional da energia de deformação do elemento, contendo as parcelas que realmente influenciam na deformação do elemento, segundo o processo de Ritz.

Sendo assim, a energia de deformação do elemento de viga de Timoshenko leva em consideração as parcelas de flexão e de cisalhamento, como segue:

$$
U=\frac{E I}{2} \cdot \int_{0}^{L}\left(\frac{1}{r}\right)^{2} d x+\frac{k \cdot G A}{2} \cdot \int_{0}^{L}(\gamma)^{2} d x
$$

de forma que se substituindo as expressões (2.24b) e (2.27) no funcional (2.28) e realizando as devidas simplificações tem-se:

$$
\begin{aligned}
& U=\frac{E I}{(1+2 g) \cdot L^{3}} \cdot\left(2 L^{2} \phi_{2}^{2}+L^{2} \phi_{2}^{2} g+2 L^{2} \phi_{1} \phi_{2}-2 L^{2} \phi_{1} \phi_{2} g-6 v_{2} \phi_{2} L+6 v_{1} \phi_{2} L\right. \\
& \left.+L^{2} \phi_{1}^{2} g+2 L^{2} \phi_{1}^{2}+6 v_{1} \phi_{1} L-6 v_{2} \phi_{1} L-12 v_{1} v_{2}+6 v_{1}^{2}+6 v_{2}^{2}\right)
\end{aligned}
$$

Fazendo-se a diferenciação da expressão da energia de deformação (2.29) em relação aos parâmetros nodais, segundo o princípio da mínima energia potencial total, tem-se:

$$
\begin{aligned}
& \frac{d U}{d v_{1}}=\frac{6 E I}{(1+2 g) \cdot L^{3}} \cdot\left(2 v_{1}+L \phi_{1}-2 v_{2}+L \phi_{2}\right) \\
& \frac{d U}{d \phi_{1}}=\frac{-2 E I}{(1+2 g) \cdot L^{2}} \cdot\left(-3 v_{1}-2 L \phi_{1}-L \phi_{1} g+3 v_{2}-L \phi_{2}+L \phi_{2} g\right)
\end{aligned}
$$




$$
\begin{aligned}
& \frac{d U}{d v_{2}}=\frac{-6 E I}{(1+2 g) \cdot L^{3}} \cdot\left(2 v_{1}+L \phi_{1}-2 v_{2}+L \phi_{2}\right) \\
& \frac{d U}{d \phi_{2}}=\frac{-2 E I}{(1+2 g) \cdot L^{2}} \cdot\left(3 v_{1}+L \phi_{1}-L \phi_{1} g-3 v_{2}+2 L \phi_{2}+L \phi_{2} g\right)
\end{aligned}
$$

Reorganizando-se as equações (2.30a) a (2.30d) na forma matricial segundo o sistema de equações $\{\mathrm{f}\}=[\mathrm{K}] \mathrm{x}\{\mathrm{u}\}$, no qual $[\mathrm{K}]$ é a matriz de rigidez do elemento:

$$
\mathrm{K}=\frac{\mathrm{EI}}{1+2 \mathrm{~g}} \cdot\left[\begin{array}{cccc}
\frac{12}{\mathrm{~L}^{3}} & \frac{6}{\mathrm{~L}^{2}} & \frac{-12}{\mathrm{~L}^{3}} & \frac{6}{\mathrm{~L}^{2}} \\
\frac{6}{\mathrm{~L}^{2}} & \frac{2}{\mathrm{~L}} \cdot(2+\mathrm{g}) & \frac{-6}{\mathrm{~L}^{2}} & \frac{2}{\mathrm{~L}} \cdot(1-\mathrm{g}) \\
\frac{-12}{\mathrm{~L}^{3}} & \frac{-6}{\mathrm{~L}^{2}} & \frac{12}{\mathrm{~L}^{3}} & \frac{-6}{\mathrm{~L}^{2}} \\
\frac{6}{\mathrm{~L}^{2}} & \frac{2}{\mathrm{~L}} \cdot(1-\mathrm{g}) & \frac{-6}{\mathrm{~L}^{2}} & \frac{2}{\mathrm{~L}} \cdot(2+\mathrm{g})
\end{array}\right]
$$

A matriz de rigidez dada na equação (2.31), determinada para o elemento de viga de Timoshenko, serve como base para a determinação da matriz de rigidez do elemento de pórtico. Porém é preciso acrescentar a contribuição do esforço normal, como será descrito no item seguinte.

\subsection{ELEMENTO DE PÓRTICO PLANO COM TIMOSHENKO}

Como o objetivo deste trabalho é a implementação de um código computacional que visa análise dos efeitos das tensões cisalhantes sobre os elementos de um pórtico plano, é preciso obter a matriz de rigidez desse elemento.

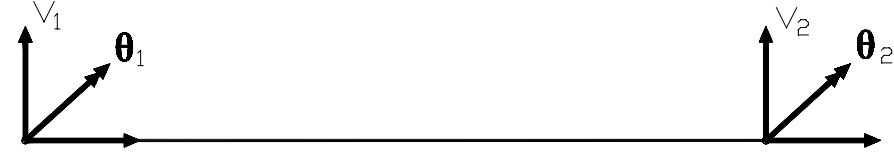

Figura (2.04): Elemento de pórtico plano 
Para isso, como mostra a figura (2.04), acrescenta-se às parcelas de flexão e cortante, consideradas no elemento de viga de Timoshenko, a parcela de esforço normal para completar a expressão da energia de deformação:

$$
U=U_{f}+U_{c}+U_{n}
$$

onde:

$U_{f}+U_{c}$ : parcelas incorporadas na matriz de rigidez da viga de Timoshenko

$$
U_{n}=\frac{E A}{2} \cdot \int_{0}^{L} u_{(x)}^{\prime}{ }^{2} d x
$$

Tomando-se uma aproximação linear para os deslocamentos longitudinais, dada por:

$$
u_{(x)}=a x+b
$$

de forma que aplicando as condições de contorno do elemento se obtém:

$$
\begin{array}{ll}
x=0 \rightarrow u_{1}=b & \Rightarrow b=u_{1} \\
x=L \rightarrow u_{2}=a L+b & \Rightarrow a=\frac{u_{2}-u_{1}}{L}
\end{array}
$$

e, finalmente:

$$
\begin{aligned}
& u_{(x)}=\frac{u_{2}-u_{1}}{L} x+u_{1} \\
& u_{(x)}^{\prime}=\frac{u_{2}-u_{1}}{L}
\end{aligned}
$$

Introduzindo-se a primeira derivada do deslocamento longitudinal, obtido de (2.35b), na expressão (2.33) da energia de deformação por esforço normal, tem-se:

$$
U_{n}=\frac{E A}{2 L} \cdot\left(u_{2}^{2}-2 u_{1} u_{2}+u_{1}^{2}\right)
$$

Aplicando-se o princípio da estacionaridade sobre o funcional da energia de deformação (2.36), tem-se:

$$
\begin{gathered}
\frac{d U_{n}}{d u_{1}}=\frac{E A}{L} \cdot\left(u_{1}-u_{2}\right) \\
\frac{d U_{n}}{d u_{2}}=\frac{E A}{L} \cdot\left(u_{2}-u_{1}\right)
\end{gathered}
$$


Reorganizando-se as equações (2.37a) e (2.37b) na forma matricial segundo o sistema de equações $\{f\}_{N}=[K]_{N} \times\{u\}_{N}$, no qual $[K]_{N}$ é a matriz de rigidez do elemento, considerando apenas a contribuição referente ao esforço normal:

$$
\left[\begin{array}{l}
N_{1} \\
N_{2}
\end{array}\right]=\frac{E A}{L}\left[\begin{array}{rr}
1 & -1 \\
-1 & 1
\end{array}\right] \times\left[\begin{array}{l}
u_{1} \\
u_{2}
\end{array}\right]
$$

Finalmente, considerando-se a ordem dos parâmetros nodais, ao se superpor a contribuição do esforço normal à matriz de rigidez da viga de Timoshenko, determina-se a matriz de rigidez do elemento de pórtico plano que considera a influência das tensões cisalhantes, dada por:

$$
\mathrm{K}=\left[\begin{array}{cccccc}
\frac{\mathrm{EA}}{\mathrm{L}} & 0 & 0 & -\frac{\mathrm{EA}}{\mathrm{L}} & 0 & 0 \\
0 & \frac{12 \mathrm{EI}}{\mathrm{L}^{3}(1+2 \mathrm{~g})} & \frac{6 \mathrm{EI}}{\mathrm{L}^{2}(1+2 \mathrm{~g})} & 0 & -\frac{12 \mathrm{EI}}{\mathrm{L}^{3}(1+2 \mathrm{~g})} & \frac{6 \mathrm{EI}}{\mathrm{L}^{2}(1+2 \mathrm{~g})} \\
0 & \frac{6 \mathrm{EI}}{\mathrm{L}^{2}(1+2 \mathrm{~g})} & \frac{2(2+\mathrm{g}) \mathrm{EI}}{\mathrm{L}(1+2 \mathrm{~g})} & 0 & -\frac{6 \mathrm{EI}}{\mathrm{L}^{2}(1+2 \mathrm{~g})} & \frac{2(1-\mathrm{g}) \mathrm{EI}}{\mathrm{L}(1+2 \mathrm{~g})} \\
-\frac{\mathrm{EA}}{\mathrm{L}} & 0 & 0 & \frac{\mathrm{EA}}{\mathrm{L}} & 0 & 0 \\
0 & -\frac{12 \mathrm{EI}}{\mathrm{L}^{3}(1+2 \mathrm{~g})} & -\frac{6 \mathrm{EI}}{\mathrm{L}^{2}(1+2 \mathrm{~g})} & 0 & \frac{12 \mathrm{EI}}{\mathrm{L}^{3}(1+2 \mathrm{~g})} & -\frac{6 \mathrm{EI}}{\mathrm{L}^{2}(1+2 \mathrm{~g})} \\
0 & \frac{6 \mathrm{EI}}{\mathrm{L}^{2}(1+2 \mathrm{~g})} & \frac{2(1-\mathrm{g}) \mathrm{EI}}{\mathrm{L}(1+2 \mathrm{~g})} & 0 & -\frac{6 \mathrm{EI}}{\mathrm{L}^{2}(1+2 \mathrm{~g})} & \frac{2(2+\mathrm{g}) \mathrm{EI}}{\mathrm{L}(1+2 \mathrm{~g})}
\end{array}\right]
$$

sendo o parâmetro g a constante de Weaver dado pela equação (2.20), que ao ser considerada nula faz com que a matriz de rigidez do elemento de pórtico plano de Timoshenko seja degenerada na matriz de rigidez do elemento de pórtico plano de Bernoulli. 


\section{ANÁLISE NÃO-LINEAR}

\subsection{CONSIDERAÇÕES INICIAIS}

Nesse trabalho, como já foi dito, busca-se estudar os efeitos provocados pelas tensões cisalhantes em análises não-lineares de pórticos de concreto armado. Para esse estudo, são considerados dois tipos de efeitos não-lineares: a não-linearidade física, distinta entre a armadura e o concreto, e a não-linearidade geométrica. Vale ressaltar que a combinação entre os efeitos, aplicada juntamente com as hipóteses do elemento de viga de Timoshenko, será discutida no Capítulo 5.

A seguir detalham-se os procedimentos, conceitos e equações envolvidos em cada tipo de análise.

\subsection{CONCEITOS AUXILIARES}

Definindo-se um campo de deslocamentos ( $\boldsymbol{\delta} \mathbf{u})$ virtuais compatível e homogêneo nas condições de contorno, a ser aplicado aos elementos infinitesimais na posição atual e uma equação para o trabalho virtual em função do resíduo (r), para um sistema conservativo, temos:

$$
\delta W=\int_{V} r \cdot \delta u \cdot d V=0
$$

No entanto, sabe-se que o trabalho virtual é dado pela soma da energia de deformação com o trabalho virtual das cargas externas. Portanto, a variação ( $\mathbf{\delta W})$ do trabalho virtual pode ser escrita como:

$$
\delta W=\delta U+\delta W_{e x t}
$$

e, portanto é correto afirmar que:

$$
\int_{V} r \cdot \delta u \cdot d V=\delta U+\delta W_{e x t}
$$


Sabendo-se, segundo PROENÇA (1997), que se $\boldsymbol{\delta} \boldsymbol{U}-\boldsymbol{\delta} \boldsymbol{W}_{\text {ext }}=\boldsymbol{0}$ para todo o campo de deslocamentos virtuais cinematicamente admissíveis (isto é, satisfazendo as condições de contorno e compatibilidade), então o estado de tensão satisfaz as condições de equilíbrio no interior e no contorno, pode-se utilizar as (3.04) e (3.05) na (3.03) para se chegar a (3.06), como mostrado abaixo:

$$
\begin{aligned}
& \delta U=\int_{V} \sigma \cdot \delta \varepsilon \cdot d V \\
& \delta W_{e x t}=\int_{V} b \cdot \delta u \cdot d V+\int_{A} t \cdot \delta u \cdot d A \\
& \int_{V} r \cdot \delta u \cdot d V=\int_{V} \sigma \cdot \delta \varepsilon \cdot d V-\int_{V} b \cdot \delta u \cdot d V-\int_{A} t \cdot \delta u \cdot d A
\end{aligned}
$$

A equação (3.06) está expressa em referência à posição atual deformada da estrutura. Porém, como os parâmetros V (volume) e A (área superficial) da posição atual são desconhecidos, para o PTV ser útil na resolução do problema, faz-se necessária uma transformação de modo a se obter a expressão geral em função dos parâmetros na posição inicial indeformada $\left(\mathrm{V}_{0}\right.$ e $\left.\mathrm{A}_{0}\right)$.

A partir dessa transformação obtém-se, da equação (3.06), a forma lagrangiana do PTV, dada por:

$$
\int_{V_{0}} r \cdot \delta u \cdot d V_{0}=\int_{V_{0}} S \cdot \delta \varepsilon \cdot d V_{0}-\int_{V_{0}} b_{0} \cdot \delta u \cdot d V_{0}-\int_{A_{0}} t_{0} \cdot \delta u \cdot d A
$$

\subsection{ANÁLISE NÃO-LINEAR FÍSICA}

$\mathrm{Na}$ análise não-linear física é levada em consideração a perda de rigidez do material durante a história de carregamento da estrutura. Sendo assim, a partir de certo valor de carga, os elementos que compõem a estrutura perdem a capacidade de recuperar a sua forma inicial, quando descarregados, ou seja, acumulam deformações permanentes chamadas deformações plásticas. Diz-se, então, que houve a plastificação de uma ou mais seções da peça.

Porém, no caso do modelo de dano de Mazars aplicado ao concreto armado, isso não ocorre, há apenas a penalização da rigidez, sem deformação permanente, mas com dissipação de energia. No material elástico não-linear não há dissipação; embora haja mudança da rigidez com o estado de deformação; este sempre será capaz de recuperar sua forma original.

$\mathrm{Na}$ tentativa de representar o comportamento dos materiais foram elaborados muitos modelos teóricos. Por serem teóricos, só conseguem representar o comportamento 
aproximado de alguns materiais. Obviamente, faz-se necessária a escolha de um modelo com aproximações compatíveis com o material utilizado na estrutura a ser analisada, que seja dependente de poucos parâmetros e possua expressão simples.

Este trabalho faz uma distinção entre os modelos utilizados para caracterizar os efeitos não-lineares físicos no aço e no concreto. A seguir, por critério didático, serão discutidos os conceitos e aspectos gerais pertinentes ao modelo não-linear físico nas armaduras. O modelo referente ao concreto será discutido somente no Capítulo 4.

\subsubsection{Análise não-linear física nas armaduras}

Destacam-se agora alguns modelos de comportamento aplicados à considerável parte dos metais, inclusive às armaduras utilizadas nas estruturas usuais de concreto armado.

Para representar o comportamento de metais, inclusive o aço, tem-se modelos elastoplásticos com encruamento isótropo linear positivo e com encruamento cinemático. A associação dos dois modelos caracteriza o modelo elastoplástico com encruamento misto e a degeneração dos mesmos modelos (tomando-se como desprezível os módulos de encruamento isótropo e cinemático do material) caracteriza o modelo elastoplástico perfeito.

Por ser mais completo, o código do programa referente à análise da não-linearidade física baseia-se no modelo elastoplástico com encruamento misto, que pode ser degenerado para os outros três tipos de acordo com o valor dos referidos módulos de encruamento.

- Tensão no passo atual: $\sigma_{n+1}=E_{S} \cdot\left(\varepsilon_{n+1}-\varepsilon^{p}{ }_{n+1}\right)$

- Deformação no passo atual: $\varepsilon_{n+1}=\varepsilon_{n}+\Delta \varepsilon_{n}$

- Critério de plastificação: $f_{n+1}=\left|\sigma_{n+1}-q_{n+1}\right|-\left(\sigma_{y 1}+K \cdot \alpha_{n+1}\right) \leq 0$

- Condição de consistência: $\Delta \lambda \cdot f_{n+1}=0$

- $\quad$ Def. plástica atual: $\varepsilon_{n+1}^{p}=\varepsilon^{p}{ }_{n}+\Delta \lambda \cdot \operatorname{sinal}\left(\sigma_{n+1}-q_{n+1}\right)$

- $\quad$ Lei de encruamento: $\alpha_{n+1}=\alpha_{n}+\Delta \lambda$

- $\quad$ Lei de encruamento: $q_{n+1}=q_{n}+\Delta \lambda \cdot H \cdot \operatorname{sinal}\left(\sigma_{n+1}-q_{n+1}\right)$

A atualização das variáveis de encruamento no processo incremental de NewtonRaphson acarreta em substituição do módulo de elasticidade inicial pelo módulo de elasticidade corrigido nas parcelas da matriz de rigidez referente aos elementos plastificados, de modo que: 


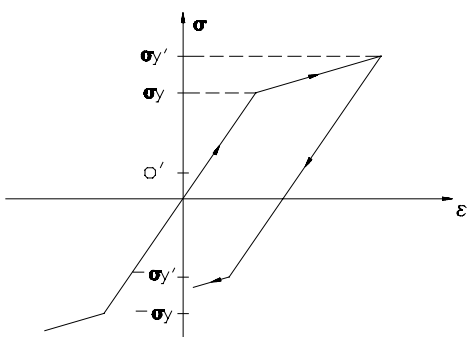

$$
E_{S c o r}=\frac{E_{S} \cdot(H+K)}{E_{S}+H+K}
$$

Figura (3.01): Modelo elastoplástico com encruamento misto

\subsection{ANÁLISE NÃO-LINEAR GEOMÉTRICA}

Por simplificação, no cálculo de muitas estruturas usuais considera-se que os deslocamentos, que aparecem na estrutura, são diretamente proporcionais ao carregamento aplicado, sem que se esteja cometendo erro significativo. No entanto, esse comportamento linear pode estar longe de ser o comportamento real da estrutura (erro significativo) quando nos problemas em análise aparecem deslocamentos relativamente elevados, figura (3.02), ou, simplesmente, se com a mudança do referencial de equilíbrio houver o "surgimento" de esforços adicionais significativos, mesmo que os deslocamentos sejam pequenos, figura (3.03).
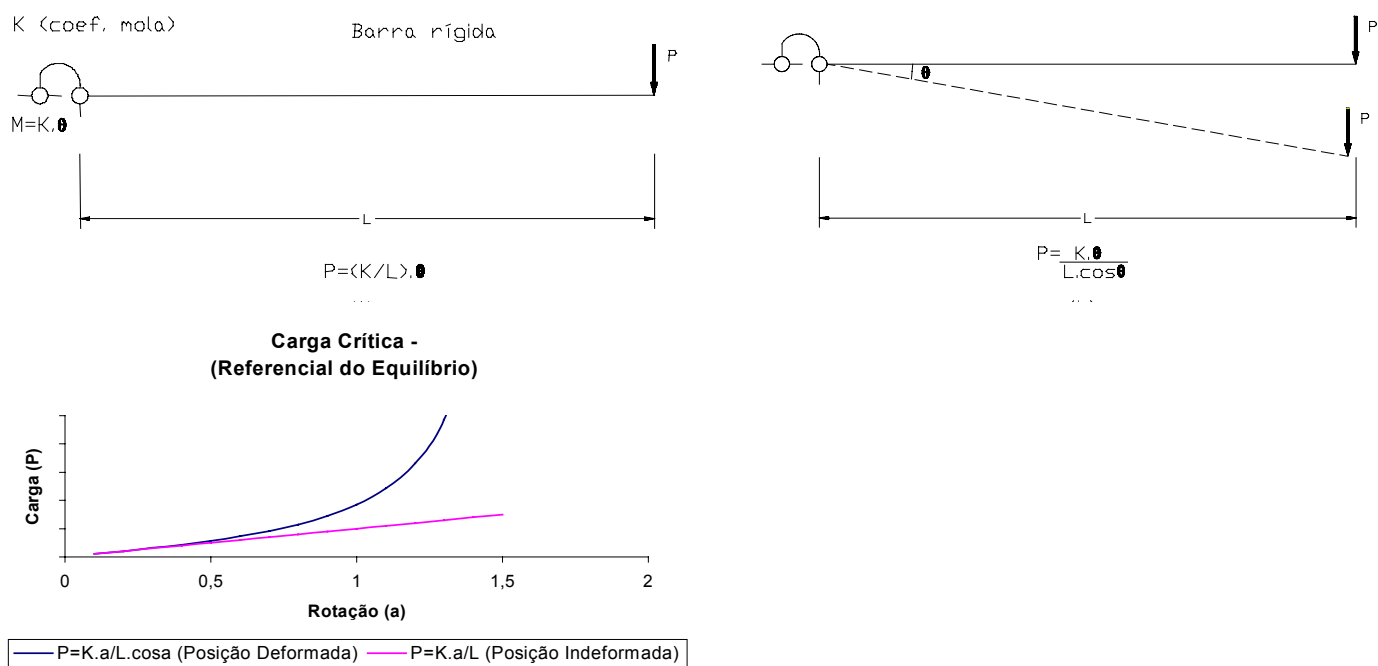

Figura (3.02): Barra rígida c/ carga concentrada transversal 


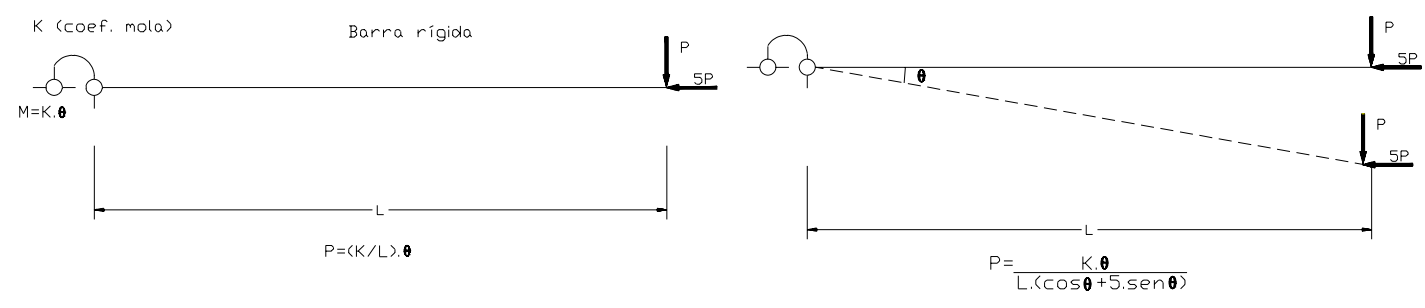

Carga Crítica - (Referencial do Equilíbrio)

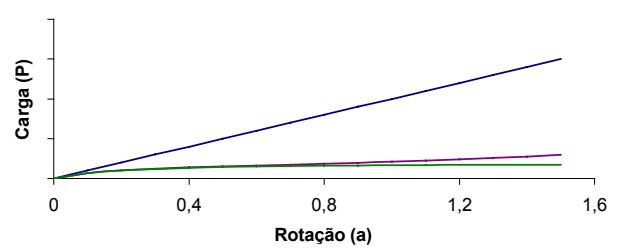

- Posição Indeformada

Posição Deformada $(a<0,3)$

Figura (3.03): Barra rígida c/ cargas concentradas transversal e longitudinal

$\mathrm{Na}$ análise não-linear geométrica consegue-se determinar esses acréscimos de esforços (efeitos de $2^{\mathrm{a}}$ ordem), pois toma como referência para o equilíbrio a posição deformada da estrutura, de forma que os deslocamentos ocorridos, bem como as deformações, serão levados em conta na composição do equilíbrio.

Como na análise não-linear geométrica o equilíbrio é determinado na posição deformada, o grau de precisão obtido para os resultados depende das aproximações adotadas - independentemente da ordem de grandeza dos deslocamentos - tem-se possibilidade de avaliar a perda de estabilidade em problemas com bifurcação do equilíbrio, figura (3.04), e em problemas de ponto limite, figura (3.05).
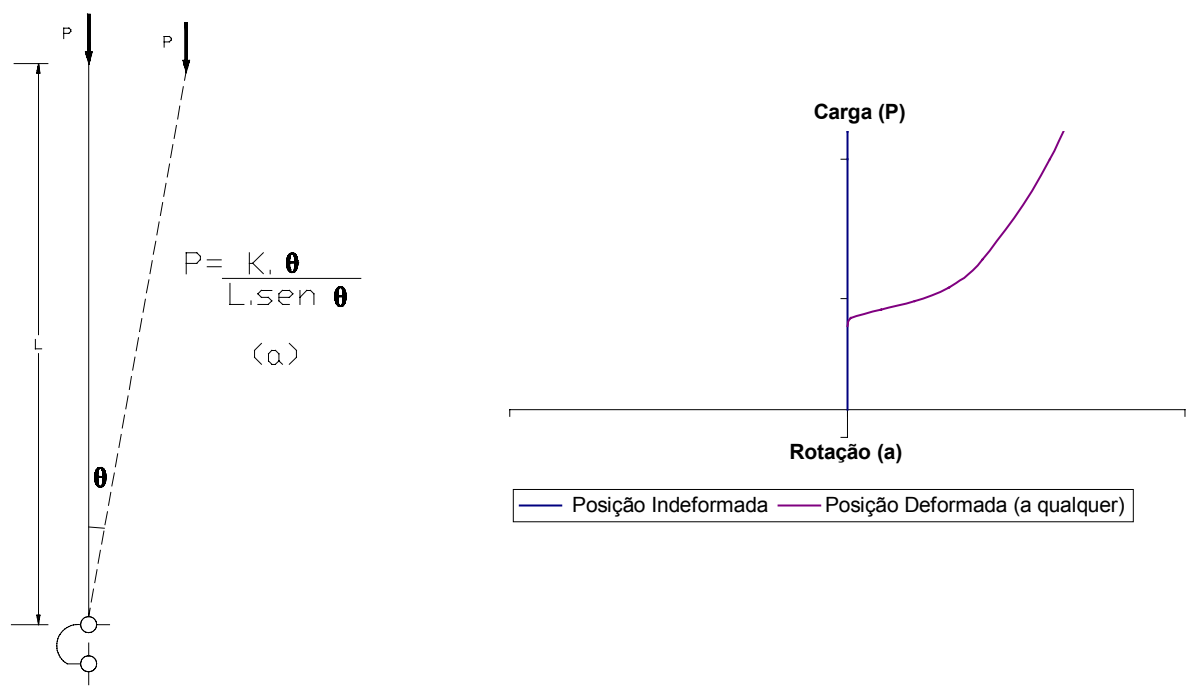

Figura (3.04): Bifurcação do equilíbrio 

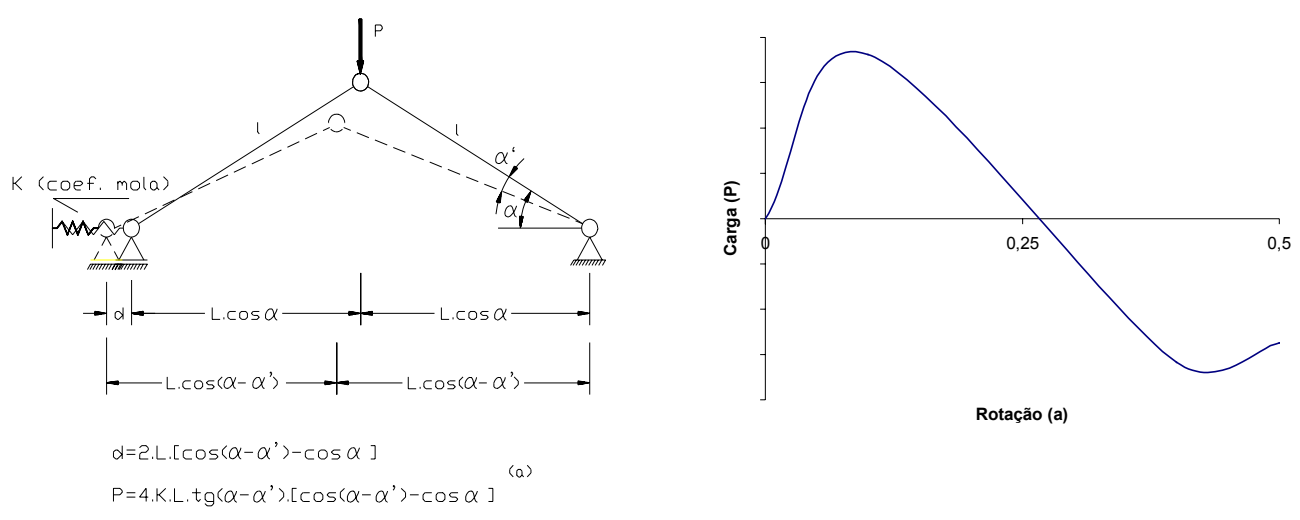

Figura (3.05): Ponto limite

RACHID \& MORI (1989) definem problemas com bifurcação do equilíbrio como: "aqueles em que ao se atingir o carregamento crítico, ocorre a passagem qualitativa de uma forma de equilíbrio para a outra. Isto é, na eminência de atingir o carregamento crítico, o equilíbrio torna-se indiferente e qualquer perturbação provoca a instabilidade".

Por outro lado, segundo os mesmos autores: "problemas de ponto limite são aqueles que, depois de grandes deslocamentos, é atingida uma posição na qual o equilíbrio torna-se indiferente e a mudança do estado de equilíbrio não é acompanhada de bifurcação".

A formulação geral para o equilíbrio é realizada com o auxílio do principio dos trabalhos virtuais que, através de uma única equação escalar, consegue representar o equilíbrio em todo o corpo.

A resolução da equação (3.07) é realizada seguindo-se o modelo de descrição lagrangiana. Com esse modelo pode-se optar pela formulação lagrangiana total, na qual o equilíbrio é feito diretamente na posição final; porém usando-se a configuração inicial indeformada, ou a formulação lagrangiana atualizada, cuja configuração está referida ao início do incremento.

Escolhido o tipo de descrição lagrangiana a ser usado e sabendo-se que as expressões do PTV são não-lineares nos deslocamentos, deve-se adotar um procedimento eficiente para encontrar a solução.

Uma forma eficaz de solução consiste na linearização da expressão do equilíbrio, combinada a um procedimento iterativo, admitindo-se um passo finito de tempo, tomando-se os termos lineares no tempo da equação lagrangiana do PTV desenvolvida em séries na variável tempo. 
Adotando-se uma forma incremental para o equilíbrio combinado à técnica dos elementos finitos, chega-se a uma forma aproximada para as equações do equilíbrio e para a solução.

A seguir, será discutida a aplicação da não-linearidade geométrica a pórticos planos de concreto armado, de forma a ser obtida a formulação para obtenção da matriz de rigidez tangente e do vetor de esforços internos.

\subsection{APLICAÇÃO DA NLG A PÓRTICOS PLANOS}

Este item discute a aplicação da não-linearidade geométrica a pórticos planos de concreto armado. Para tanto adota-se, no programa, a forma lagrangiana atualizada para análise do equilíbrio. Considerando-se, na equação constitutiva, a deformação quadrática (ou de Green) em lugar da deformação linear e, em correspondência, o tensor de tensão de PiolaKirchhoff de $2^{\mathrm{a}}$ espécie. No entanto, no cálculo dos esforços internos e na montagem da matriz de rigidez, não se considera o efeito do estiramento $\lambda=\mathbf{1}$. A consideração do efeito do estiramento $(\lambda \neq \mathbf{1})$ permitiria o cálculo da não-linearidade geométrica para estruturas com grandes deformações (ex: treliças não abatidas,).

\subsubsection{Descrição do campo de deslocamentos}

Com base na figura (3.06) e na hipótese cinemática, observa-se que o deslocamento arbitrário de um ponto $\mathbf{P}(\mathbf{x}, \mathbf{y})$ qualquer, cujas componentes são $\mathbf{u}_{\mathbf{p}}$ e $\mathbf{v}_{\mathbf{p}}$, pode ser expresso na forma:

$$
\begin{aligned}
& u_{p}(x, y)=u(x)-y \operatorname{sen} \theta \\
& v_{p}(x, y)=v(x)-y+y \cos \theta
\end{aligned}
$$

lembrando-se que $\mathbf{v}(\mathbf{x})$ é o deslocamento do ponto de referência, conforme dado pela equação (2.01), reescrita como:

$$
v=v_{f}+v_{c}
$$




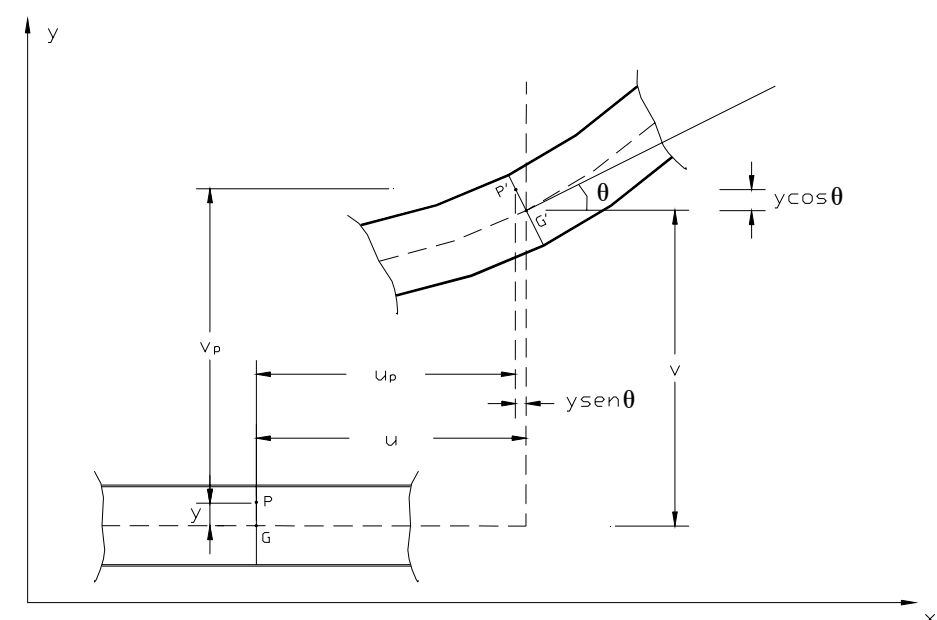

Figura (3.06): Deslocamento de pontos da barra

Considerando-se a aproximação de $2^{\mathrm{a}}$ ordem, dada por:

$$
\operatorname{sen} \theta=\theta \text { e } \cos \theta=1-\frac{v^{\prime 2}}{2}
$$

pode-se reescrever as equações (3.10) e (3.11) na forma:

$$
\begin{aligned}
& u_{p}=u-y v^{\prime} \\
& v_{p}=v-y \frac{v^{\prime 2}}{2}
\end{aligned}
$$

\subsubsection{Relação deformação-deslocamento}

Sabendo-se que o tensor de deformação é dado por:

$$
\varepsilon=\left[\begin{array}{ll}
\varepsilon_{x x} & \gamma_{x y} \\
\gamma_{x y} & \varepsilon_{y y}
\end{array}\right]
$$

onde:

$$
\begin{aligned}
& \varepsilon_{x x}=\frac{\partial u_{p}}{\partial x}+\frac{1}{2}\left[\left(\frac{\partial u_{p}}{\partial x}\right)^{2}+\left(\frac{\partial v_{p}}{\partial x}\right)^{2}\right] \\
& \gamma_{x y}=\frac{\partial u_{p}}{\partial y}+\frac{\partial v_{p}}{\partial x}+\left(\frac{\partial u_{p}}{\partial x} \cdot \frac{\partial u_{p}}{\partial y}+\frac{\partial v_{p}}{\partial x} \cdot \frac{\partial v_{p}}{\partial y}\right) \\
& \varepsilon_{y y}=0
\end{aligned}
$$


As expressões (3.17a e b) representam, respectivamente as deformações longitudinal e tangencial e foram obtidas da Teoria da Elasticidade Não-Linear, de forma que possuem um termo de $1^{\mathrm{a}}$ ordem acrescido de outro de $2^{\mathrm{a}}$, capaz de computar os efeitos não-lineares geométricos.

Aplicando-se às equações (3.17a e b) as expressões (3.14) e (3.15) e desprezando-se os termos que contêm produtos de ordem superior, obtém-se expressões simplificadas para os campos de deformações longitudinais e tangenciais para o elemento de pórtico plano, dadas por:

$$
\begin{aligned}
& \varepsilon_{x x}=u^{\prime}+\frac{1}{2}\left(u^{\prime}\right)^{2}+\frac{1}{2}\left(v^{\prime}\right)^{2}-y v^{\prime \prime}\left(1+u^{\prime}\right) \\
& \gamma_{x y}=v^{\prime}-\phi-u^{\prime} v^{\prime}-\frac{v^{\prime 3}}{2}
\end{aligned}
$$

Antes do estudo das relações entre tensões e deformações, fazem-se necessários mais alguns comentários a respeito dessas deformações.

Como demonstrado por SILVA (1995), a expressão (3.17a) da deformação longitudinal pode ser obtida a partir da associação entre a expressão da deformação quadrática de Green, a definição de estiramento e a compatibilização de deformações após o equilíbrio.

Quanto à deformação tangencial, a expressão (3.17b) difere da obtida geometricamente no Capítulo 2, justamente pelo acréscimo do termo de $2^{\mathrm{a}}$ ordem que, a partir daqui, torna-se extremamente importante.

Contudo, visando a implementação computacional, observa-se que a expressão da deformação longitudinal dada por (3.18a) representa uma função linear na altura da seção transversal e, portanto, pode ser reescrita na forma:

$$
\varepsilon_{x x}=\varepsilon_{x 0}-y \cdot k
$$

onde $\boldsymbol{\varepsilon}_{x x}$ e $\boldsymbol{k}$ são a deformação e a curvatura do eixo da seção, respectivamente, e dados por:

$$
\begin{aligned}
& \varepsilon_{x 0}=u^{\prime}+\frac{1}{2}\left(u^{\prime}\right)^{2}+\frac{1}{2}\left(v^{\prime}\right)^{2} \\
& k=v^{\prime \prime}\left(1+u^{\prime}\right)
\end{aligned}
$$

Segundo o mesmo ponto de vista, o valor dado por (3.18b) para a deformação tangencial representa a deformação média da seção. No entanto, da Resistência dos Materiais sabe-se que a distribuição de deformação tangencial ao longo de uma seção transversal é parabólica. 


\subsubsection{Relação entre tensores de tensão e de deformação}

Conforme citado anteriormente, outra forma de serem obtidas medidas referentes à deformações envolve o conceito de estiramento, como mostra a figura (3.07). De onde se tira que:

$$
\lambda=\frac{d s}{d x}=\sqrt{\left(\frac{d u+d x}{d x}\right)^{2}+\left(\frac{d v}{d x}\right)^{2}}
$$

e que a deformação quadrática de Green e a Linear valem respectivamente:

$$
\begin{aligned}
& \varepsilon_{G}=\frac{\lambda^{2}-1}{2}=\frac{d u}{d x}+\frac{1}{2}\left[\left(\frac{d u}{d x}\right)^{2}+\left(\frac{d v}{d x}\right)^{2}\right] \\
& \varepsilon_{L}=\lambda-1=\sqrt{1+2 \frac{d u}{d x}+\left(\frac{d u}{d x}\right)^{2}+\left(\frac{d v}{d x}\right)^{2}}-1
\end{aligned}
$$

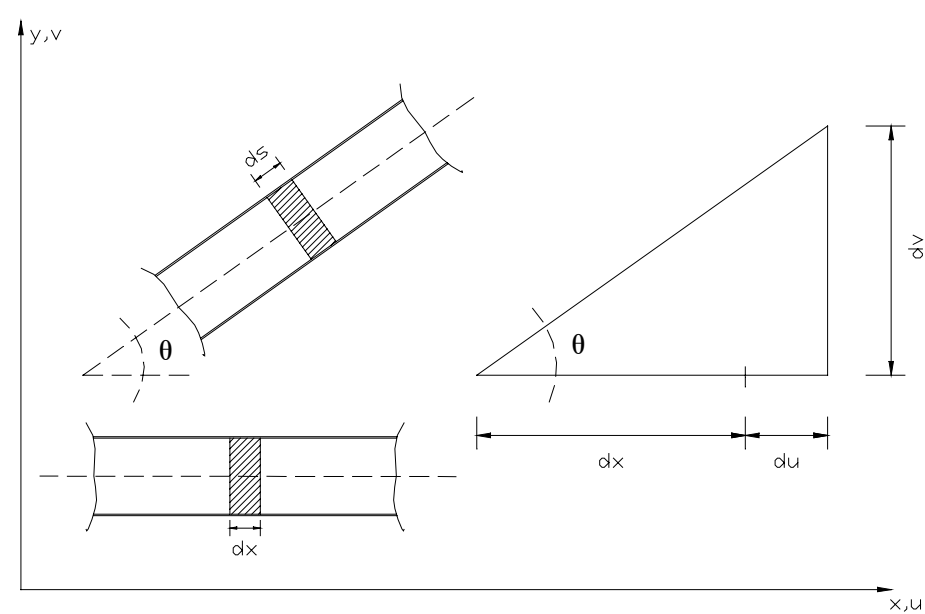

Figura (3.07): Deformação de uma fibra genérica - adaptada de Silva (1995)

Para que haja consistência na formulação adotada, faz-se necessário conjugar o tensor de deformação com um tensor de tensão compatível, sendo ele o tensor de PiolaKirchhoff de $2^{\mathrm{a}}$ espécie para a deformação de Green e o tensor de Biot para a deformação Linear, dados por:

$$
S=\left\{\begin{array}{l}
S_{x x} \\
S_{x y}
\end{array}\right\}=\left\{\begin{array}{l}
\frac{\sigma_{x x}}{\lambda} \\
\frac{\tau_{x y}}{\lambda}
\end{array}\right\}
$$




$$
\sigma=\left\{\begin{array}{l}
\sigma_{x x} \\
\tau_{x y}
\end{array}\right\}=\left\{\begin{array}{l}
\frac{N}{A_{0}} \\
\frac{V}{A_{0}}
\end{array}\right\}
$$

sendo $\mathbf{N}$ a normal e $\mathbf{V}$ cortante que atuam na seção transversal da barra, enquanto que $\mathbf{A}_{\mathbf{0}}$ é a área da mesma.

Pode-se observar da relação entre as equações (3.23 a e b) que:

$$
S=\lambda^{-1} \cdot \sigma
$$

Partindo-se de um modelo elástico-linear, no qual a lei de Hooke representa a relação entre tensão e deformação, considerando-se a deformação linear, tem-se que:

$$
\sigma=\underline{\underline{D}}_{0} \cdot\left\{\begin{array}{l}
\varepsilon_{L} \\
\gamma
\end{array}\right\}
$$

e, considerando-se a deformação de Green:

$$
\sigma=\underline{\underline{D}}_{0 G} \cdot\left\{\begin{array}{l}
\lambda \varepsilon_{G} \\
\gamma
\end{array}\right\}
$$

onde $\underline{\underline{\boldsymbol{D}}}_{0}$ é a matriz contendo as propriedades elásticas do material, enquanto que $\underline{\underline{\boldsymbol{D}}}_{\boldsymbol{}}$ é a matriz correspondente que relaciona $\boldsymbol{S} \operatorname{com} \boldsymbol{\varepsilon}_{G}$, conforme:

$$
S=\underline{\underline{D}}_{0 G} \cdot\left\{\begin{array}{l}
\varepsilon_{G} \\
\gamma
\end{array}\right\}
$$

A relação (3.27) pode ser considerada como verdadeira, pois igualando-se (3.25) e (3.26) e tendo-se em vista as expressões (3.22a e b) obtém-se $\underline{\underline{D}}_{o G}$ em função de $\underline{\underline{D}}_{0}$, na forma:

$$
\underline{\underline{D}}_{0 G}=\frac{2}{\lambda(1+\lambda)} \underline{D}_{0}
$$

comprovando a veracidade de (3.27).

Nos problemas que envolvem pequenas deformações, ou seja, em que $\lambda \approx 1$, as matrizes das propriedades elásticas coincidem, de modo que:

$$
\begin{aligned}
& \underline{\underline{D}}_{0 G}=\underline{\underline{D}}_{0}=\left[\begin{array}{ll}
E & 0 \\
0 & G
\end{array}\right] \\
& G=\frac{E}{2(1+v)}
\end{aligned}
$$

e, com isso a equação (3.27) pode ser escrita como: 


$$
S=\underline{\underline{D}}_{0} \cdot\left\{\begin{array}{l}
\varepsilon_{G} \\
\gamma
\end{array}\right\}
$$

\subsubsection{Matriz de rigidez tangente e vetor de esforços internos}

Tomando-se como base o elemento de pórtico plano, onde foram consideradas as hipóteses de Timoshenko, dado no Capítulo 2 e reproduzido na figura (3.08), associado a um referencial cartesiano local, tal que o eixo $\boldsymbol{x}$ coincide com o eixo do elemento, o cálculo das integrais necessárias à obtenção da matriz de rigidez tangente e do vetor de esforços internos para o elemento utilizado requer que sejam adotadas funções interpoladoras para as componentes $\boldsymbol{u}$ e $\boldsymbol{v}$ do deslocamento - a rotação total $\theta$, obtida pela derivação do deslocamento transversal - cuja representação matricial e dada por:

$$
d_{0}=\underline{\phi}(x) \cdot u
$$

onde o vetor de deslocamentos do eixo e a matriz que contem as funções interpoladoras são dadas respectivamente por:

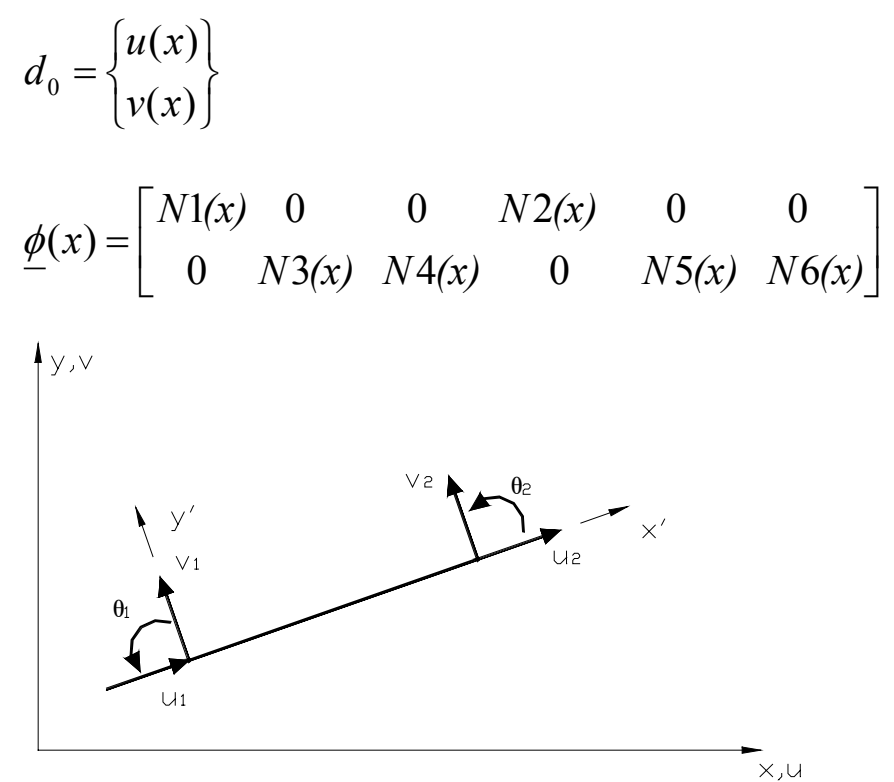

Figura (3.08): Elemento de pórtico plano c/ Timoshenko nos sistemas global e local

Na realidade, esse procedimento já foi mostrado no Capítulo 2. No entanto, a partir de agora é interessante que esse procedimento seja descrito em seqüência um pouco diferente, para facilitar a aplicação da não-linearidade geométrica. Sendo assim, conhecendose $\boldsymbol{u}(\boldsymbol{x})$ e $\boldsymbol{v}(\boldsymbol{x})$, pode-se dizer que: 


$$
\begin{aligned}
& N 1(x)=\left(1-\frac{x}{L_{0}}\right) \\
& N 2(x)=\left(\frac{x}{L_{0}}\right) \\
& N 3(x)=\frac{1}{1+2 g} \cdot\left[(1+2 g)-2 g\left(\frac{x}{L_{0}}\right)-3\left(\frac{x}{L_{0}}\right)^{2}+2\left(\frac{x}{L_{0}}\right)^{3}\right] \\
& N 4(x)=\frac{L_{0}}{1+2 g} \cdot\left[(1+g)\left(\frac{x}{L_{0}}\right)-(2+g)\left(\frac{x}{L_{0}}\right)^{2}+\left(\frac{x}{L_{0}}\right)^{3}\right] \\
& N 5(x)=\frac{1}{1+2 g} \cdot\left[2 g\left(\frac{x}{L_{0}}\right)+3\left(\frac{x}{L_{0}}\right)^{2}-2\left(\frac{x}{L_{0}}\right)^{3}\right] \\
& N 6(x)=\frac{L_{0}}{1+2 g} \cdot\left[-g\left(\frac{x}{L_{0}}\right)-(1-g)\left(\frac{x}{L_{0}}\right)^{2}+\left(\frac{x}{L_{0}}\right)^{3}\right]
\end{aligned}
$$

Utilizando-se as funções de forma dadas em (3.33) e aplicando-as na equação (3.31), tem-se que:

$$
\begin{aligned}
& u(x)=[N 1(x) \quad 0 \quad 0 \quad N 2(x) \quad 0 \quad 0] \cdot u \\
& v(x)=\left[\begin{array}{llllll}
0 & N 3(x) & N 4(x) & 0 & N 5(x) & N 6(x)
\end{array}\right] \cdot u
\end{aligned}
$$

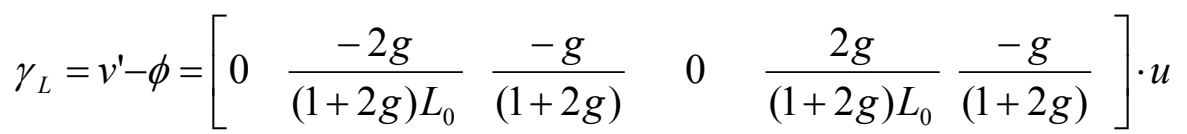

Para escrever matricialmente as deformações dadas pelas equações (3.18), recorre-se às equações (3.32) e suas derivadas, expressas por:

$$
\begin{aligned}
& u^{\prime}(x)=\left[N 1^{\prime}(x) \quad 0 \quad 0 \quad N 2^{\prime}(x) \quad 0 \quad 0\right] \cdot u=A^{T} u \\
& v^{\prime}(x)=\left[\begin{array}{lllll}
0 & N 3^{\prime}(x) & N 4^{\prime}(x) & 0 & N 5^{\prime}(x) \quad N 6^{\prime}(x)
\end{array}\right] \cdot u=B^{T} u \\
& v^{\prime \prime}(x)=\left[\begin{array}{llllll}
0 & N 3^{\prime \prime}(x) & N 4^{\prime \prime}(x) & 0 & N 5^{\prime \prime}(x) & N 6^{\prime \prime}(x)
\end{array}\right] \cdot u=C^{T} u
\end{aligned}
$$

Portanto, tem-se que:

$$
\varepsilon_{x x}=A^{T} u+\frac{1}{2}\left(A^{T} u\right)\left(A^{T} u\right)+\frac{1}{2}\left(B^{T} u\right)\left(B^{T} u\right)-y C^{T} u-y\left(A^{T} u\right)\left(C^{T} u\right)
$$




$$
\gamma_{x y}=D^{T} u-\left(A^{T} u\right)\left(B^{T} u\right)-\frac{1}{2}\left(B^{T} u\right)\left(B^{T} u\right)\left(B^{T} u\right)
$$

onde $D^{T} \boldsymbol{u}$ é dado pela equação (3.34c).

Sabendo-se que as deformações virtuais são dadas por:

$$
\begin{aligned}
& \delta \varepsilon_{x x}=\underline{B}_{x x} \cdot \delta u \\
& \delta \gamma_{x y}=\underline{B}_{x y} \cdot \delta u
\end{aligned}
$$

de modo que:

$$
\begin{aligned}
& \underline{B}_{x x}=A^{T}+\left(A^{T} u\right) A^{T}+\left(B^{T} u\right) B^{T}-y C^{T}-y\left(C^{T} u\right) A^{T}-y\left(A^{T} u\right) C^{T} \\
& \underline{B}_{x y}=D^{T}-\left(B^{T} u\right) A^{T}-\left(A^{T} u\right) B^{T}-\frac{3}{2}\left(B^{T} u\right) B^{T}\left(B^{T} u\right)
\end{aligned}
$$

Semelhantemente, as taxas das deformações e das deformações virtuais são dadas por:

$$
\begin{aligned}
& \dot{\varepsilon}_{x x}=\underline{B}_{x x} \cdot \dot{u} \\
& \dot{\gamma}_{x y}=\underline{B}_{x y} \cdot \dot{u} \\
& \dot{\delta \dot{\varepsilon}_{x x}}=\delta u^{T} \cdot \underline{G}_{x x} \cdot \dot{u} \\
& \dot{\delta \gamma_{x y}}=\delta u^{T} \cdot \underline{G}_{x y} \cdot \dot{u}
\end{aligned}
$$

sendo que:

$$
\begin{aligned}
& \underline{G}_{x x}=A A^{T}+B B^{T}-y A C^{T}-y C A^{T} \\
& \underline{G}_{x y}=-B A^{T}-A B^{T}-3\left(B^{T} u\right) B B^{T}
\end{aligned}
$$

Partindo-se da forma matricial da equação (3.07), com o vetor de deslocamentos virtuais colocados em evidência e levando-se em consideração as parcelas de esforços longitudinal e tangencial, o vetor de esforços internos fica definido como:

$$
F^{\mathrm{int}}=\int_{V_{0}} \underline{B}_{x x} \cdot S_{x x} \cdot d V_{0}+\int_{V_{0}} \underline{B}_{x y} \cdot S_{x y} \cdot d V_{0}
$$

Como a equação (3.07) é não-linear, para a obtenção de solução satisfatória, faz-se necessária a sua linearização. O método de Newton-Raphson é adotado para linearização a partir do truncamento em $1^{\mathrm{a}}$ ordem do seu desenvolvimento em série, em torno do instante t, de modo que: 


$$
\left(\int_{V_{0}} r_{0} \cdot \delta u \cdot d V_{0}\right)_{t+\Delta t}=\left(\int_{V_{0}} r_{0} \cdot \delta u \cdot d V_{0}\right)_{t}+\frac{d}{d t}\left(\int_{V_{0}} r_{0} \cdot \delta u \cdot d V_{0}\right)_{t} \cdot \Delta t
$$

Para facilitar a identificação da matriz de rigidez na linearização do equilíbrio, reescreve-se a equação (3.42) na forma:

$$
(r)_{t}+\left(K_{T} \dot{u}-\dot{f}_{b}-\dot{f}_{t}\right) \cdot \Delta t=0
$$

que restrita à analise considerando apenas forças conservativas resulta em:

$$
\frac{d}{d t}\left(\int_{V_{0}} r_{0} \cdot \delta u \cdot d V_{0}\right)_{t}=\int_{V_{0}} \dot{S} \cdot \delta \varepsilon \cdot d V_{0}+\int_{V_{0}} S \cdot \dot{\delta} \dot{\varepsilon} \cdot d V_{0}
$$

Desenvolvendo-se esta última, obtém-se a matriz de rigidez tangente da análise nãolinear geométrica para o elemento de pórtico plano com Timoshenko. Dessa forma:

$$
\begin{aligned}
& K_{T f}=\int_{V_{0}} \underline{B}_{x x}{ }^{T} \cdot E \cdot \underline{B}_{x x} \cdot d V_{0}+\int_{V_{0}} \underline{G}_{x x} \cdot S_{x x} \cdot d V_{0} \\
& K_{T c}=\int_{V_{0}} \underline{B}_{x y}{ }^{T} \cdot G \cdot \underline{B}_{x y} \cdot d V_{0}+\int_{V_{0}} \underline{G}_{x y} \cdot S_{x y} \cdot d V_{0} \\
& K_{T}=K_{T f}+K_{T c}
\end{aligned}
$$

\subsubsection{Formulação lagrangiana atualizada}

$\mathrm{Na}$ formulação lagrangiana atualizada, todas as integrais são calculadas em relação à última configuração equilibrada, sendo mais adequada nos casos de grandes deslocamentos e rotações, pois permite o uso de aproximações feitas para as rotações sem que seja afetada a precisão numérica da solução.

Para que a implementação numérica seja adequadamente realizada, faz-se necessária, primeiramente, a atualização contínua das coordenadas cartesianas nodais, acrescentando o vetor dos deslocamentos incrementais à última configuração de equilíbrio, de modo que:

$$
\{X\}=\left\{X_{0}\right\}+\{\Delta u\}
$$

onde $\{\boldsymbol{X}\}$ é o vetor contendo as coordenadas cartesianas nodais atualizadas.

Posteriormente, como complemento, realiza-se a atualização da descrição do tensor de tensão pois, na descrição atualizada, a mudança contínua de referencial impõe que o tensor de Piola-Kirchhoff de $2^{\mathrm{a}}$ espécie seja transformado para a nova configuração, rotacionada em relação à anterior, segundo a forma: 


$$
S=R^{T} \cdot S_{0} \cdot R
$$

onde $\boldsymbol{S}_{\boldsymbol{0}}$ é o tensor de Piola-Kirchhoff de $2^{\mathrm{a}}$ espécie relativo à configuração anterior e $\boldsymbol{R}$ o tensor ortogonal de rotação.

No entanto, como presente em PAULA (2001), a formulação adequada utiliza o tensor de Cauchy que necessita ser relacionado com o tensor de Piola-Kirchhoff de $2^{\mathrm{a}}$ espécie, na forma:

$$
\sigma=R^{T} \cdot S \cdot R=R R^{T} \cdot S_{0} \cdot R R^{T}=S_{0}
$$

Sendo assim, como mostra a equação (3.51), para pequenas deformações, o tensor de Cauchy na configuração atual coincide com o tensor de Piola-Kirchhoff de $2^{\mathrm{a}}$ espécie da configuração anterior. Com isso, a cada passo de carga é gerado um incremento de tensão $\Delta \boldsymbol{S}$ que é adicionado à tensão $\boldsymbol{S}_{\boldsymbol{0}}$, de modo que:

$$
S=S_{0}+\Delta S
$$

Finalizadas essas considerações, resta comentar que o cálculo das integrais referentes ao equilíbrio é realizado numericamente a partir das quadraturas de Gauss e Gauss-Lobatto, tanto na altura da seção quanto ao longo da barra, como será detalhado no Capítulo 5. 


\section{MODELO CONSTITUTIVO DE DANO}

\subsection{CONSIDERAÇÕES INICIAIS}

Os modelos de dano buscam representar as perdas progressivas de rigidez e de resistência do material devidas ao seu processo de degradação, levando-se em conta as perturbações infinitesimais distribuídas continuamente no interior do volume do sólido de forma aleatória. Por outro lado, a mecânica da fratura considera os defeitos discretos do material e desprezando qualquer perturbação nas vizinhanças do defeito, de forma que as propriedades do material nessas regiões encontram-se inalteradas.
Mec. da Fratura
Mec. do Dano
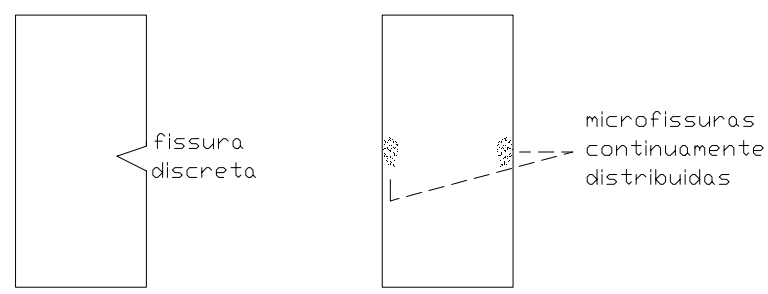

Figura (4.01): Mecânica da fratura e mecânica do dano

No presente trabalho, pretende-se simular o comportamento do concreto através de um modelo de dano, o que é perfeitamente viável, pois como cita NEVES (2000): “os modelos definidos no contexto da mecânica do dano são adequados para levar-se em conta o efeito causado pela evolução dos microdefeitos no interior do volume do sólido nas propriedades físicas e mecânicas dos corpos que estão sujeitos a quaisquer ações". 
$\mathrm{Na}$ realidade, o processo de microfissuração que se desenvolve no concreto, principalmente após o início do carregamento, altera significativamente as respectivas propriedades do concreto. Tal alteração, no caso de vigas fletidas, fica evidenciada, pelo deslocamento da linha neutra em direção à borda mais comprimida à medida que o carregamento aumenta, de modo que ocorre redução na inércia da peça e na capacidade resistente da mesma.

Geralmente, a formação de uma determinada fissura é o resultado da interligação (coalescência) de inúmeras microfissuras, o que torna praticamente impossível conhecer a quantidade e a localização exata das fissuras. Sendo, então, as múltiplas fissuras característica preponderante no comportamento de degradação do concreto, os modelos de dano representam esse comportamento com bastante eficácia.

Dentre os modelos de dano encontrados na literatura, foi escolhido o modelo proposto por Mazars (1984) devido à sua eficiente adequação à modelagem de peças de concreto armado, principalmente em módulo I, como mostram inúmeros trabalhos de vários centros de pesquisa, inclusive diversos desenvolvidos na EESC - USP que utilizaram esse modelo.

A seguir, descreve-se detalhadamente o modelo isótropo de Mazars, segundo as aplicações realizadas neste trabalho.

\section{2 - DESCRIÇÃO DO MODELO DE MAZARS}

No modelo isótropo de Mazars consideram-se um estado biaxial de deformações para o concreto e um estado local de deterioração, que provoca a ruptura de um elemento representativo de volume, avaliado a partir da variável escalar $\mathbf{D}$, que está intimamente relacionada com os níveis de fissuração, variando de 0 (peça íntegra) até 1 (peça rompida); é definida como escalar nos modelos isótropos, ou seja, onde o dano é considerado independe da direção analisada.

Outra característica do modelo é a desconsideração das deformações plásticas, de modo que, no descarregamento, a rigidez seja secante à curva tensão x deformação e passe pela origem dos eixos e pelo ponto onde o descarregamento foi iniciado. Contudo, o modelo representa bem o comportamento do concreto, com resultados satisfatórios. 


\subsection{1 - Elemento representativo de volume}

Devido ao fato de o concreto não ser microscopicamente um material homogêneo, apesar de macroscopicamente sugerir a existência de tal propriedade, há limitações na aplicabilidade de teorias e processos baseados no princípio da continuidade do meio. Surge, então, a necessidade de limitar as regiões dentro do volume onde a continuidade pode ser aplicada.

Portanto, define-se elemento representativo de volume como uma região do volume do sólido que possui as mesmas características físicas do material; seja a mínima onde as teorias do meio contínuo continuem válidas; seja grande o suficiente para que o material possa ser considerado homogêneo e seja suficientemente pequena de modo a poder desprezar os infinitésimos de ordem superior.

\subsection{2 - Hipóteses básicas}

Tomando-se o elemento representativo de volume conforme a figura (4.02), definese a superfície $\mathbf{S}$, com versor normal $\mathbf{n}$, que contem uma área $\mathbf{S}_{\mathbf{0}}$ de microdefeitos que representam e são proporcionais à danificação.

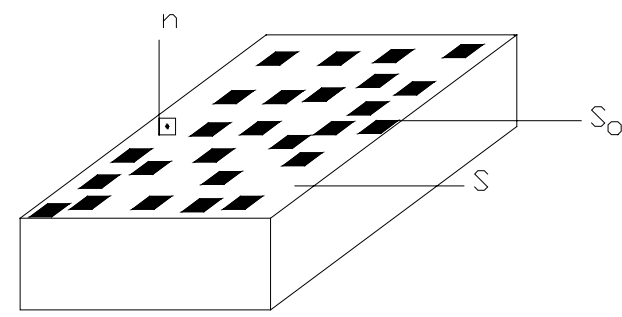

Figura (4.02): Elemento representativo de volume

Sendo assim, define-se o dano como a razão entre a área de microdefeitos (danificada) e a área total. De modo que:

$$
D=\frac{S_{0}}{S}
$$

De acordo com a equação (4.01) confirma-se como foi dito antes que D está definida no intervalo fechado $[0,1] \subset \mathrm{R}$ em cada ponto do corpo do material para quantificar 
localmente o seu grau de deterioração. Ao se admitir a isotropia do material, ou seja, que o dano independe da direção da normal $\mathbf{n}$, a variável $\mathbf{D}$ passa a ser considerada escalar.

Supondo-se que a tensão seja constante na área $S$ da figura (4.02), sobre a qual atua uma força $\mathbf{F}$ cuja direção é a mesma da normal $\mathbf{n}$, pode-se então definir a tensão efetiva que atua no material, através da relação:

$$
\tilde{\sigma}=\frac{F}{\tilde{S}}
$$

onde: $\tilde{S}=S-S_{0}$ : área de material intacto ou efetiva.

A partir da manipulação das equações (4.01) e (4.02) e lembrando-se que $\sigma$ é a tensão resultante da ação de $\mathbf{F}$ sobre a área total $\mathbf{S}$, tem-se:

$$
\tilde{\sigma}=\frac{\sigma}{1-D}
$$

No modelo de Mazars, ao se considerar um sólido de material danificado como um meio contínuo, segundo as características do elemento representativo de volume, utiliza-se, por facilidade de formulação, a hipótese de deformação equivalente. Segundo essa hipótese pode-se afirmar que a deformação de um material danificado é equivalente à do material íntegro, com a tensão efetiva no lugar da tensão atuante, como mostra a figura (4.03).

Portanto, baseado na lei de Hooke, pode-se escrever:

$$
\varepsilon=\frac{\sigma}{(1-D) E}=\frac{\tilde{\sigma}}{E}
$$

onde $\mathbf{E}$ é o módulo de elasticidade do concreto.
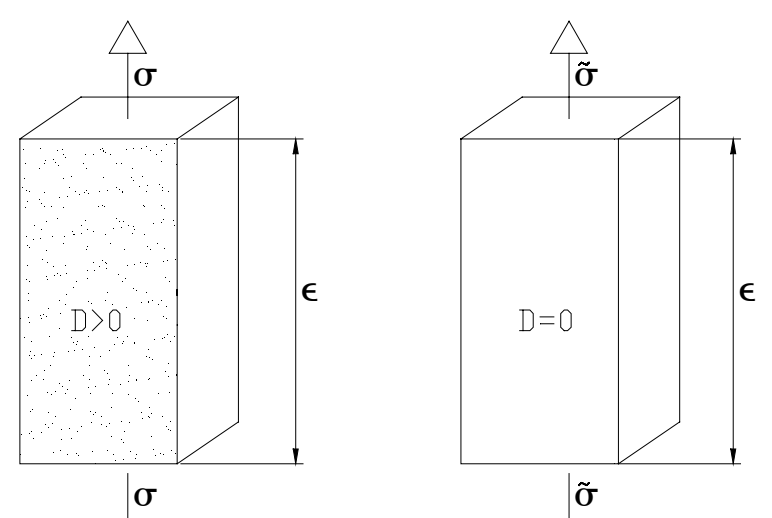

Figura (4.03): Deformação equivalente 
Geralmente, o estado de deformações em um ponto é conhecido para problemas usuais da engenharia, como a análise de pórticos. Com o auxílio da equivalente relação constitutiva obtêm-se as tensões. No entanto, é necessária a associação do dano a uma propriedade do concreto, no caso o módulo de elasticidade, através da relação:

$$
\tilde{E}=(1-D) E
$$

que aplicada sobre a equação (4.04) resulta em:

$$
\varepsilon=\frac{\sigma}{\tilde{E}}
$$

O modelo está baseado na hipótese principal que considera que a degradação do material esteja associada à existência de deformações de tração em pelo menos uma das direções principais. Portanto, para representar o estado de alongamento em um determinado ponto da estrutura, define-se a grandeza deformação equivalente a partir de:

$$
\tilde{\varepsilon}=\sqrt{\left(\varepsilon_{1}\right)_{+}^{2}+\left(\varepsilon_{2}\right)_{+}^{2}+\left(\varepsilon_{3}\right)_{+}^{2}}
$$

onde os $\left(\varepsilon_{\mathrm{i}}\right)_{+}$representam as componentes positivas do vetor de deformações principais, dadas por:

$$
\left(\varepsilon_{i}\right)_{+}^{2}=\frac{1}{2} \cdot\left[\varepsilon_{i}+\left|\varepsilon_{i}\right|\right]
$$

de forma que $\left(\varepsilon_{\mathrm{i}}\right)_{+}=\varepsilon_{\mathrm{i}}$ quando $\varepsilon_{\mathrm{i}}$ é positivo e $\left(\varepsilon_{\mathrm{i}}\right)_{+}=0$ quando $\varepsilon_{\mathrm{i}}$ é negativo.

Tabela (4.01): Particularização para deformação equivalente

\begin{tabular}{|c|c|c|}
\hline \multicolumn{2}{|c|}{ Estado de tensões } & Deformação equivalente $\tilde{\varepsilon}$ \\
\hline $\begin{array}{c}\text { Tração } \\
\text { Uniaxial }\end{array}$ & $\tilde{\varepsilon}=\varepsilon_{1}$ \\
\hline $\begin{array}{c}\text { Compressão } \\
\text { Uniaxial }\end{array}$ & $\tilde{\varepsilon}=\sqrt{\left(\varepsilon_{2}\right)^{2}+\left(\varepsilon_{3}\right)^{2}}=-v \varepsilon_{1} \sqrt{2}$ \\
\hline $\begin{array}{c}\text { Compressão } \\
\text { Biaxial }\end{array}$ & $\rightarrow$ & $\tilde{\varepsilon}=\sqrt{\left(\varepsilon_{3}\right)^{2}}=-\frac{v}{1-v}\left(\varepsilon_{1}+\varepsilon_{2}\right)$ \\
\hline $\begin{array}{c}\text { Compressão } \\
\text { Hidrostática }\end{array}$ & $\sim$ & $\tilde{\varepsilon}=0$ \\
\hline Multiaxial & $\rightarrow$ & $\tilde{\varepsilon}=\sqrt{\left(\varepsilon_{1}\right)_{+}^{2}+\left(\varepsilon_{2}\right)_{+}^{2}+\left(\varepsilon_{3}\right)_{+}^{2}}$ \\
\hline
\end{tabular}


A partir de particularizações sobre as equações (4.07) e (4.08) obtém-se a tabela (4.01) adaptada de NEVES (2000).

Na convenção adotada pelo modelo, admite-se que o início da danificação acontece quando o valor da deformação equivalente atinge o valor dado pela deformação correspondente ao pico de tensão em um ensaio uniaxial de tração. Denomina-se $\varepsilon_{\mathrm{d} 0}$ esse valor, como mostra a figura (4.04).

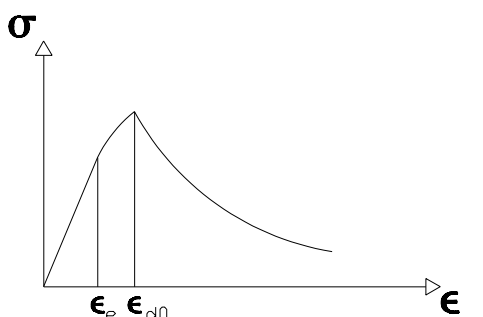

Figura (4.04): Diagramas do concreto à tração uniaxial

\subsection{3 - Critério de danificação}

Partindo-se da hipótese que a danificação seja iniciada a partir de deformações equivalentes maiores que $\varepsilon_{\mathrm{d} 0}$, pode-se definir o seguinte critério de danificação:

$$
f(\tilde{\varepsilon}, D)=\tilde{\varepsilon}-\hat{S}(D) \leq 0
$$

onde $\hat{\mathbf{S}}(\mathbf{D})$ representa a deformação equivalente em função do dano.

No modelo, a variável escalar do dano $\mathbf{D}$ apresenta lei de evolução definida em taxas de variação no tempo, dada por:

$$
\begin{aligned}
& \dot{D}=0 \text { se } f<0 \text { ou } f=0 \text { e } \dot{f}<0 \\
& \dot{D}=F(\tilde{\varepsilon}) \cdot(\dot{\sim}) \text { se } f=0 \text { e } \dot{f}=0
\end{aligned}
$$

sendo a função $\mathbf{F}(\boldsymbol{\varepsilon})$ contínua e positiva, baseada em resultados experimentais de modo a reproduzir as curvas de ensaios uniaxiais de corpos de prova de concreto. Vale ressaltar a correspondência entre a variação de deformação e a variação do dano, como segue:

$$
\stackrel{\sim}{\varepsilon} \geq 0 \Rightarrow \dot{D} \geq 0
$$




\subsection{4 - Equacionamento}

Para o equacionamento adequado do modelo de Mazars, definem-se duas variáveis independentes, $\mathbf{D}_{\mathbf{T}}$ e $\mathbf{D}_{\mathbf{C}}$, que representam os ramos não lineares das curvas tensão $\mathrm{x}$ deformação do concreto tracionado e comprimido.

O procedimento é justificável, pois uma das características do modelo de Mazars é a formulação para carregamento crescente, de forma que em problemas nos quais os descarregamentos possuem influência significativa, há necessidade de se considerar o comportamento unilateral do concreto, como mostra a figura (4.05). Esse comportamento leva ao fenômeno da recuperação da rigidez provocado pelo fechamento das fissuras quando uma peça é tracionada e posteriormente comprimida.

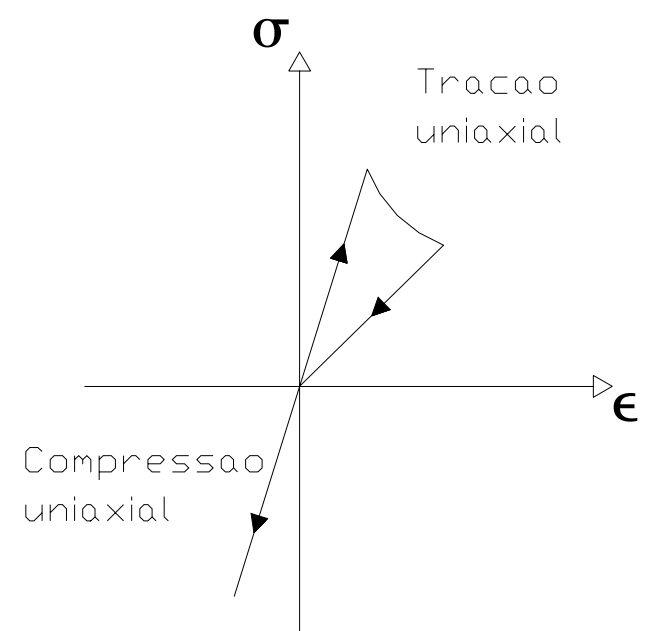

Figura (4.05): Comportamento unilateral do concreto

Além disso, os comportamentos do concreto tracionado e comprimido são distintos. No primeiro caso, o desenvolvimento do processo de fissuração ocorre perpendicularmente à direção da carga, enquanto que no segundo, a evolução é paralela à direção da carga.

Portanto, tem-se:

$$
\begin{aligned}
& \dot{D}_{T}=F_{T}(\tilde{\varepsilon}) \cdot(\dot{\tilde{\varepsilon}})_{+} \\
& \dot{D}_{C}=F_{C}(\tilde{\varepsilon}) \cdot\left(\begin{array}{c}
\dot{\tilde{\varepsilon}} \\
\varepsilon
\end{array}\right)_{+}
\end{aligned}
$$


que ao serem devidamente integradas no tempo, conforme a figura (4.06), resultam em:

$$
\begin{gathered}
D_{T}=1-\frac{\varepsilon_{d 0}\left(1-A_{T}\right)}{\tilde{\varepsilon}}-\frac{A_{T}}{B_{T}\left(\tilde{\varepsilon}-\varepsilon_{d 0}\right)} \\
D_{C}=1-\frac{\varepsilon_{d 0}\left(1-A_{C}\right)}{\tilde{\varepsilon}}-\frac{e_{C}}{e^{B_{C}\left(\tilde{\varepsilon}-\varepsilon_{d 0}\right)}}
\end{gathered}
$$

\section{$\epsilon$}

Figura (4.06): Representação das variáveis de dano em função de $\tilde{\varepsilon}$

Vale ressaltar que os valores $\mathbf{A}_{\mathbf{T}}, \mathbf{B}_{\mathbf{T}}, \mathbf{A}_{\mathbf{C}}, \mathbf{B}_{\mathbf{C}}$ e $\boldsymbol{\varepsilon}_{\mathrm{d} 0}$ são parâmetros característicos do material, identificados experimentalmente ou através do ajuste teórico das expressões das variáveis de dano do modelo, de forma a aproximar ao máximo possível a curva tensão $\mathrm{x}$ deformação obtida da curva experimental. No entanto, Mazars propõe limites de variação para os parâmetros do modelo baseado nas análises experimentais, de modo que:

$$
\begin{array}{ll}
10^{-5} \leq \boldsymbol{\varepsilon}_{\mathbf{d} 0} \leq 10^{-4} & \\
0,7 \leq \mathbf{A}_{\mathbf{T}} \leq 1 & 1 \leq \mathbf{A}_{\mathbf{C}} \leq 1,5 \\
10^{4} \leq \mathbf{B}_{\mathbf{T}} \leq 10^{5} & 10^{3} \leq \mathbf{B}_{\mathbf{C}} \leq 2.10^{3}
\end{array}
$$

A figura (4.07) retrata as curvas experimentais e teóricas para os casos uniaxiais de tração e compressão, na qual pode ser verificada a inexistência de deformações permanentes nos modelos teóricos e a diminuição da rigidez nas retas de descarregamento.
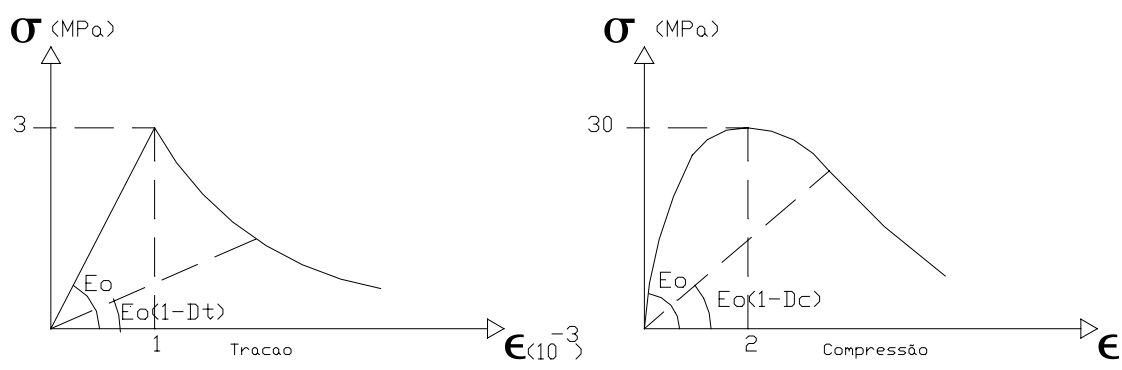

Figura (4.07): Diagramas teóricos para o concreto 
Nos casos multiaxiais, propõe-se uma combinação linear das variáveis $\mathbf{D}_{\mathrm{T}}$ e $\mathbf{D}_{\mathbf{C}}$ para a determinação de $\mathbf{D}$, conforme a expressão:

$$
D=\alpha_{T} D_{T}+\alpha_{C} D_{C}
$$

A tabela (4.02) fornece os valores dos coeficientes $\alpha_{T}$ e $\alpha_{C}$, definidos no intervalo fechado $[0,1] \subset R$ e da variável $\mathbf{D}$ para os casos particulares de tração e compressão uniaxial e estados multiaxiais.

Tabela (4.02): Particularizações para $\alpha_{T}$ e $\alpha_{C}$ e D

\begin{tabular}{|l|c|c|c|}
\hline Estado de tensão & $\alpha_{\mathbf{T}}$ & $\alpha_{\mathbf{C}}$ & $\boldsymbol{D}$ \\
\hline Tração uniaxial & 1 & 0 & $\mathrm{D}_{\mathrm{T}}$ \\
\hline Compressão uniaxial & 0 & 1 & $\mathrm{D}_{\mathrm{C}}$ \\
\hline Multiaxiais & \multicolumn{2}{|c|}{$\alpha_{\mathrm{T}}+\alpha_{\mathrm{C}}=1$} & $\alpha_{\mathrm{T}} \cdot \mathrm{D}_{\mathrm{T}}+\alpha_{\mathrm{C}} \cdot \mathrm{D}_{\mathrm{C}}$ \\
\hline
\end{tabular}

A aplicação do modelo de dano de Mazars em um estado biaxial de tensões, objetivo deste trabalho, segue um roteiro que se inicia com a determinação das deformações nas fibras correspondentes aos pontos de Gauss. A seguir, a partir da lei de Hooke, calcula-se o tensor das deformações principais em cada ponto. Ao se relacionar o tensor anterior com o tensor elástico $\underline{\underline{\mathbf{D}}}_{\mathbf{0}}$ obtém-se o tensor das tensões principais do instante em análise, segundo a equação:

$$
\tilde{\tilde{\sigma}}=\underline{\underline{D}}_{0} \cdot \underline{\varepsilon}
$$

Em termos matriciais o tensor de tensões principais é dado por:

$$
\tilde{\sigma_{i}}=\left[\begin{array}{ccc}
\frac{E}{1-v^{2}}\left(\varepsilon_{x}+v \varepsilon_{y}\right) & 0 & 0 \\
0 & \frac{E}{1-v^{2}}\left(\varepsilon_{y}+v \varepsilon_{x}\right) & 0 \\
0 & 0 & 0
\end{array}\right]
$$

que devido ao comportamento distinto do concreto à tração e à compressão é decomposto em uma parcela positiva e outra negativa, segundo:

$$
\underline{\tilde{\sigma}}=(\underline{\sigma})_{+}+(\underline{\sigma})_{-}
$$


onde:

$$
\begin{aligned}
& \left(\underline{\left.\sigma_{i}\right)_{+}}=\frac{1}{2}\left(\sigma_{i}+\left|\sigma_{i}\right|\right)\right. \\
& \left({\underline{\sigma_{i}}}_{-}=\frac{1}{2}\left(\sigma_{i}-\left|\sigma_{i}\right|\right)\right.
\end{aligned}
$$

A partir das expressões (4.19) e (4.20), conclui-se que o tensor $(\underline{\sigma})_{+}$é composto apenas por parcelas positivas, enquanto o tensor $(\underline{\sigma})$ - pelas componentes negativas, sendo nulos os demais termos em ambos os tensores.

Seguindo a mesma linha de raciocínio, pode-se decompor o tensor de deformações principais em duas partes, de modo que uma parte represente as deformações por tração (alongamento) e, a outra, as deformações por compressão (encurtamento), como segue:

$$
\underline{\varepsilon}=\underline{\varepsilon}_{T}+\underline{\varepsilon}_{C}
$$

onde:

$$
\begin{gathered}
\underline{\varepsilon}_{T}=\frac{1+v}{E}(\underline{\sigma})_{+}-\frac{v}{E}\left(\sum \underline{\sigma}_{i}\right)_{+} \cdot \underline{I} \\
\underline{\varepsilon}_{C}=\frac{1+v}{E}(\underline{\sigma})_{-}-\frac{v}{E}\left(\sum \underline{\sigma}_{i}\right)_{-} \cdot \underline{I}
\end{gathered}
$$

sendo $\mathbf{I}$ um tensor identidade de quarta ordem, $\mathbf{E}$ o módulo de elasticidade e $v$ o coeficiente de Poisson.

Como os tensores $\underline{\varepsilon}_{\mathrm{T}}$ e $\underline{\varepsilon}_{\mathrm{C}}$ podem conter valores positivos e negativos, tomam-se as partes positivas desses tensores, dadas por: $\left(\varepsilon_{T}\right)_{+}$e $\left(\varepsilon_{C}\right)_{+}$. Com isso define-se:

$$
\underline{\varepsilon}_{V}^{+}=\left(\underline{\varepsilon}_{T i}\right)_{+}+\left(\underline{\varepsilon}_{C i}\right)_{+}
$$

e para o cálculo dos coeficientes $\alpha_{\mathrm{T}}$ e $\alpha_{\mathrm{C}}$ define-se:

$$
\begin{aligned}
\alpha_{T}=\frac{\sum_{i}\left(\underline{\varepsilon}_{T i}\right)_{+}}{\underline{\varepsilon}_{V}^{+}} \\
\alpha_{C}=\frac{\sum_{i}\left(\underline{\varepsilon}_{C i}\right)_{+}}{\underline{\varepsilon}_{V}^{+}}
\end{aligned}
$$

Finalmente, conhecidos os coeficientes $\alpha_{\mathrm{T}}$ e $\alpha_{\mathrm{C}}$ e os parâmetros variáveis $\mathbf{D}_{\mathrm{T}}$ e $\mathbf{D}_{\mathrm{C}}$, calcula-se a variável $\mathbf{D}$ e posteriormente, com o auxílio das relações constitutivas, determinase o tensor de tensões reais, conforme:

$$
\underline{\sigma}=(1-D) \underline{\underline{D}}_{0} \cdot \underline{\varepsilon}
$$




\section{IMPLEMENTAÇÃO NUMÉRICA}

\subsection{CONSIDERAÇÕES INICIAIS}

Neste capítulo discutem-se os critérios e conceitos envolvidos na implementação numérica, destacando primeiramente o modelo de resistência ao cisalhamento e, na seqüência, a combinação do modelo de dano e a NLG, incluindo o processo de integração numérica e o método de Newton-Raphson para a solução do sistema não-linear de equações. No final, é apresentado um exemplo simples de aplicação, no qual a resposta teórica é comparada à numérica.

\subsection{MECANISMO DE ATUAÇÃO DAS TENSÕES CISALHANTES}

\subsubsection{Princípios gerais}

Sob ação de um carregamento vertical qualquer, com ou sem esforço normal, as vigas trabalham em flexão simples ou composta, com momento fletor variável, portanto, com força cortante diferente de zero. Portanto, nesse caso haverá nas seções transversais, além das tensões normais, tensões tangenciais.

As tensões tangenciais levam a um processo de ruptura muito complexo cuja análise não possui soluções fechadas e por isso deve ser evitada nas estruturas correntes em favor da segurança. Ao ser analisado isoladamente, o esforço cortante produz tensões de compressão e de tração diagonal em planos que formam ângulos de $45^{\circ}$ com o plano da seção transversal. 
No entanto, é impossível ocorrer cisalhamento sem flexão, de modo que sempre existe atuação de tensões normais de flexão que juntamente com as tensões tangenciais, constituem estados biaxiais de tensões. Nesse caso, a inclinação entre os planos de ação das tensões de compressão e de tração torna-se diferente de $45^{\circ}$, caracterizando a complexidade do modelo.

Devido à dificuldade em se determinar uma solução fechada precisa e simples, o procedimento comumente adotado para cálculo de vigas trata de forma independente as tensões de flexão e as cisalhantes. Admite, também, que a contribuição das armaduras transversais e do concreto comprimido, na resistência ao esforço cortante, pode ser obtida através da analogia da treliça de Mörsch.

Vale ressaltar que as vigas e demais estruturas fletidas devem ser dimensionadas de modo que a ruína ocorra pela ação do momento fletor, com observação de grandes deformações, antes que os efeitos do cisalhamento ocorram de forma pronunciada.

$\mathrm{Na}$ análise do cisalhamento, alguns fatores têm influência significativa, dentre os quais podem ser citados: forma da seção; variação da mesma ao longo da peca; coeficiente de esbeltez do elemento (relação entre comprimento e altura); disposição das armaduras longitudinais e transversais; aderência e condições de apoio e carregamento.

Baseado nesses fatores, deve-se verificar como ocorre a absorção das tensões cisalhantes por uma peça de concreto armado, com destaque para a separação entre as parcelas absorvidas pelo concreto, que obedece ao critério de dano descrito no Capítulo 4 e pela armadura transversal, representada pelo estribo.

\subsubsection{Modelo implementado}

Ciente das considerações destacadas no item anterior, foi implementado ao programa um modelo aproximado, e relativamente simples, para simular o mecanismo resistente ao cisalhamento do elemento de pórtico plano de Timoshenko em concreto armado, conjunto entre aço e concreto. Tal modelo considera que o resíduo de esforço cortante proveniente do modelo de dano do concreto é totalmente absorvido pela armadura transversal, conforme figura (5.01).

Portanto, o concreto absorve a parte de força cortante dada pelo modelo adotado. A parte restante não é distribuída. Considera-se que esta é diretamente transferida para a armadura transversal. Para se obter uma distribuição média de tensões tangenciais, em uma 
seção retangular de concreto armado, compatível com a distribuição parabólica da figura (5.01), foi utilizado o fator de forma $\boldsymbol{k}$, resultando na figura (5.02).

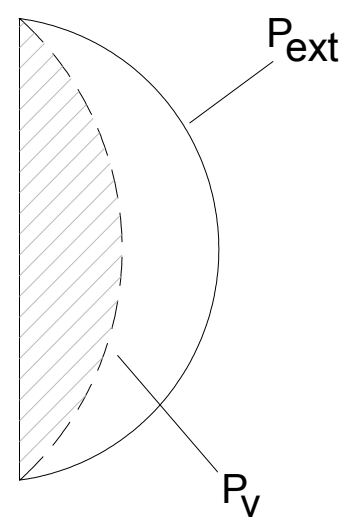

Figura (5.01): Distribuição real de tensões tangenciais

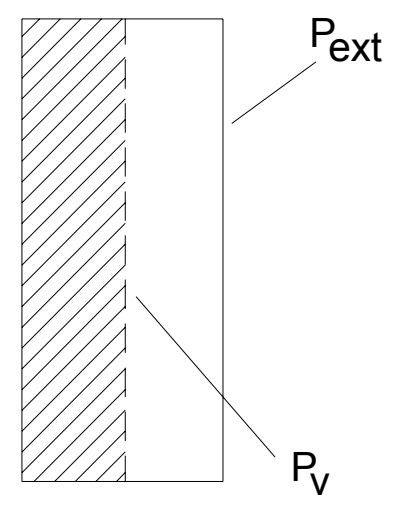

Figura (5.02): Distribuição média de tensões tangenciais

\subsection{COMBINAÇÃO DO MODELO DE DANO COM A NLG}

De acordo com as considerações da não-linearidade geométrica e o modelo de dano proposto por Mazars, discutidos, respectivamente, nos Capítulos 3 e 4, apresenta-se aqui uma proposta para a combinação do dano com a não-linearidade geométrica, semelhante à encontrada em PAULA (2001) e diferenciada apenas pela consideração, no presente trabalho, das hipóteses para a viga de Timoshenko e do modelo resistente ao cisalhamento.

\subsubsection{Matriz de rigidez tangente e vetor de esforços internos}

Partindo-se das propriedades do elemento de pórtico plano, considerando-se as hipóteses de Timoshenko, encontrado nos Capítulos 2 e 3, pode-se observar que esse elemento está sujeito a um estado multiaxial de tensões e deformações. Dessa forma, recorrendo-se ao modelo de Mazars obtém-se a deformação equivalente, dada pela equação (4.07). Portanto, faz-se necessária a determinação das deformações principais, conforme descrito a seguir: 


$$
\begin{aligned}
& \varepsilon_{1}=\frac{I_{1}+\sqrt{\Delta}}{2} \\
& \varepsilon_{2}=\frac{I_{1}-\sqrt{\Delta}}{2} \\
& \varepsilon_{3}=\frac{v}{v-1}\left(\varepsilon_{1}+\varepsilon_{2}\right)
\end{aligned}
$$

onde:

$$
\begin{aligned}
& \Delta=I_{1}{ }^{2}-4 I_{2} \\
& I_{1}=\varepsilon_{x x} \\
& I_{2}=-\frac{\gamma_{x y}{ }^{2}}{4}
\end{aligned}
$$

As deformações longitudinal e tangencial são dadas, respectivamente, pelas equações (3.36a) e (3.36b).

A partir da determinação das deformações principais, segue-se o processo descrito no capítulo 4 e determina-se a variável do dano. Fazendo-se uso das hipóteses de pequenas deformações, para o caso multidimensional, a expressão que representa a relação entre os tensores de tensão e deformação assume a forma:

$$
S=(1-D) \underline{\underline{D}}_{0} \cdot \varepsilon
$$

Contudo, neste trabalho, a consideração da distorção que aparece na seção torna o problema bidimensional, pois a tensão cisalhante deixa de ser nula. Sendo assim tem-se:

$$
\begin{aligned}
& S_{11}=(1-D) E \cdot \varepsilon_{x x} \\
& S_{12 V}=(1-D) G \cdot \gamma_{x y}
\end{aligned}
$$

Porém, uma parte da tensão cisalhante é transferida para armadura transversal segundo o modelo discutido no item 5.2.2. A parte restante vai para o concreto na forma:

$$
S_{12}=S_{12 V}+\sigma_{s w}
$$

onde $\sigma_{\mathrm{sw}}$ é a tensão no estribo dada por:

$$
\sigma_{s w}=D G \cdot \gamma_{x y}
$$


Como visto anteriormente, a matriz de rigidez tangente do elemento de pórtico plano resulta da expressão (3.07). No entanto, para levar-se em conta o efeito da tensão cisalhante, será reescrita como:

$$
\begin{aligned}
& \int_{V_{0}} r \cdot \delta u \cdot d V_{0}=\int_{V_{0}} S \cdot \delta \varepsilon \cdot d V_{0} \\
& \frac{d}{d t} \int_{V_{0}} r \cdot \delta u \cdot d V_{0}=\int_{V_{0}} \dot{S} \cdot \delta \varepsilon \cdot d V_{0}+\int_{V_{0}} S \cdot \dot{\delta} \dot{\varepsilon} \cdot d V_{0}
\end{aligned}
$$

Para resolver a equação (5.07) necessita-se, além da equação (5.08), da expressão referente à taxa de variação da tensão de Piolla-Kirchhoff de $2^{\mathrm{a}}$ espécie, dada por:

$$
\dot{S}=(1-D) \underline{\underline{D}}_{0} \cdot \dot{\varepsilon}+(-\dot{D}) \underline{\underline{D}}_{0} \cdot \varepsilon
$$

onde:

$$
\begin{aligned}
& \dot{D}=\frac{\partial D}{\partial \tilde{\varepsilon}} \cdot \frac{\partial \tilde{\varepsilon}}{\partial \varepsilon} \cdot \frac{\partial \varepsilon}{\partial t}=F(\tilde{\varepsilon}) \cdot \frac{\partial \tilde{\varepsilon}}{\partial \varepsilon} \cdot \dot{\varepsilon} \\
& F(\tilde{\varepsilon})_{T}=1-\frac{\varepsilon_{d 0}\left(1-A_{T}\right)}{\tilde{\varepsilon}^{2}}-\frac{A_{T} \cdot B_{T}}{B_{T}\left(\tilde{\varepsilon}-\varepsilon_{d 0}\right)} \\
& F(\tilde{\varepsilon})_{C}=1-\frac{\varepsilon_{d 0}\left(1-A_{C}\right)}{\tilde{\varepsilon}^{2}}-\frac{A_{C} \cdot B_{C}}{B_{C}\left(\tilde{\varepsilon}-\varepsilon_{d 0}\right)}
\end{aligned}
$$

sendo a função $\boldsymbol{F}(\tilde{\varepsilon})=\alpha_{T} \boldsymbol{F}(\tilde{\varepsilon})_{T}+\alpha_{C} \boldsymbol{F}(\tilde{\varepsilon})_{C}$.

A derivada da deformação equivalente em relação à parte longitudinal do tensor de deformações, depende do sentido de deformação das fibras; em outras palavras, do sinal do determinante dessa parte do tensor $\varepsilon$. Portanto:

$$
\begin{aligned}
& \frac{\partial \tilde{\varepsilon}}{\partial \varepsilon_{x x}}=1, \text { na tração } \\
& \frac{\partial \tilde{\varepsilon}}{\partial \varepsilon_{x x}}=-v \sqrt{2} \text {, na compressão }
\end{aligned}
$$


Finalmente, obtém-se a matriz de rigidez tangente para o elemento de pórtico plano, com dano de Mazars associado à não-linearidade geométrica e influência do cisalhamento, a partir das expressões:

$$
K_{T}=\int_{V_{0}} \underline{B}^{T}(1-D) \underline{\underline{D}}_{0} \underline{B} d V_{0}+\int_{V_{0}} \underline{B}^{T} \eta \underline{\underline{D}}_{0} \varepsilon \underline{B} d V_{0}+\int_{V_{0}} \underline{G} S d V_{0}
$$

e o vetor dos esforços internos a partir das expressões:

$$
F^{\mathrm{int}}=\int_{V_{0}} \underline{B}^{T} S d V_{0}
$$

onde:

$$
\eta=F(\tilde{\varepsilon}) \cdot \frac{\partial \tilde{\varepsilon}}{\partial \varepsilon}
$$

e as parcelas longitudinais e tangenciais das matrizes $\underline{\boldsymbol{B}}$ e $\underline{\boldsymbol{G}}$ são dadas pelas expressões (3.38a), (3.38b), (3.40a) e (3.40b).

Contudo as integrais no volume, nas equações (5.13) e (5.14), podem ser substituídas por integrais duplas, uma ao longo do comprimento do elemento e outra em sua altura, multiplicadas pela base da seção transversal, como descrito a seguir:

$$
\begin{aligned}
& K_{T}=b \int_{L} \int_{h} \underline{B}^{T}(1-D) \underline{\underline{D}}_{0} \underline{B} d h d x+b \int_{L} \int_{h} \underline{B}^{T} \eta \underline{\underline{D}}_{0} \varepsilon \underline{B} d h d x+b \int_{L} \int_{h} \underline{G} S d h d x \\
& F^{\mathrm{int}}=b \int_{L} \int_{h} \underline{B}^{T} S d h d x
\end{aligned}
$$

\subsubsection{Processo de integração numérica}

No intuito de obter a parcela de contribuição do concreto nas integrais contidas nas equações (5.15) e (5.16), referentes à matriz de rigidez e ao vetor de esforços internos, respectivamente, foi adotado um processo de integração numérica baseado nas quadraturas de Gauss e Gauss-Lobatto, como mostra a figura (5.3a).

As quadraturas de Gauss e Gauss-Lobatto são processos numéricos aproximados de integração que substituem as integrais analíticas por somatórios, cuja precisão depende do numero de pontos adotados. Portanto, necessita-se de quantidade de pontos capaz de representar a função a ser integrada em seu domínio, para que o erro tenda a zero. 


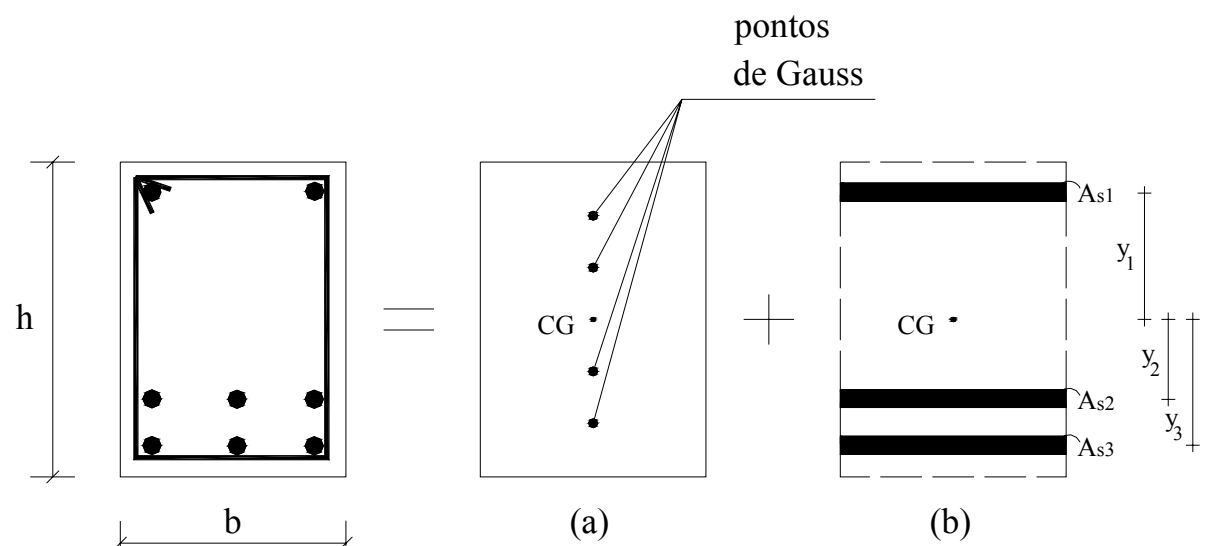

Figura (5.03): Discretização da seção - (a) concreto

(b) aço equivalente

Por isso, é de fundamental importância que seja adotado um número de pontos adequados ao tipo de análise realizada. Em caso de análises com linearidade física, para integração das tensões na altura da seção transversal, 2 pontos são suficientes, pois como mostra a figura (5.4a), a distribuição de tensões é linear. No entanto, em análises nãolineares físicas, como o modelo de dano de Mazars mostrado na figura (5.4b), recomenda-se a utilização de quantidade de pontos superior a 10 (a distribuição de tensões será sempre aproximada). Para formulação lagrangiana atualizada, PAULA (2001) sugere que sejam utilizados no mínimo 6 pontos para as integrais ao longo do comprimento.

(a)

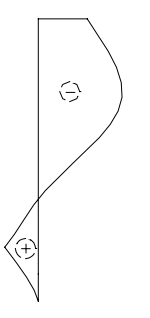

(b)

Figura (5.04): Distribuição de tensões - (a) Linear

(b) Dano de Mazars

Com isso, a expressão numérica que representa a contribuição do concreto à matriz de rigidez é dada por:

$$
K_{c}=\sum_{i=1}^{n l}\left[\sum_{j=1}^{n h}\left(\underline{B}_{i j}^{T}\left(1-D_{j i}\right) \underline{\underline{D}}_{0} \underline{B}_{i j}+\underline{B}_{i j}^{T} \eta_{i j} \underline{D}_{0} \underline{B}_{i j}+\underline{G}_{i j} S_{i j}\right) \frac{b h}{2} w y_{j}\right] \frac{L}{2} w x_{i}
$$


enquanto que a expressão numérica que representa a contribuição do concreto ao vetor de esforços internos é dada por:

$$
\mathbf{F}_{c}^{\mathrm{int}}=\sum_{i=1}^{n l}\left[\sum_{j=1}^{n h}\left(\underline{B}_{i j}^{T} S_{i j}\right) \frac{b h}{2} w y_{j}\right] \frac{L}{2} w x_{i}
$$

A parcela de contribuição das armaduras longitudinais nas integrais contidas nas equações (5.15) e (5.16) é dada por um processo baseado nas quadraturas de Gauss e GaussLobatto para integração numérica ao longo do comprimento do elemento e 3 pontos, referentes às camadas de aço, para integração numérica ao longo da altura da seção transversal, conforme figura (5.3b).

Dessa forma, a parcela de contribuição da armadura à matriz de rigidez é dada por:

$$
K_{s}=\sum_{i=1}^{n l}\left[\sum_{j=1}^{3}\left(\underline{B}_{i j}^{T} E_{s} \underline{B}_{i j}+\underline{G}_{i j} \sigma_{s i j}\right) A_{s j}\right] \frac{L}{2} w x_{i}
$$

e a parcela de contribuição ao vetor de esforços internos é dada por:

$$
\mathbf{F}_{s}^{\mathrm{int}}=\sum_{i=1}^{n l}\left[\sum_{j=1}^{n h}\left(\underline{B}_{i j}^{T} \sigma_{s i j}\right) A_{s j}\right] \frac{L}{2} w x_{i}
$$

Finalmente, somando-se as parcelas de contribuição do concreto e das armaduras longitudinais, dadas pelas equações (5.17), (5.18), (5.19) e (5.20), obtém-se as expressões para a matriz de rigidez e para o vetor de esforços internos, conforme as equações (5.21) e (5.22), respectivamente.

$$
\begin{aligned}
& K_{T}=K_{c}+K_{s} \\
& F_{T}^{\mathrm{int}}=F_{c}^{\mathrm{int}}+F_{s}^{\mathrm{int}}
\end{aligned}
$$

\subsubsection{Processo de Newton-Raphson}

A estratégia de Newton-Raphson para resolução do problema não-linear, baseia-se em um processo de passos finitos no qual: conhecidos o carregamento que atua na estrutura e o deslocamento por ela sofrido no instante t, obtêm-se as variáveis do modelo elastoplástico com encruamento misto para a armadura, e o modelo de dano para o concreto. 
Para tanto é possível seguir um procedimento que alia o PTV ao método dos elementos finitos e leva em consideração a atualização das variáveis de acordo com a forma incremental implícita. Nesse procedimento, a carga total aplicada à estrutura é dividida em um número finito de partes iguais e aplicada em incrementos.

Em cada incremento de carga a primeira iteração é linear, mantendo-se a rigidez final do incremento anterior (na primeira iteração do primeiro incremento a rigidez é a inicial) e as características usuais do método dos deslocamentos, baseada em uma previsão que pode ou não ser confirmada ao se avaliar o critério de plastificação da armadura e de danificação do concreto. Verifica-se também o equilíbrio do sistema.

O equilíbrio da estrutura é alcançado quando a resultante de forças sobre ela é nula (passos elásticos) ou menor que uma tolerância admitida (valor de convergência para os demais passos e iterações); ou seja, quando a diferença entre a força externa (aplicada) e a força interna (devido aos esforços internos) satisfaz os requisitos citados. Essa diferença é o chamado resíduo ou forças nodais desequilibradas.

Se a previsão for confirmada para todas as peças, passa-se para o incremento seguinte sem alterações de suas propriedades. Na realidade, a convergência geralmente é verificada pela norma, média dos resíduos, sendo que em um ponto particular o critério pode não ser atendido, e ainda assim, a previsão é confirmada. Em caso de falha da previsão para pelo menos uma das peças, nova iteração deve ser realizada, atualizando-se as variáveis nãolineares.

Atualizada a rigidez, aplica-se sobre a estrutura o resíduo proveniente do equilíbrio da iteração anterior. O procedimento deve ser repetido até ser alcançada a condição de equilíbrio ou atingido o número estipulado de iterações.

Se para o número estipulado de iterações o equilíbrio não for verificado (condição para se determinar que a carga última foi ultrapassada), deve-se dividir a carga total aplicada em incrementos menores e recomeçar o processo. Se a análise for realizada com deslocamento controlado, o ponto limite é naturalmente obtido. 


\subsection{CONSIDERAÇÕES INICIAIS}

Este capítulo visa justificar, a partir de exemplos numéricos, a utilização dos modelos propostos nos capítulos anteriores utilizando as hipóteses de Timoshenko para vigas, a formulação lagrangiana atualizada e o dano de Mazars. Os exemplos também têm como objetivo comprovar a adequada implementação computacional dos modelos e demonstrar a eficiência dos mesmos.

Para tanto, a precisão dos resultados é avaliada por meio de comparação com resultados experimentais e teóricos disponíveis na bibliografia e com valores provenientes de programas comerciais, como o ANSYS ${ }^{\circledR}$.

No intuito de se obter uma apresentação mais didática, os exemplos foram separados por tipo de análise, na ordem em que foram apresentados os capítulos referentes aos modelos elaborados. Após a avaliação particular de cada modelo discutido, foi feita a análise de exemplos caracterizados por apresentarem efeitos combinados.

Com isso, no exemplo 1, a análise linear de vigas é tratada, considerando-se distintas condições de contorno, para verificar a influência da distorção. Nos dois exemplos seguintes, buscou-se avaliar a eficiência da descrição lagrangiana atualizada para a solução de um problema de NLG em uma viga em balanço, exemplo 2, e de uma estrutura aporticada, exemplo 3 .

Os exemplos 4 e 5 serviram para comprovar a eficiência do modelo de dano de Mazars. No primeiro é avaliada a influencia da perda de rigidez da estrutura na determinação dos deslocamentos da mesma e no segundo são determinados a carga última e o deslocamento horizontal associado a um nó de um pórtico. Neste último em uma mesma análise, combinaram-se os efeitos não-lineares físicos e os geométricos. Essa situação foi ampliada com o acréscimo da influência da distorção para a viga em balanço do exemplo 6. No exemplo 7, a mesma análise é para pórtico plano. 


\subsection{EXEMPLO 1}

A análise deste exemplo tem como objetivo caracterizar a eficiência do programa desenvolvido na obtenção de resultados em análises lineares de vigas com diferentes condições de contorno, utilizando tanto as hipóteses de Bernoulli quanto as de Timoshenko. Para tanto, tomou-se como referência os resultados exatos disponíveis em livros de Resistência dos Materiais e em WANG (1995). As características mecânicas do material são:

- Módulo de elasticidade longitudinal do concreto $-E=25000000 \mathrm{KN} / \mathrm{m}^{2}$

- Módulo de elasticidade transversal do concreto $-\mathrm{G}=10420000 \mathrm{KN} / \mathrm{m}^{2}$

- Coeficiente de Poisson do concreto $-v=0,2$
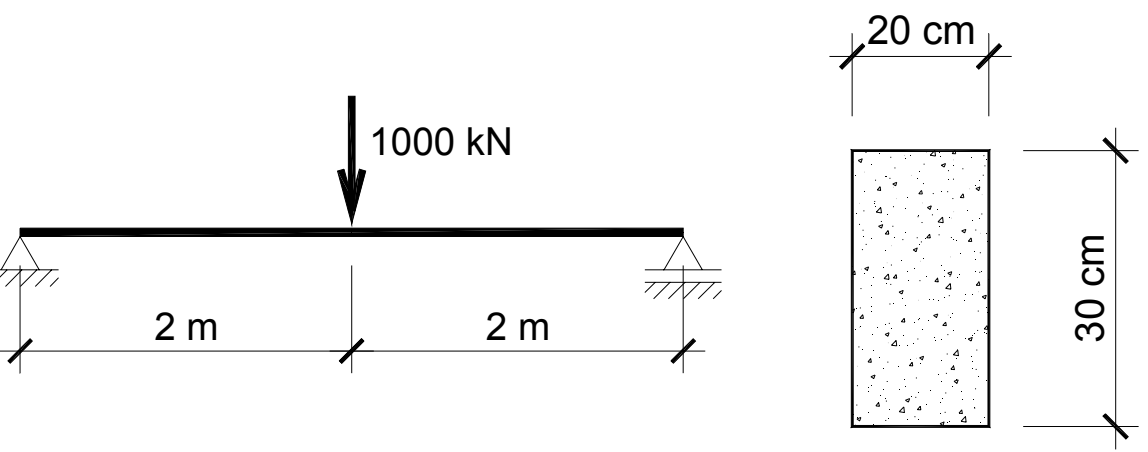

Figura (6.01): Viga biapoiada (geometria e carregamento)

Na figura (6.01), são dadas as características geométricas de uma viga bi-apoiada cujo coeficiente de esbeltez é 13, que, portanto pode ser considerada uma viga longa. Assim, espera-se que os deslocamentos transversais dos pontos ao longo da viga não se modifiquem, de forma significativa, quando a influência da distorção for considerada. Espera-se ainda que as rotações, os diagramas de momentos fletores e esforços cortantes sejam idênticos aos de uma análise baseada nas hipóteses de Bernoulli, de acordo com WANG (1995).
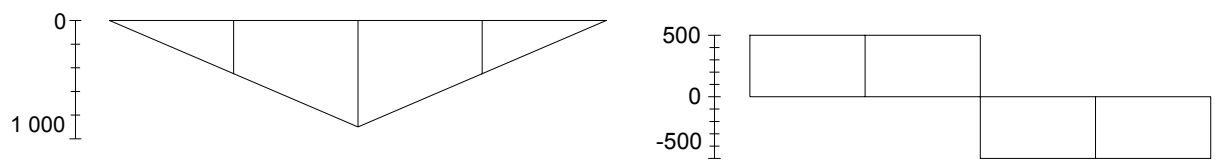

Figura (6.02): Diagrama de momentos Figura (6.03): Diagrama de esforços fletores (fig. 6.01) cortantes (fig. 6.01) 
Observando-se a tabela (6.01) confirma-se a expectativa inicial quanto aos deslocamentos transversais - variação máxima de aproximadamente 1,6\% - e as rotações sem variação. O mesmo se nota nas figuras (6.02) e (6.03) que representam os diagramas de momentos fletores e esforços cortantes, respectivamente.

Tabela (6.01): Deslocamentos e rotações para o caso da figura (6.01)

\begin{tabular}{|c|c|c|c|c|c|c|}
\hline \multirow{2}{*}{ Grandeza } & \multirow{2}{*}{ Nó } & \multicolumn{2}{|c|}{ Exato } & \multicolumn{2}{|c|}{ PORTNL } & \multirow{2}{*}{$\begin{array}{c}\text { Diferença } \\
\%\end{array}$} \\
\hline & & Bernoulli & Timoshenko & Bernoulli & Timoshenko & \\
\hline \multirow{5}{*}{ V } & 1 & 0,000000 & 0,000000 & 0,000000 & 0,000000 & 0,0000 \\
\hline & 2 & $-0,081481$ & $-0,082441$ & $-0,081481$ & $-0,082441$ & 1,1645 \\
\hline & 3 & $-0,118519$ & $-0,120439$ & $-0,118519$ & $-0,120439$ & 1,5942 \\
\hline & 4 & $-0,081481$ & $-0,082441$ & $-0,081481$ & $-0,082441$ & 1,1645 \\
\hline & 5 & 0,000000 & 0,000000 & 0,000000 & 0,000000 & 0,0000 \\
\hline \multirow{5}{*}{$\theta$} & 1 & $-0,088889$ & $-0,088889$ & $-0,088889$ & $-0,088889$ & 0,0000 \\
\hline & 2 & $-0,066667$ & $-0,066667$ & $-0,066667$ & $-0,066667$ & 0,0000 \\
\hline & 3 & 0,000000 & 0,000000 & 0,000000 & 0,000000 & 0,0000 \\
\hline & 4 & 0,066667 & 0,066667 & 0,066667 & 0,066667 & 0,0000 \\
\hline & 5 & 0,088889 & 0,088889 & 0,088889 & 0,088889 & 0,0000 \\
\hline
\end{tabular}

Para as condições de contorno especificadas para a viga da figura (6.04), viga em balanço, WANG (1995), para os deslocamentos e diagramas, faz considerações semelhantes às da viga da figura (6.01), diferenciando apenas o acréscimo dado ao deslocamento transversal obtido considerando-se as hipóteses de Bernoulli para transformá-lo em valores dados pelas hipóteses de Timoshenko.
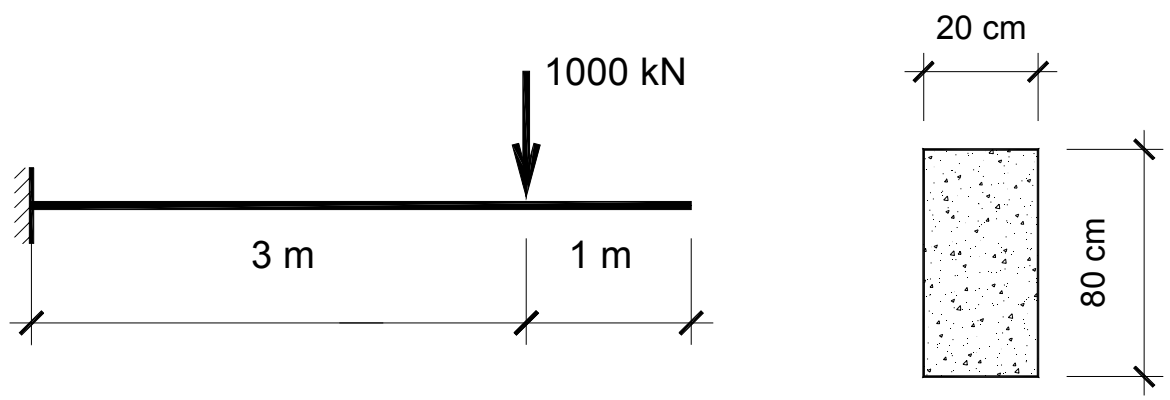

Figura (6.04): Viga em balanço (geometria e carregamento) 
$-3000$

0

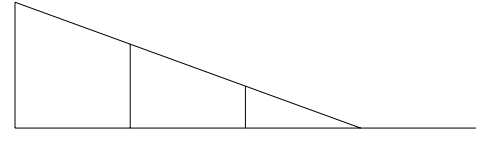

Figura (6.05): Diagrama de momentos Figura (6.06): Diagrama de esforços fletores (fig. 6.04)

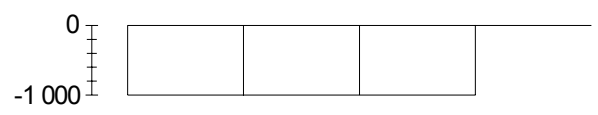

cortantes (fig. 6.04)

Devido à redução do coeficiente de esbeltez para 5, essa viga pode ser considerada pouco longa, esperando-se que os deslocamentos transversais dos pontos ao longo da viga variem de forma um pouco mais significativa.

Tabela (6.02): Deslocamentos e rotações para o caso da figura (6.04)

\begin{tabular}{|c|c|c|c|c|c|c|}
\hline \multirow{2}{*}{ Grandeza } & \multirow{2}{*}{ Nó } & \multicolumn{2}{|c|}{ Exato } & \multicolumn{2}{|c|}{ PORTNL } & \multirow{2}{*}{$\begin{array}{c}\text { Diferença } \\
\%\end{array}$} \\
\hline & & Bernoulli & Timoshenko & Bernoulli & Timoshenko & \\
\hline \multirow{5}{*}{ V } & 1 & 0,000000 & 0,000000 & 0,000000 & 0,000000 & 0,0000 \\
\hline & 2 & $-0,006250$ & $-0,006970$ & $-0,006250$ & $-0,006970$ & 10,3300 \\
\hline & 3 & $-0,021875$ & $-0,023315$ & $-0,021875$ & $-0,023315$ & 6,1763 \\
\hline & 4 & $-0,042188$ & $-0,044348$ & $-0,042188$ & $-0,044348$ & 4,8706 \\
\hline & 5 & $-0,063281$ & $-0,065441$ & $-0,063281$ & $-0,065441$ & 0,0000 \\
\hline \multirow{5}{*}{$\theta$} & 1 & 0,000000 & 0,000000 & 0,000000 & 0,000000 & 0,0000 \\
\hline & 2 & $-0,011719$ & $-0,011719$ & $-0,011719$ & $-0,011719$ & 0,0000 \\
\hline & 3 & $-0,018750$ & $-0,018750$ & $-0,018750$ & $-0,018750$ & 0,0000 \\
\hline & 4 & $-0,021094$ & $-0,021094$ & $-0,021094$ & $-0,021094$ & 0,0000 \\
\hline & 5 & $-0,021094$ & $-0,021094$ & $-0,021094$ & $-0,021094$ & 0,0000 \\
\hline
\end{tabular}

A expectativa inicial, quanto aos deslocamentos transversais e as rotações, novamente foi confirmada a partir dos resultados da tabela (6.02) - variação máxima da ordem de $10 \%$ para os deslocamentos transversais e nula para as rotações, enquanto os diagramas de momentos fletores e esforços cortantes foram dados, respectivamente, pelas figuras (6.05) e (6.06).

A figura (6.07) representa as características geométricas de uma viga apoiadaengastada com coeficiente de esbeltez 3 , considerada viga curta. Portanto, espera-se que os deslocamentos transversais e rotações dos pontos ao longo da viga sejam significativamente diferentes quando se adota uma ou outra teoria, devido à grande influência da distorção. 
Nesse caso, de acordo com WANG (1995), há alterações também nos diagramas de momentos fletores e esforços cortantes com relação aos obtidos a partir das hipóteses de Bernoulli.

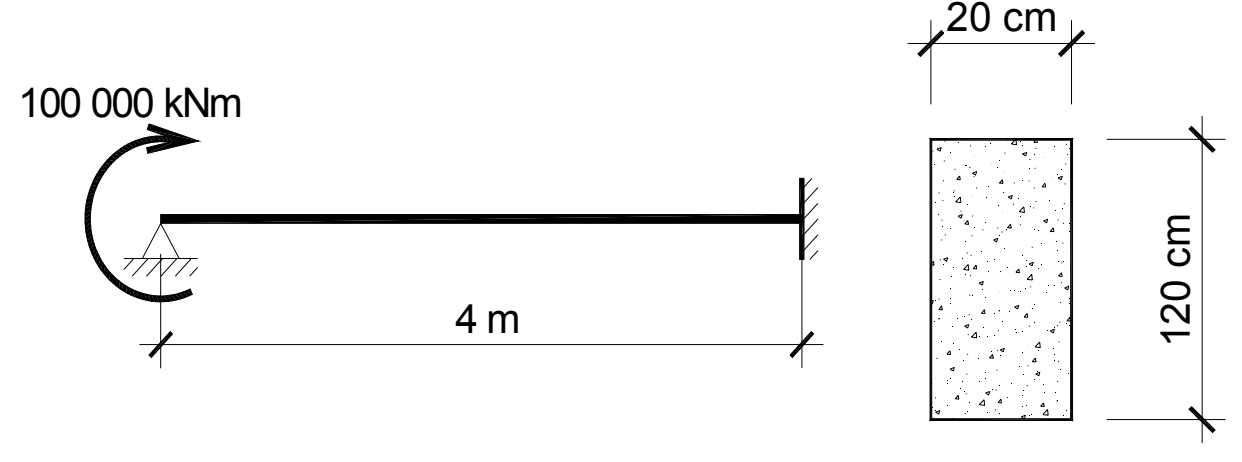

Figura (6.07): Viga apoiada-engastada (geometria e carregamento)

Tabela (6.03): Deslocamentos e rotações para o caso da figura (6.07)

\begin{tabular}{|c|c|c|c|c|c|c|}
\hline \hline \multirow{2}{*}{ Grandeza } & \multirow{2}{*}{ Nó } & \multicolumn{2}{|c|}{ Exato } & \multicolumn{2}{c|}{ PORTNL } & Diferença \\
\cline { 3 - 6 } & & Bernoulli & Timoshenko & Bernoulli & Timoshenko & $\%$ \\
\hline & 1 & 0,000000 & 0,000000 & 0,000000 & 0,000000 & 0,0000 \\
\hline & 2 & $-0,078125$ & $-0,086047$ & $-0,078125$ & $-0,086047$ & 9,2062 \\
\hline & 3 & $-0,069444$ & $-0,082119$ & $-0,069444$ & $-0,082119$ & 15,4345 \\
& 4 & $-0,026042$ & $-0,037132$ & $-0,026042$ & $-0,037132$ & 29,8673 \\
\hline & 5 & 0,000000 & 0,000000 & 0,000000 & 0,000000 & 0,0000 \\
\hline & 1 & $-0,138889$ & $-0,164238$ & $-0,138889$ & $-0,164238$ & 0,0000 \\
& 2 & $-0,026042$ & $-0,049807$ & $-0,026042$ & $-0,049807$ & 47,7144 \\
\hline & 4 & 0,034722 & 0,015710 & 0,034722 & 0,015710 & 121,0159 \\
\hline & 5 & 0,043403 & 0,032312 & 0,043403 & 0,032312 & 34,3220 \\
\hline
\end{tabular}
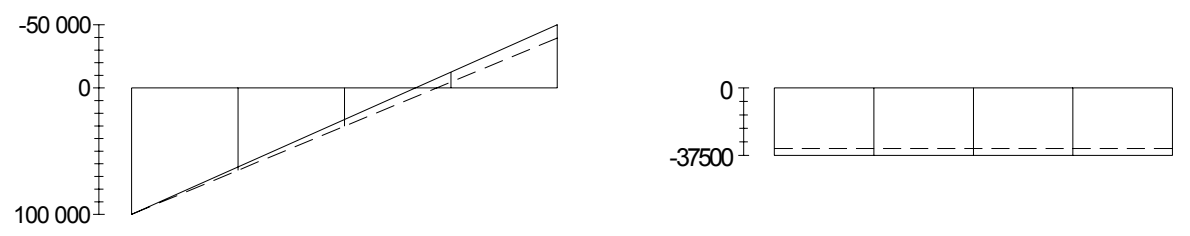

Figura (6.08): Diagrama de momentos Figura (6.09): Diagrama de esforços fletores (fig. 6.07) cortantes (fig. 6.07) 
Os resultados da tabela (6.03), como era de se esperar, confirmam a expectativa inicial quanto aos deslocamentos transversais - variação máxima da ordem de $30 \%$ - e as rotações - variação máxima da ordem de $121 \%$. Já as figuras (6.08) e (6.09) mostram a variação nos diagramas de momentos fletores e esforços cortantes, respectivamente.

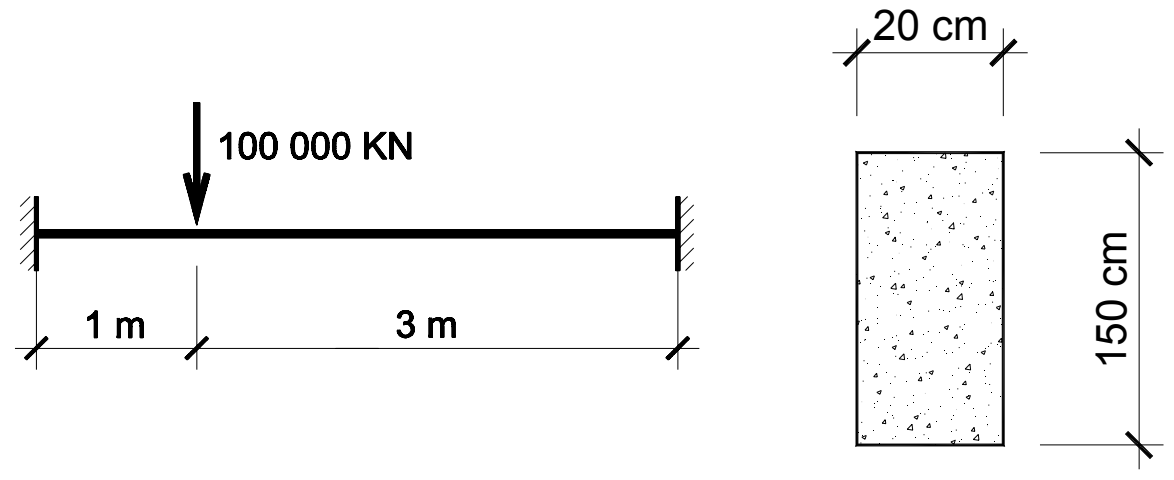

Figura (6.10): Viga bi-engastada (geometria e carregamento)

Segundo WANG (1995), para a condição de contorno da figura (6.10), viga biengastada, há variação nos deslocamentos, rotações e diagramas de Bernoulli quando se adota as hipóteses de Timoshenko. Para o coeficiente de esbeltez igual a 2, a viga pode ser considerada muito curta, por isso espera-se que os deslocamentos transversais e rotações dos pontos ao longo da viga variem de forma bastante significativa.

Tabela (6.04): Deslocamentos e rotações para o caso da figura (6.10)

\begin{tabular}{|c|c|c|c|c|c|c|}
\hline \multirow{2}{*}{ Grandeza } & \multirow{2}{*}{ Nó } & \multicolumn{2}{|c|}{ Exato } & \multicolumn{2}{|c|}{ PORTNL } & \multirow{2}{*}{$\begin{array}{c}\text { Diferença } \\
\%\end{array}$} \\
\hline & & Bernoulli & Timoshenko & Bernoulli & Timoshenko & \\
\hline \multirow{5}{*}{ V } & 1 & 0,000000 & 0,000000 & 0,000000 & 0,000000 & 0,0000 \\
\hline & 2 & $-0,010000$ & $-0,039751$ & $-0,010000$ & $-0,039751$ & 74,8437 \\
\hline & 3 & $-0,011852$ & $-0,031046$ & $-0,011852$ & $-0,031046$ & 61,8240 \\
\hline & 4 & $-0,004815$ & $-0,013451$ & $-0,004815$ & $-0,013451$ & 64,2052 \\
\hline & 5 & 0,000000 & 0,000000 & 0,000000 & 0,000000 & 0,0000 \\
\hline \multirow{5}{*}{$\theta$} & 1 & 0,000000 & 0,000000 & 0,000000 & 0,000000 & 0,0000 \\
\hline & 2 & $-0,010000$ & $-0,007118$ & $-0,010000$ & $-0,007118$ & 40,4870 \\
\hline & 3 & 0,004444 & 0,008287 & 0,004444 & 0,008287 & 46,3737 \\
\hline & 4 & 0,007778 & 0,010660 & 0,007778 & 0,010660 & 27,0354 \\
\hline & 5 & 0,000000 & 0,000000 & 0,000000 & 0,000000 & 0,0000 \\
\hline
\end{tabular}


A expectativa inicial, quanto aos deslocamentos transversais e as rotações, foi novamente confirmada a partir da análise dos resultados da tabela (6.04), confirmada também pelas variações dos diagramas de momentos fletores e esforços cortantes dados, respectivamente, pelas figuras (6.11) e (6.12).

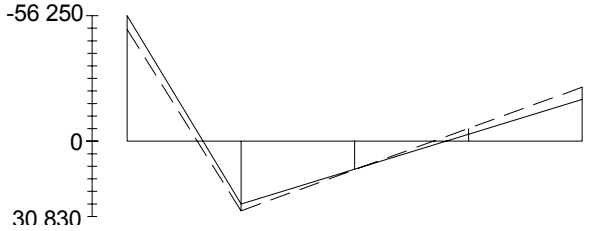

Figura (6.11): Diagrama de momentos fletores (fig. 6.10)

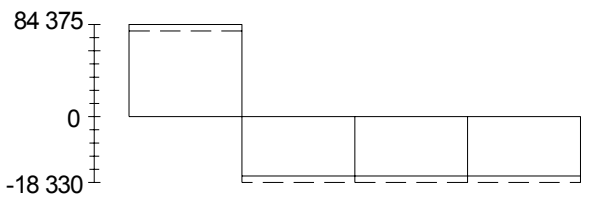

(6.12): Diagrama de esforços cortantes (fig. 6.10)

Pode-se também observar que para as 4 condições de contorno especificadas, os resultados obtidos com o programa implementado coincidiram com os valores exatos, o que garante sua confiabilidade para este tipo de análise. Nas figuras (6.08), (6.09), (6.11) e (6.12) as linhas contínuas representam os valores obtidos a partir da teoria de Bernoulli, enquanto que as linhas tracejadas correspondem aos valores obtidos com a teoria de Timoshenko.

\subsection{EXEMPLO 2}

O exemplo analisado agora é definido por uma viga em balanço com carregamento vertical na extremidade livre, com geometria dada na figura (6.13). É o mesmo exemplo estudado por SILVA (1995) e também por PAULA (2001). Com esse exemplo buscou-se avaliar a eficiência da descrição lagrangiana atualizada para análise de vigas, de acordo com a implementação realizada no programa.

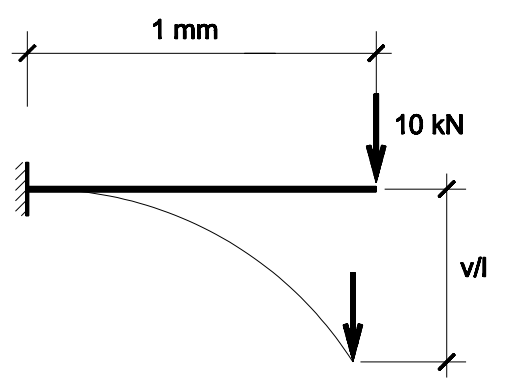

Figura (6.13): Geometria e carregamento da estrutura

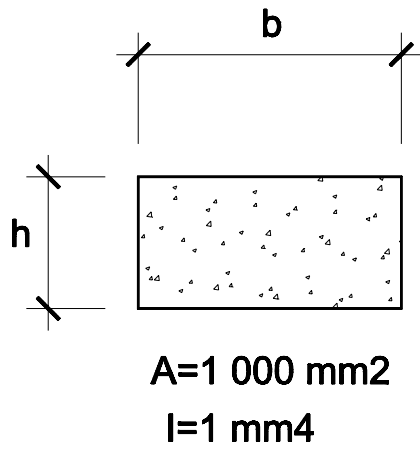


Em uma primeira etapa, a análise foi realizada utilizando discretização com 10 elementos iguais de barra, segundo as hipóteses de Bernoulli. Para o processo incremental iterativo dividiu-se o carregamento em 100 incrementos iguais, permitindo-se o máximo de 100 iterações, considerando-se ainda $0,1 \%$ de tolerância em forças e deslocamentos (normas euclidianas). Para realização das integrações numéricas foram utilizados 3 pontos de Gauss ao longo da altura da seção transversal e 6 pontos ao longo do eixo de cada elemento. As propriedades mecânicas do material são:

- Módulo de elasticidade longitudinal do concreto $-\mathrm{E}=0,001 \mathrm{KN} / \mathrm{mm}^{2}$

- Módulo de elasticidade transversal do concreto $-\mathrm{G}=0,0004 \mathrm{KN} / \mathrm{mm}^{2}$

- Coeficiente de Poisson do concreto $-v=0,2$

Os resultados, apresentados em valores de deslocamentos adimensionais $\mathbf{v} / \mathbf{l}$, foram comparados com os disponíveis em SILVA (1995) e estão mostrados na figura (6.14).

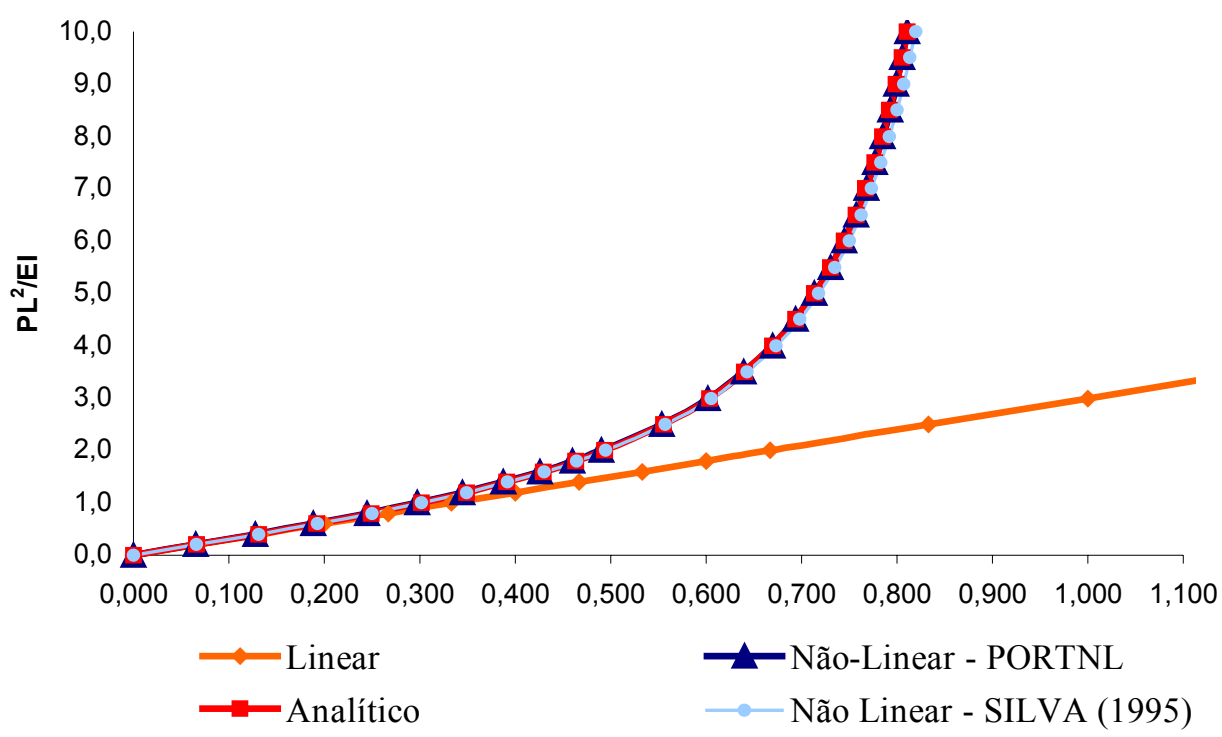

Figura (6.14): Deslocamentos adimensionais v/l - Bernoulli

Posteriormente, foi feita uma segunda análise com manutenção dos dados iniciais, utilizando, porém, as hipóteses de Timoshenko. Na falta de análises disponíveis na literatura, a precisão dos resultados obtidos foi avaliada a partir da comparação com valores obtidos através do software comercial ANSYS $®$. A figura (6.15) apresenta um resumo desses resultados. 
Os resultados apresentados nas figuras (6.14) e (6.15) levam à conclusão que os valores numéricos obtidos com o programa implementado estão de acordo com o esperado, uma vez que são praticamente os mesmos encontrados por SILVA (1995) quando se adota as hipóteses de Bernoilli, e com diferença muito pequena em relação à resposta analítica. Valores obtidos a partir das hipóteses de Timoshenko apresentam pequena variação em relação aos valores de referência e dentro de uma tolerância aceitável para as aproximações adotadas na Engenharia de Estruturas.

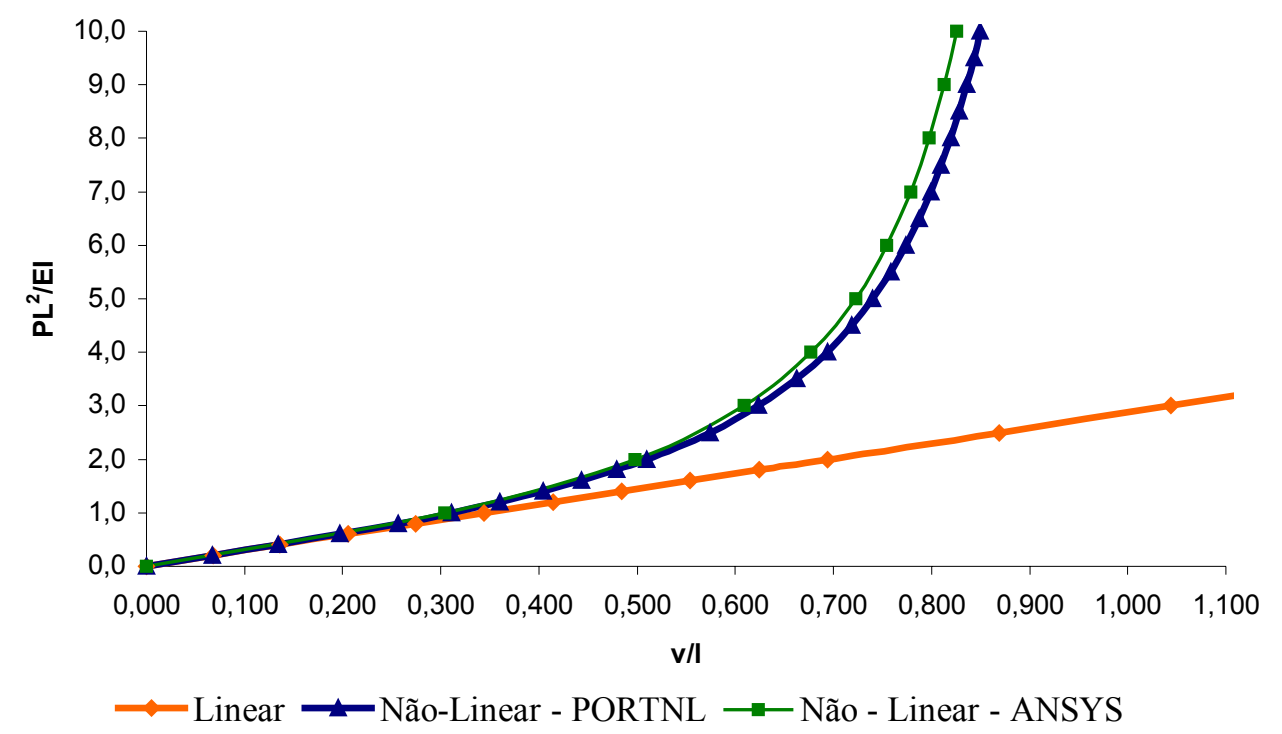

Figura (6.15): Deslocamentos adimensionais v/l - Timoshenko

\subsection{EXEMPLO 3}

A análise deste exemplo, baseado no modelo proposto por ELIAS (1986), serviu para avaliar a eficiência da descrição lagrangiana atualizada na análise não-linear geométrica de uma estrutura aporticada, conforme figura (6.16). Propriedades mecânicas material utilizado:

- Módulo de elasticidade longitudinal do concreto - E = $30000 \mathrm{Ksi}$

- Módulo de elasticidade transversal do concreto $-\mathrm{G}=12000 \mathrm{Ksi}$

- Coeficiente de Poisson do concreto $-v=0,2$ 
Tal como no exemplo anterior, inicialmente procedeu-se à análise utilizando as hipóteses de Bernoulli, discretizando-se o pórtico com 18 elementos de barra iguais ( 6 barras para cada trecho). Para a aplicação do processo incremental iterativo dividiu-se o carregamento em 10 incrementos iguais, admitindo-se um máximo de 100 iterações e $10^{-6} \%$ de tolerância em forças e deslocamentos (normas euclidianas). Para realização das integrações numéricas, foram utilizados 3 pontos de Gauss ao longo da altura da seção transversal e 6 pontos ao longo do eixo de cada elemento. Na seqüência, são mantidos os dados iniciais, mas com as hipóteses de Timoshenko.

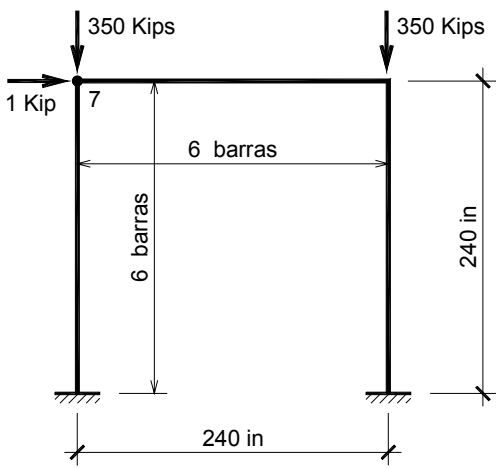

PILARES e VIGA

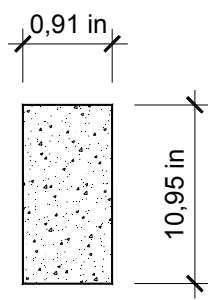

Figura (6.16): Geometria e carregamento da estrutura

A tabela (6.05) contém os valores obtidos para as análises, bem como os valores de referência provenientes de ELIAS (1986), plotados na figura (6.17).

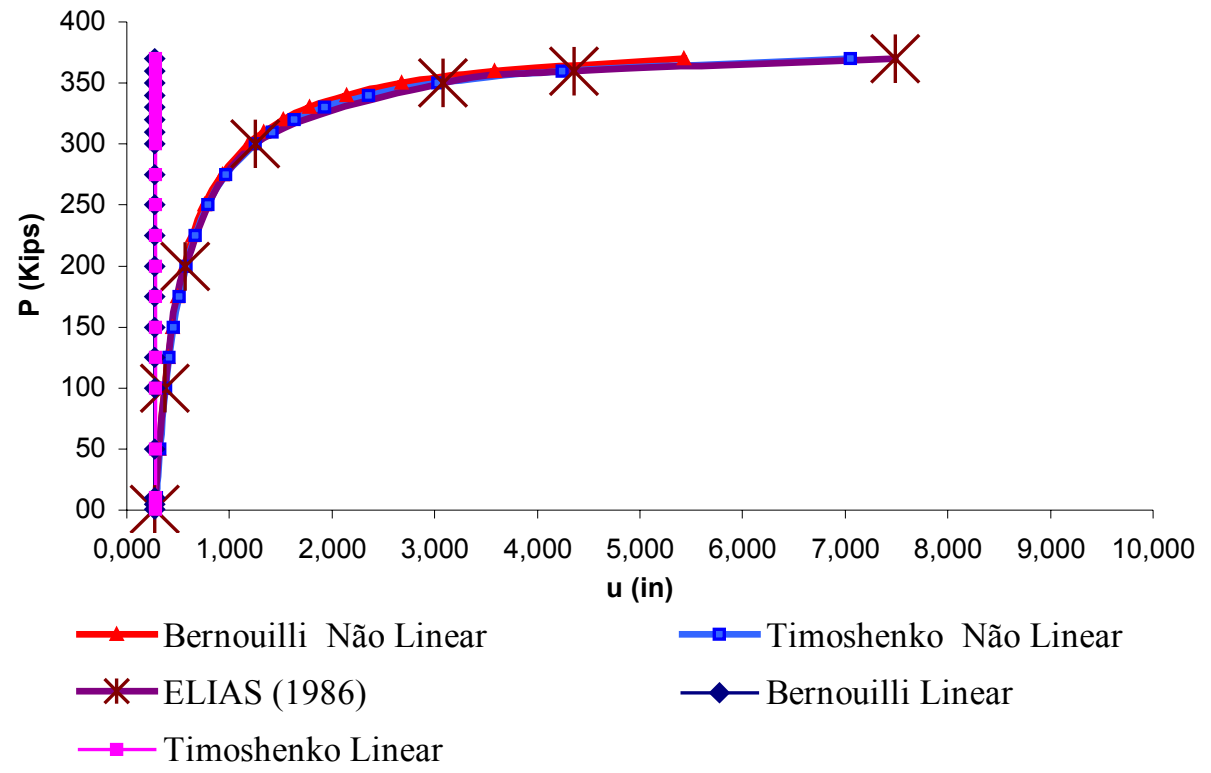

Figura (6.17): Gráfico força x deslocamento horizontal do nó 7- pórtico da figura (6.16) 
Tabela (6.05): Deslocamento horizontal do nó 7 da figura (6.16)

\begin{tabular}{|c|c|c|c|c|c|c|}
\hline Resultados & & POR & TNL & & & $\Gamma \mathrm{I} \wedge \mathrm{C}$ \\
\hline Carga & $\begin{array}{l}\text { Bernoulli } \\
\text { Linear }\end{array}$ & $\begin{array}{c}\text { Timoshenko } \\
\text { Linear }\end{array}$ & $\begin{array}{l}\text { Bernoulli } \\
\text { Não Linear }\end{array}$ & $\begin{array}{l}\text { Timoshenko } \\
\text { Não Linear }\end{array}$ & Carga & (1986) \\
\hline 01 & 0,27477968 & 0,27641958 & 0,27550440 & 0,27715014 & 1 & 0,275 \\
\hline 05 & 0,27477968 & 0,27641958 & 0,27833326 & 0,28206040 & 100 & 0,37 \\
\hline 10 & 0,27477968 & 0,27641958 & 0,28196205 & 0,28578257 & 200 & 0,57 \\
\hline 50 & 0,27477968 & 0,27641958 & 0,31483677 & 0,31953651 & 300 & 1,25 \\
\hline 100 & 0,27477968 & 0,27641958 & 0,36869374 & 0,37504581 & 350 & 3,08 \\
\hline 125 & 0,27477968 & 0,27641958 & 0,40325173 & 0,41080367 & 360 & 4,36 \\
\hline 150 & 0,27477968 & 0,27641958 & 0,44501891 & 0,45416770 & 370 & 7,49 \\
\hline 175 & 0,27477968 & 0,27641958 & 0,49651485 & 0,50785472 & - & - \\
\hline 200 & 0,27477968 & 0,27641958 & 0,56158807 & 0,57605026 & - & - \\
\hline 225 & 0,27477968 & 0,27641958 & 0,64642539 & 0,66555610 & - & - \\
\hline 250 & 0,27477968 & 0,27641958 & 0,76164621 & 0,78821283 & - & - \\
\hline 275 & 0,27477968 & 0,27641958 & 0,92713923 & 0,96662634 & - & - \\
\hline 300 & 0,27477968 & 0,27641958 & 1,18500330 & 1,25000060 & - & - \\
\hline 310 & 0,27477968 & 0,27641958 & 1,33352210 & 1,41625350 & - & - \\
\hline 320 & 0,27477968 & 0,27641958 & 1,52475030 & 1,63368000 & - & - \\
\hline 330 & 0,27477968 & 0,27641958 & 1,78022130 & 1,93015270 & - & - \\
\hline 340 & 0,27477968 & 0,27641958 & 2,13888610 & 2,35842010 & - & - \\
\hline 350 & 0,27477968 & 0,27641958 & 2,67921800 & 3,03138560 & - & - \\
\hline 360 & 0,27477968 & 0,27641958 & 3,58648640 & 4,24214340 & - & - \\
\hline 370 & 0,27477968 & 0,27641958 & 5,42721050 & 7,05185640 & - & - \\
\hline
\end{tabular}

A partir da observação da tabela (6.05) e da figura (6.17), confirma-se a expectativa quanto à precisão dos resultados, cuja variação máxima ocorreu próxima à carga que leva à perda de estabilidade da estrutura. Pode-se também verificar que as respostas lineares praticamente coincidiram para as hipóteses de Bernoulli e de Timoshenko, devido à pouca influência da distorção - evidenciada pela grande esbeltez da viga. Apesar disso, nota-se que a aproximação obtida a partir das hipóteses de Timoshenko corresponde a uma melhoria da precisão do programa, com aproximação dos resultados aos valores dados por ELIAS (1986) e que também foram obtidos por análise numérica. 


\subsection{EXEMPLO 4}

O exemplo agora analisado foi estudado por NEVES (2000) que utilizou dados experimentais de ÁLVARES (1993). O objetivo é avaliar a eficiência do modelo de dano de Mazars e sua implementação computacional e mostrar como a perda de rigidez da estrutura, observada em análises não-lineares físicas e negligenciada em análises lineares, pode propiciar significante aumento de deslocamentos na mesma.

O exemplo consiste em uma viga bi-apoiada com duas cargas concentradas, simetricamente dispostas em relação ao centro da peça, de acordo com a figura (6.18).

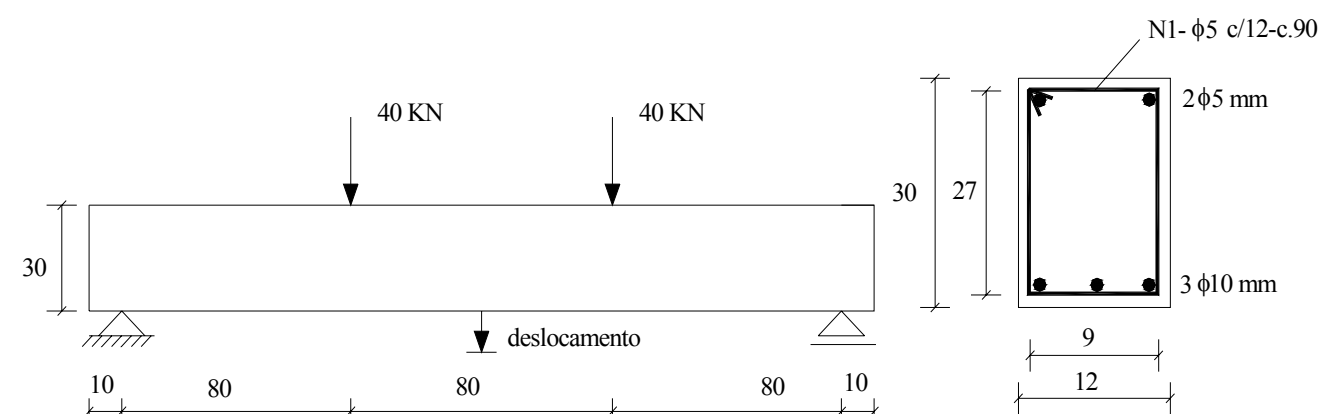

Figura (6.18): Geometria e carregamento da estrutura

Foram analisadas quatro situações distintas, duas lineares e duas não-lineares considerando alternadamente as hipóteses de Bernoulli e de Timoshenko. Propriedades mecânicas:

- Módulo de elasticidade longitudinal do concreto $-\mathrm{E}=2920 \mathrm{KN} / \mathrm{cm}^{2}$

- Módulo de elasticidade transversal do concreto $-\mathrm{G}=1217 \mathrm{KN} / \mathrm{cm}^{2}$

- Coeficiente de Poisson do concreto $-v=0,2$

- Resistência ao escoamento do aço $-\mathrm{f}_{\mathrm{y}}=50 \mathrm{KN} / \mathrm{cm}^{2}$

- Módulo de elasticidade longitudinal do aço $-\mathrm{E}_{\mathrm{s}}=19600 \mathrm{KN} / \mathrm{cm}^{2}$

- Módulo plástico do aço $-\mathrm{K}_{\mathrm{s}}=1960 \mathrm{KN} / \mathrm{cm}^{2}$

- Parâmetros do dano:

$$
-\varepsilon_{\mathrm{d} 0}=0,00007 ; \mathrm{AT}=0,995 ; \mathrm{BT}=8000 ; \mathrm{AC}=0,850 ; \mathrm{BC}=1620
$$


As análises não-lineares foram realizadas com discretização de 12 elementos iguais de barra. Para o processo incremental iterativo dividiu-se o carregamento em 20 passos de carga iguais, permitindo-se um máximo de 200 iterações e $10^{-2} \%$ de tolerância em forças e deslocamentos (normas euclidianas). Para as integrações numéricas foram utilizados 12 pontos de Gauss ao longo da altura da seção transversal e 6 ao longo do eixo de cada elemento.

Os resultados comparados aos obtidos por NEVES (2000) estão dispostos a seguir.

Tabela (6.06): Deslocamento vertical do ponto central da figura (6.18)

\begin{tabular}{|c|c|c|c|c|c|c|}
\hline \multirow{2}{*}{$\begin{array}{c}\text { Resultados } \\
\text { Carga } \\
\end{array}$} & \multicolumn{4}{|c|}{ PORTNL } & \multicolumn{2}{|r|}{ Ensaio } \\
\hline & $\begin{array}{l}\text { Bernoulli } \\
\text { Linear }\end{array}$ & $\begin{array}{c}\text { Timoshenko } \\
\text { Linear }\end{array}$ & $\begin{array}{c}\text { Bernoulli } \\
\text { Não Linear }\end{array}$ & $\begin{array}{l}\text { Timoshenko } \\
\text { Não Linear }\end{array}$ & $\begin{array}{l}\text { Carga } \\
\text { Ensaio }\end{array}$ & Experimental \\
\hline 00 & 0,0000000 & 0,0000000 & 0,0000000 & 0,0000000 & 0 & 0 \\
\hline 02 & 0,0112732 & 0,0117116 & 0,0111529 & 0,0117079 & 2 & 0,011 \\
\hline 04 & 0,0225465 & 0,0234232 & 0,0223058 & 0,0238419 & 4 & 0,026 \\
\hline 06 & 0,0338198 & 0,0351349 & 0,0335897 & 0,0365303 & 6 & 0,036 \\
\hline 08 & 0,0450931 & 0,0468465 & 0,0468786 & 0,0518592 & 8 & 0,051 \\
\hline 10 & 0,0563663 & 0,0585581 & 0,0645158 & 0,0725114 & 10 & 0,08 \\
\hline 12 & 0,0676396 & 0,0702698 & 0,0968020 & 0,1158791 & 12 & 0,124 \\
\hline 14 & 0,0789129 & 0,0819814 & 0,1871285 & 0,2251348 & 14 & 0,172 \\
\hline 16 & 0,0901862 & 0,0936930 & 0,2526009 & 0,2909041 & 16 & 0,215 \\
\hline 18 & 0,1014595 & 0,1054047 & 0,3013897 & 0,3441876 & 18 & 0,272 \\
\hline 20 & 0,1127327 & 0,1171163 & 0,3513996 & 0,4026877 & 20 & 0,322 \\
\hline 22 & 0,1240060 & 0,1288279 & 0,4047915 & 0,4642882 & 22,5 & 0,375 \\
\hline 24 & 0,1352793 & 0,1405396 & 0,4516870 & 0,5189081 & 25 & 0,44 \\
\hline 26 & 0,1465526 & 0,1522512 & 0,4971385 & 0,5741246 & 27,5 & 0,505 \\
\hline 28 & 0,1578259 & 0,1639629 & 0,5421273 & 0,6295847 & 30 & 0,567 \\
\hline 30 & 0,1690991 & 0,1756745 & 0,5872948 & 0,6857762 & 32,5 & 0,634 \\
\hline 32 & 0,1803724 & 0,1873861 & 0,6331421 & 0,7432342 & 35 & 0,709 \\
\hline 34 & 0,1916457 & 0,1990978 & 0,6814831 & 0,8030809 & 40 & 1,058 \\
\hline 36 & 0,2029190 & 0,2108094 & 0,7310669 & 0,8670945 & - & - \\
\hline 38 & 0,2141923 & 0,2225210 & 0,7780157 & 0,9814349 & - & - \\
\hline 40 & 0,2254655 & 0,2342327 & 0,9298290 & 1,2446465 & - & - \\
\hline
\end{tabular}


Observando-se a tabela (6.06) e a figura (6.19), chega-se à conclusão que os resultados do programa implementado estão bem próximos aos esperados. No entanto há divergência relativamente alta no trecho próximo à ruína da estrutura, uma vez que existe certa dificuldade em medir-se o comportamento da estrutura e o processo de degradação do material nessa situação. Novamente foi observado que a consideração das hipóteses de Timoshenko - em lugar das hipóteses de Bernoulli - deixou a estrutura com comportamento mais flexível.

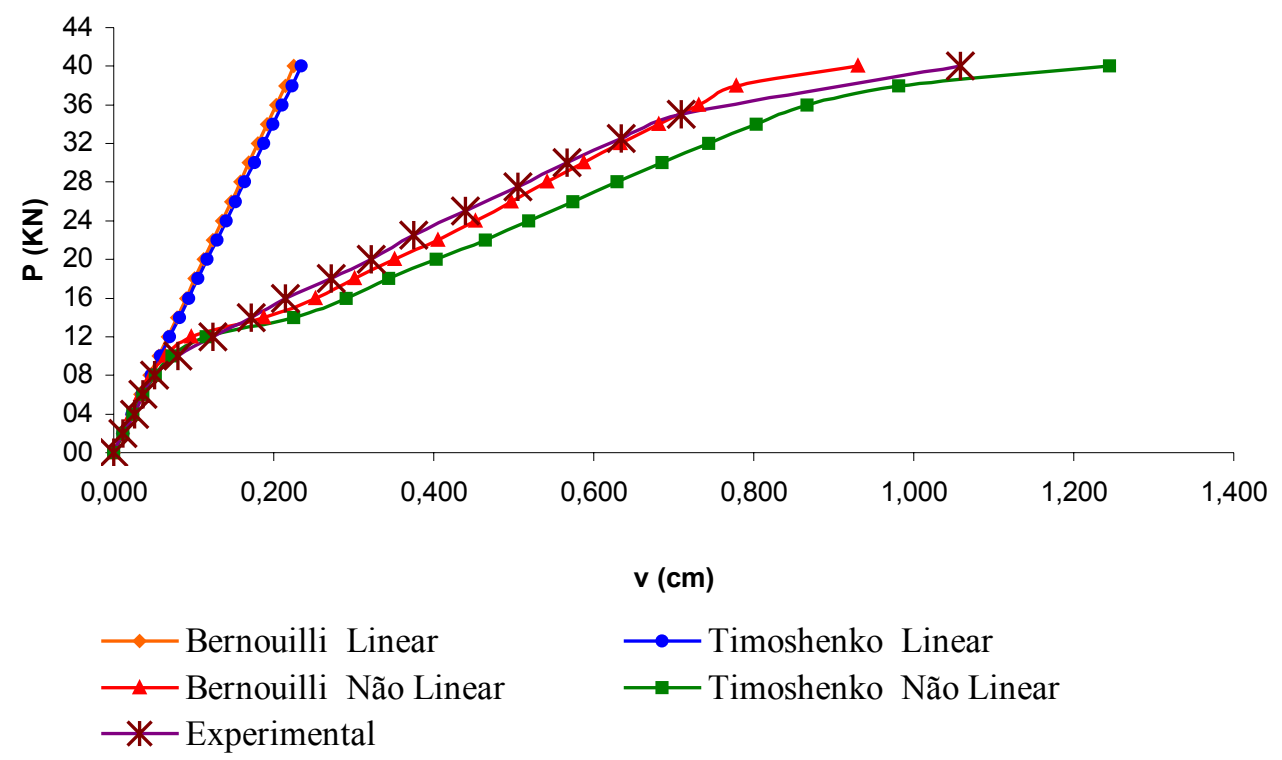

Figura (6.19): Gráfica força $x$ deslocamento para viga da figura (6.18)

\subsection{EXEMPLO 5}

Neste exemplo, que foi objeto de estudo de PAULA (2001), procurou-se determinar a carga última e o deslocamento horizontal associado ao nó 11 do pórtico da figura (6.20) considerando-se um modelo não-linear físico baseado no modelo de dano de Mazars. Na seqüência realizou-se nova análise com combinação dos efeitos não-lineares físicos e geométricos. As propriedades mecânicas do material são:

- Módulo de elasticidade longitudinal do concreto $-\mathrm{E}=2343 \mathrm{KN} / \mathrm{cm}^{2}$

- Módulo de elasticidade transversal do concreto $-\mathrm{G}=938 \mathrm{KN} / \mathrm{cm}^{2}$

- Coeficiente de Poisson do concreto $-v=0,2$

- Resistência ao escoamento do aço $-\mathrm{f}_{\mathrm{y}}=42 \mathrm{KN} / \mathrm{cm}^{2}$ 
- Módulo de elasticidade longitudinal do aço $-\mathrm{E}_{\mathrm{s}}=21000 \mathrm{KN} / \mathrm{cm}^{2}$

- Módulo plástico do aço $-\mathrm{K}_{\mathrm{s}}=2100 \mathrm{KN} / \mathrm{cm}^{2}$

- Parâmetros do dano:

$-\varepsilon_{\mathrm{d} 0}=0,00007 ; \mathrm{AT}=0,995 ; \mathrm{BT}=8000 ; \mathrm{AC}=0,850 ; \mathrm{BC}=1050$
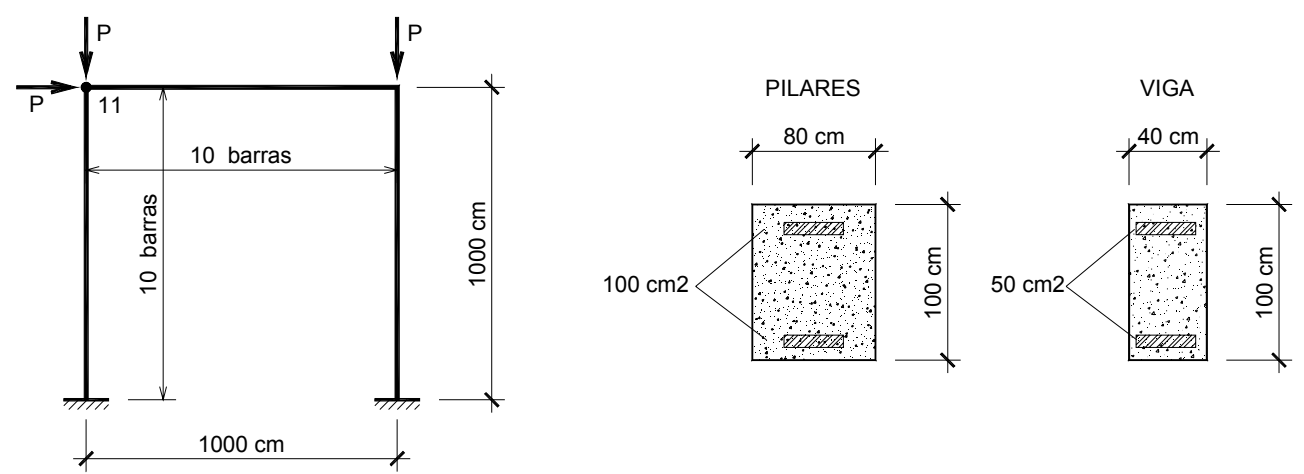

Figura (6.20): Geometria e carregamento da estrutura

A estrutura foi discretizada com 30 elementos iguais de barra (10 por trecho), consideradas as hipóteses de Bernoulli. No processo incremental iterativo, o carregamento foi aplicado em incrementos iguais, de $\mathbf{1 0 0} \mathbf{~ K N}$ cada, até que o limite máximo de 100 iterações em um determinado incremento fosse atingido. Para esse incremento, a carga última fica caracterizada pela incapacidade do sistema alcançar o equilíbrio. Para realização das integrações numéricas, foram utilizados 20 pontos de Gauss ao longo da altura da seção transversal e 6 pontos ao longo do eixo de cada elemento.

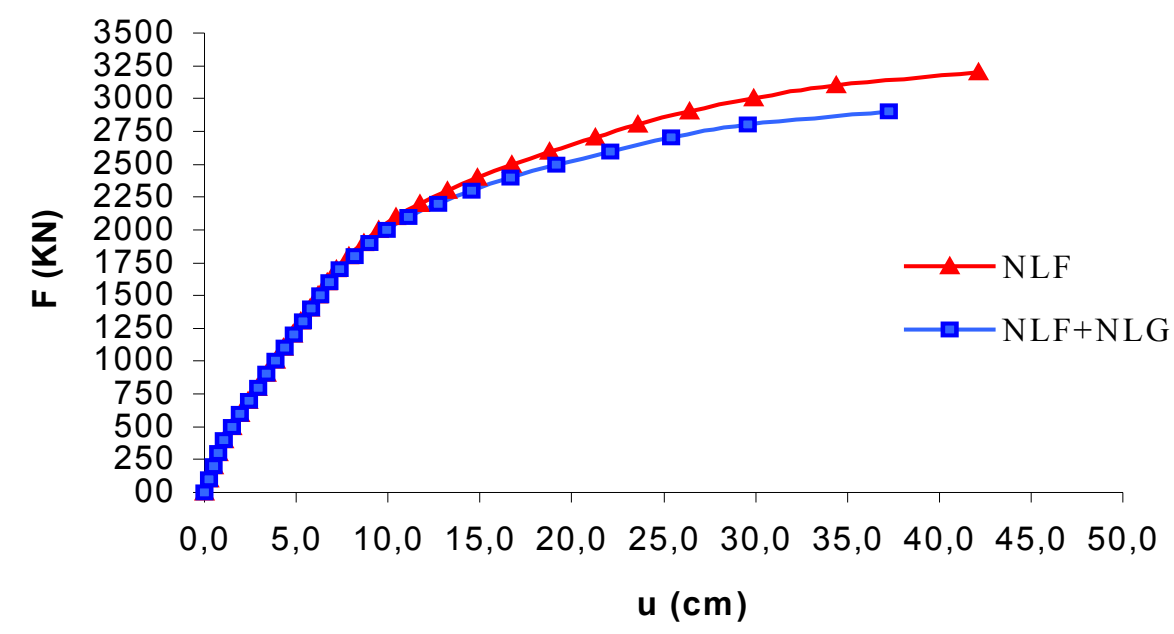

Figura (6.21): Deslocamento horizontal do nó 11 da figura (6.20) 
Os resultados para as duas análises estão dispostos na figura (6.21). Para a NLF a carga última foi da ordem de $3200 \mathrm{KN}$ com deslocamento aproximado de $\mathbf{4 2} \mathbf{~ c m}$. Pode-se observar que a consideração conjunta da NLF e da NLG deixou a estrutura um pouco mais flexível, de forma que a carga última foi da ordem de $2900 \mathrm{KN}$ com deslocamento aproximado de $37 \mathbf{~ c m}$. No entanto essa maior flexibilidade fica evidenciada de forma mais significativa à medida que ocorre a danificação do concreto, uma vez que o dano aumenta os deslocamentos nas peças, inclusive os horizontais os quais, combinados às forças verticais, destacam a NLG.

\subsection{EXEMPLO 6}

Com este exemplo busca-se realizar uma análise não-linear da viga em balanço da figura (6.22), considerando o efeito combinado da não-linearidade física com a geométrica, acrescentada à influência da distorção. No intuito de verificar a influência do cisalhamento, a altura da seção transversal foi variada para valores crescentes de: $35 \mathrm{~cm}, \mathbf{4 0} \mathbf{~ c m}, \mathbf{4 5} \mathbf{~ c m}$ e $50 \mathrm{~cm}$, de modo a forçar o encurtamento da viga.
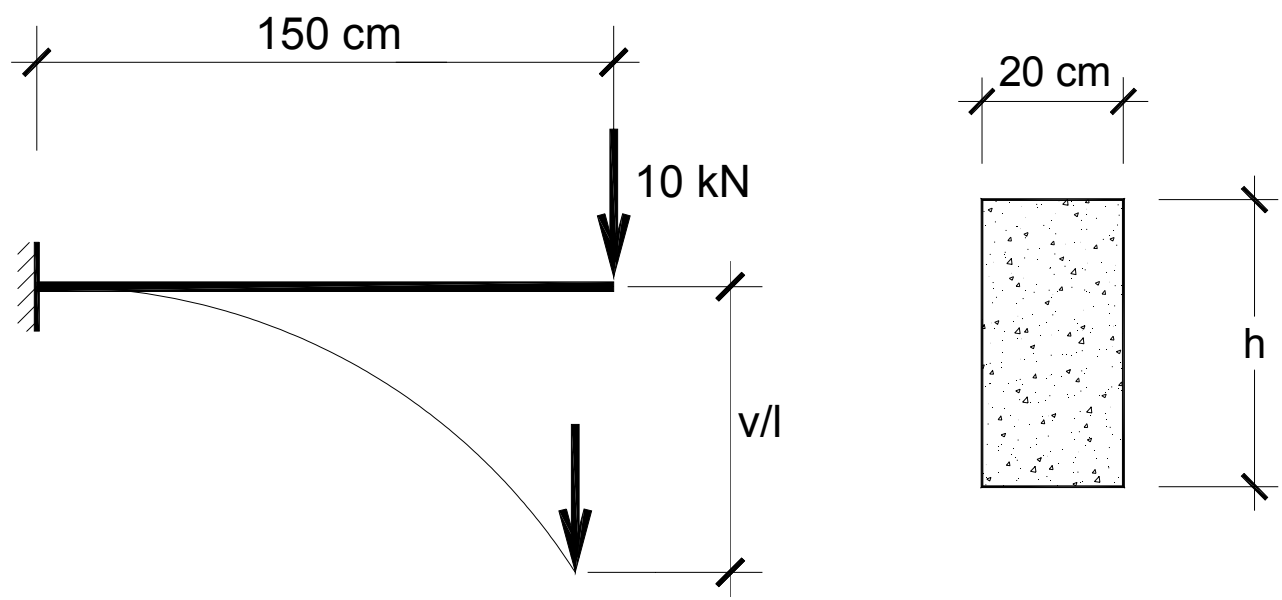

Figura (6.22): Geometria e carregamento da estrutura

Para esta análise discretizou-se a estrutura com 10 elementos iguais de barra. No processo incremental iterativo dividiu-se o carregamento em 20 incrementos iguais, permitindo-se um máximo de 100 iterações e $10^{-2} \%$ de tolerância em forças e deslocamentos (normas euclidianas). Para realização das integrações numéricas foram utilizados 20 pontos de Gauss ao longo da altura da seção transversal e 6 pontos ao longo do eixo de cada elemento. Propriedades mecânicas: 
- Módulo de elasticidade longitudinal do concreto $-\mathrm{E}=2920 \mathrm{KN} / \mathrm{cm}^{2}$

- Módulo de elasticidade transversal do concreto $-\mathrm{G}=1217 \mathrm{KN} / \mathrm{cm}^{2}$

- Coeficiente de Poisson do concreto $-v=0,2$

- Parâmetros do dano:

$-\varepsilon_{\mathrm{d} 0}=0,00007 ; \mathrm{AT}=0,995 ; \mathrm{BT}=8000 ; \mathrm{AC}=0,850 ; \mathrm{BC}=1050$

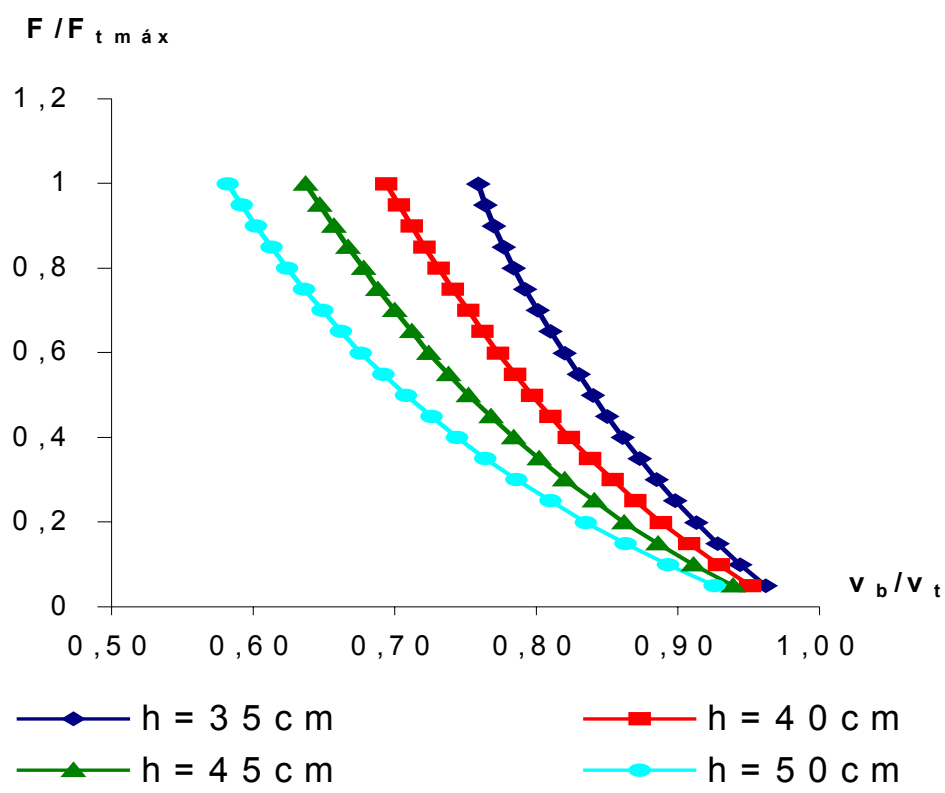

Figura (6.23): Deslocamentos verticais adimensionais - extremidade em balanço

Como nos exemplos anteriores já foi devidamente comprovada a precisão dos resultados individuais das análises não-lineares física e geométrica, se utilizadas as hipóteses de Timoshenko, bem como da combinação da NLG com a NLF, pode-se acreditar que sejam confiáveis os valores contidos na figura (6.23) - pelo menos para uma primeira avaliação mesmo que, a princípio, sem estar amparado por resultado experimental ou teórico disponíveis na literatura.

A figura (6.23) representa a relação entre os deslocamentos verticais e adimensionais da extremidade em balanço da figura (6.22), em função dos níveis de carregamento. Os valores adimensionais dados pela relação $v_{b} / v_{t}$ mostra que foram menores os deslocamentos obtidos com a teoria de Bernoulli $\left(\boldsymbol{v}_{\boldsymbol{b}}\right)$ comparados aos da teoria de Timoshenko $\left(v_{t}\right)$. A mesma relação confirma o aumento da diferença percentual entre os resultados obtidos nas duas teorias, à medida que ocorre o encurtamento da viga (ou aumento do coeficiente de esbeltez). 


\subsection{EXEMPLO 7}

A finalidade deste exemplo é a mesma do exemplo anterior, porém agora analisando o pórtico da figura (6.24). A estrutura será analisada para 4 valores crescentes de altura da seção transversal dos elementos $(\mathbf{h}=\mathbf{5 0} \mathbf{~ c m}, 55 \mathbf{c m}, \mathbf{6 0} \mathbf{~ c m}$ e $\mathbf{6 5} \mathbf{c m})$ e suas propriedades mecânicas são:

- Módulo de elasticidade longitudinal do concreto $-\mathrm{E}=3500 \mathrm{KN} / \mathrm{cm}^{2}$

- Módulo de elasticidade transversal do concreto $-\mathrm{G}=1400 \mathrm{KN} / \mathrm{cm}^{2}$

- Coeficiente de Poisson do concreto $-v=0,2$

- Parâmetros do dano:

$-\quad \varepsilon_{\mathrm{d} 0}=0,00007 ; \mathrm{AT}=0,995 ; \mathrm{BT}=8000 ; \mathrm{AC}=0,850 ; \mathrm{BC}=1050$

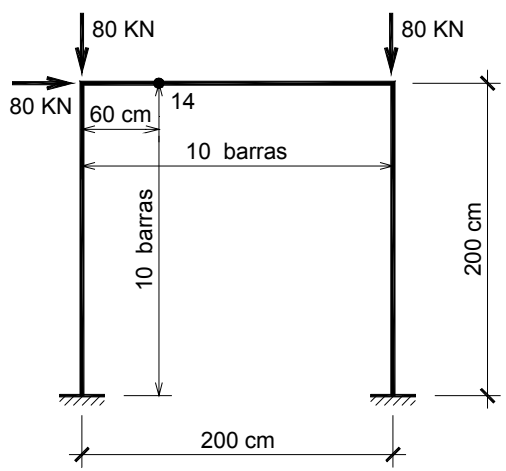

PILARES e VIGA

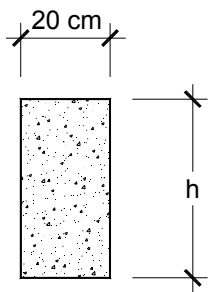

Figura (6.24): Geometria e carregamento da estruturada estrutura

A discretização foi feita com 30 elementos iguais de barra (10 por peça), enquanto que para o processo incremental iterativo dividiu-se o carregamento em 20 incrementos iguais com um máximo de 100 iterações e $10^{-4} \%$ de tolerância em forças e deslocamentos (normas euclidianas). Foram utilizados 20 pontos de Gauss ao longo da altura da seção transversal e 6 pontos ao longo do eixo de cada elemento para realização das integrações numéricas.

Em princípio, aplicam-se aqui os mesmos comentários feitos para o caso anterior; contudo pode-se observar, através da figura (6.25) que o comportamento conjunto dos elementos que compõem o pórtico fez com que no ponto de maior deslocamento vertical houvesse inversão no sentido da influência do cisalhamento. Assim, com a teoria de Timoshenko, ao invés de se obter maiores deslocamentos, obteve-se deslocamentos menores em relação aos valores da teoria de Bernoulli. 


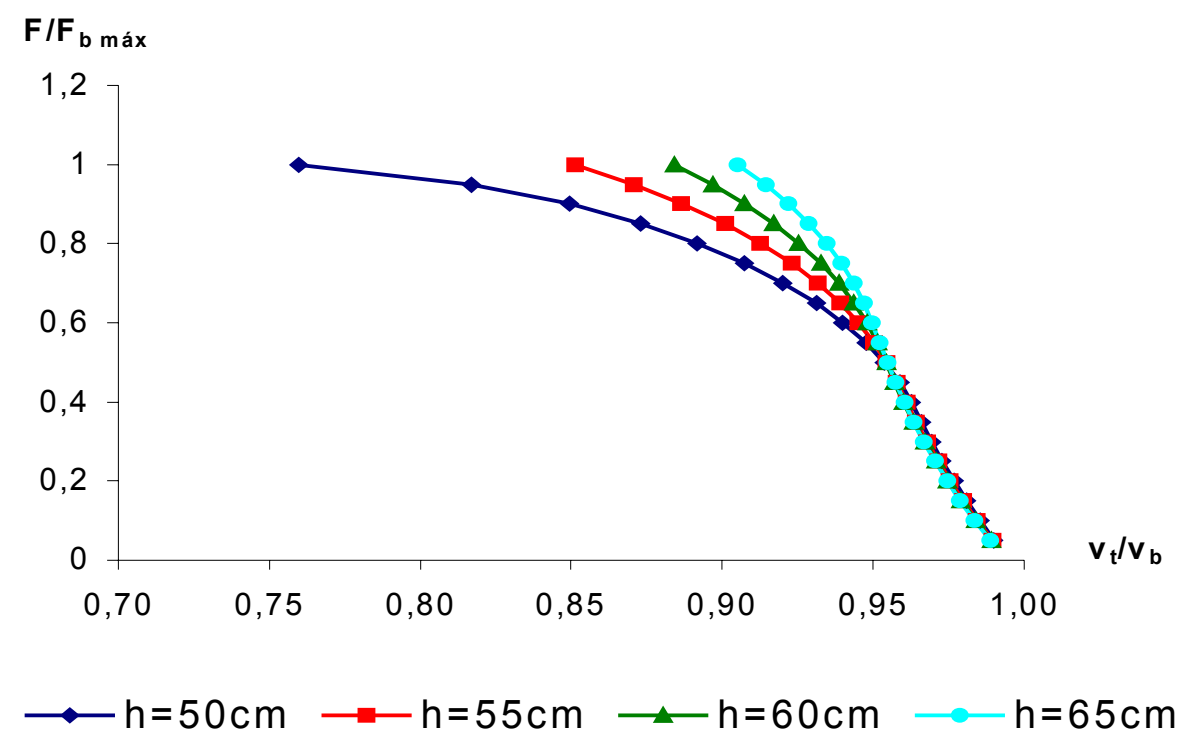

Figura (6.25): Deslocamentos verticais adimensionais - nó 14

Observa-se, também, que o aumento da altura da seção transversal aumenta a rigidez da estrutura; por isso, para o mesmo nível de carga, ocorre diminuição dos deslocamentos nodais e da influência dos efeitos não-lineares. Este fato, associado ao do parágrafo anterior, faz com que a diferença percentual máxima entre os valores obtidos com as duas teorias, para o ponto em análise, diminua com o encurtamento dos elementos.

Ainda que, à primeira vista, os resultados deste exemplo pareçam contraditórios ao que se esperava, não houve equívoco algum. Na realidade, a teoria de Timoshenko realmente torna a estrutura mais flexível, em termos globais. No entanto, os resultados apresentados referem-se a um efeito local, específico para a seção da viga representada pelo nó 14 .

Assim, com este exemplo, pode-se concluir que a combinação dos dois efeitos nãolineares com a teoria de Timoshenko produz efeitos locais que variam com a posição e com o grau de não-linearidade de cada seção e que podem ou não coincidir com o comportamento global. 


\section{CONCLUSÃO}

\subsection{CONSIDERAÇÕES FINAIS}

De acordo com o exposto neste trabalho, a partir dos conceitos teóricos e exemplos apresentados, chega-se a algumas conclusões importantes acerca dos temas propostos e suas aplicações, de modo que, mesmo sem ter o propósito de encerrar o assunto, podem servir de base ou ponto de partida para futuros trabalhos afins.

Primeiramente, comprovou-se a eficiência da formulação em elementos finitos para o elemento de pórtico, levando-se em conta as hipóteses de Timoshenko, caracterizando-a como uma aproximação mais precisa que o modelo de Bernoulli para análise de vigas - e também de pórticos planos - principalmente nas situações em que o coeficiente de esbeltez da peça ou o módulo de elasticidade transversal são baixos.

$\mathrm{Na}$ seqüência, verificou-se que a formulação lagrangiana atualizada gera resultados bastante satisfatórios para a NLG, tanto para vigas como para pórticos planos, como ressaltado pelos exemplos 2 e 3, respectivamente. Novamente ficou evidenciada a influência do cisalhamento na precisão dos resultados e que sua adaptação à formulação lagrangiana atualizada, nos moldes propostos por este trabalho, é bem razoável.

O modelo físico proposto, baseado no modelo de dano de Mazars, apesar de muito rigoroso leva a resultados de boa aplicabilidade prática. O rigor do modelo fica evidenciado pela consideração que o dano varia tanto na altura quanto no comprimento da peça. Como era de se esperar, a introdução dos efeitos do cisalhamento alterou a precisão dos resultados, deixando a estrutura mais flexível.

Finalmente, a combinação dos modelos de NLF e NLG, juntamente com a influência da distorção, levou a resultados, à princípio, muito bons. No entanto, para tirar qualquer dúvida quanto aos resultados ou à formulação implementada seria importante a comparação desses resultados a valores experimentais - algo que não foi viável neste trabalho. 
Portanto, fica como sugestão para futuros trabalhos a comprovação experimental da eficiência da formulação implementada, ou seguindo outra linha de pesquisa, através da utilização de modelos mais sofisticados como, por exemplo, pela substituição do elemento de barra pelo elemento de sólido.

$\mathrm{Na}$ realidade, a formulação apresentada possui algumas simplificações que também poderão ser alteradas futuramente, no intuito de melhorar sua precisão, eficiência e aplicabilidade. Com isso pode-se: corrigir o modelo de resistência aos esforços cisalhantes e implementar o modelo da treliça de Morsch, incluída a plastificação da armadura de cisalhamento; tornar o modelo capaz de realizar análises dinâmicas ou expandi-lo para pórtico espacial. 


\section{REFERÊNCIAS BIBLIOGRÁFICAS}

ÁLVARES, M.S. (1993). Estudo de um modelo de dano para o concreto: formulação, identificação paramétrica e aplicação com emprego do método dos elementos finitos. Dissertação (Mestrado) - EESC/USP.

ASSOCIAÇÃO BRASILEIRA DE NORMAS TÉCNICAS (2000). NBR - 6118 - projeto de revisão. $A B N T$

BATHE, K.J. (1996). Finite element procedures analysis. Prentice Hall.

BOTTA, A.S. (1998). Cálculo de esforços e deslocamentos em estruturas reticuladas considerando-se a mecânica do dano para a modelagem do concreto armado. Dissertação (Mestrado) - EESC/USP.

BURR, A \& HILD, F\& LECKIE, A. (1995). Micro-mechanics and continuum mechanics. Archive of applied mechanics. 65, p437-456.

CABOCHE (1988). Continuum damage mechanics: Part I - General concepts. Journal of applied mechanics. Vol. 55, P59-64.

CERVERA, M.; OLIVER, J.; MANZOLI, O. (1996). A rate-dependent isotropic damage model for the seismic analysis of concrete dams. Earthquake Engineering and Structural Dynamics, vol. 25, p 987-1010.

COWPER, G.R. (1966). The shear coefficient in Timoshenko's beam theory. Journal of Applied Mechanics, p 335-340. 
DIAO, (1995). A statistical equation of damage evolution. Engineering fracture mechanics. Vol 52, n ${ }^{\circ} 1, \mathrm{p} 33-42$.

DRIEMEIER, L. (1995). Considerações sobre a fadiga em metais e o comportamento do concreto sob solicitação cíclica. Dissertação (Mestrado) - EESC/USP.

ELIAS, Z.(1986). Theory and methods of structural analysis. JOHN WILEY\&SONS.

FERNANDES, G.R. (1998). O método dos elementos de contorno aplicado à análise nãolinear de placas. Dissertação (Mestrado) - EESC/USP.

FUSCO, P.B. (1981). Estruturas de concreto - solicitações tangenciais. Grêmio politécnico, São Paulo, SP.

GERE, J.M. \& WEAVER Jr, W. (1987). Análise de estruturas reticuladas. Guanabara. Rio de janeiro, RJ.

KACHANOV, L.M. (1958). On the time to failure under creep condition. Izv. Akad. Nauk. SSR, otd. Tekhn. N.8, 26-31.

KRAJCINOVIC, D. (1989). Damage mechanics. Mechanics of materials. 8, p117-197.

MAZARS, J. (1984). Application de la mécanique de l'endommagement au comportement nonlinéare et à la rupture du beton de structure. Dr of Science thesis. University of Paris 6.

MAZARS, J. \& PIJAUDIER-CABOT. (1989). Continuum damage theory - application to concrete. Journal of Eng. Mechs. Vol 115,2, p345-365.

NARAYANASWAMI, R. \& ADELMAN, H.M. (1974). Inclusion of transverse shear deformation in finite element displacement formulation. AIAA Journal vol $12 \mathrm{n}^{\mathrm{o}} 11$. P16131614.

NÓBREGA, S.H.S. (1997). Sobre o desenvolvimento de elementos finitos de casca. Uma classe de formulações mistas. Tese (Doutorado) - EPUSP. 
PAAS et al. (1993). A continuum approach to brittle and fatigue damage: Theory and numerical procedures. Int. J. Solids Structures. Vol. 30, 4, p 579-599

PAULA, C.F. (2001). Contribuição ao estudo das respostas numéricas não-lineares estática e dinâmica de estruturas reticuladas planas. Tese de Doutorado, EESC/USP.

PEREGO, M.A. (1989). Dannegiamento dei materiali lapidei: leggi costitutive, analisi per elementi finiti ed applicazioni. Politecnico di Milano.

PROENÇA, S.P.B. (1997). Análise Não Linear de Estruturas - Notas de Aula - São Carlos, EESC/USP.

RACHID, M; MORI, D. D. (1989). Instabilidade: conceito - aplicação na flambagem por flexão. São Carlos: EESC-USP.

RIGITANO, A.C. (1998). Contribuição para a determinação de matrizes de rigidez e vetores de ações nodais equivalentes com o emprego da formulação hermitiana livre. Tese de doutorado - EESC/USP.

RODRIGUES, R.O. (1997). Análise dinâmica bidimensional não-linear física e geométrica de treliças de aço e pórticos de concreto armado. Tese de Doutorado, EESC/USP.

SILVA, R.M. (1995). Análise não-linear de pórticos planos de concreto armado: modelagem numérica e avaliação dos métodos aproximados. Tese de Doutorado, $\mathrm{EESC} / \mathrm{USP}$.

THOMAS, J. \& ABBAS, B.A.H.. (1975). Finite element model for dynamic analysis of Timoshenko beam. Journal of Sound and Vibration. 41(3) p291-299.

TIMOSHENKO, S.P. (1955). Vibration problems in engineering. New York, Van Nostrand.

TIMOSHENKO, S.P. \& GERE, J.E. (1983). Mecânica dos sólidos, voll. Rio de Janeiro, Livros Técnicos e Científicos Editora. 
TIMOSHENKO, S.P. \& GERE, J.E. (1984). Mecânica dos sólidos, vol2. Rio de Janeiro, Livros Técnicos e Científicos Editora.

WANG, C.M. (1995). Timoshenko beam-bending solutions in terms of Euler-Bernoulli solutions. Journal of Engineering Mechanics, vol 121, p 763-765, 1995. 


\section{BIBLIOGRAFIA COMPLEMENTAR}

ASSOCIAÇÃO BRASILEIRA DE NORMAS TÉCNICAS (1978). NBR - 6120 - Cargas para o cálculo de estruturas de edificações. ABNT.

BUSSAMRA, F.L.S. (1993). Equações constitutivas do concreto baseadas na mecânica do dano contínuo. Dissertação (Mestrado) - EPUSP.

CHEN, W.F. (1994). Constitutive equations for engineering materials - volume 2: Plasticity and modeling. Elsevier.

CORREAA, M.R.S. (1991). Aperfeiçoamento de modelos usualmente empregados no projeto de sistemas estruturais de edificios. Tese de doutorado - EESC/USP.

CRISFIELD, M.A. (1982). Solution procedures for non-linear structural analysis. In: HINTON, E.; OWEN, D.R.J.; TAYLOR, C. ed. Recent advances in nonlinear computational mechanics. Swansea, UK: Pineridge Press, p. 1-39.

EYLIGER, P.R. \& REDDY, J.N. (1998). A higher order beam finite element for bending and vibration problems. Journal of sound and vibration. 126(2), p309-326.

HINTON, E. \& OWEN, D.R. Finite elements in plasticity. (1980). Swansea, U.K, Pineridge Press.

HINTON, E. (1993). Introduction to nonlinear finite element. Glasgow, U.K, NAFEMS. 
LEMAITRE, J. \& CHABOCHE, J-L. (1994). Mechanics of solid materials. Cambridge University Press.

NICKEL, R.E. \& SECOR, G.A. (1972). Convergence of consistently derived Timoshenko beam finite elements. Int. J. Num. Meth. Eng., 5, p243-253.

OLIVEIRA, R.S. (1997). Análise de pavimentos de edifícios de concreto armado com a consideração da não-linearidade fisica. Dissertação (Mestrado) - EESC/USP.

PAULA, C.F. (1997). Estudo das descrições lagrangiana e euleriana na análise não-linear geométrica com o emprego do método dos elementos finitos. Dissertação de Mestrado, EESC/USP.

PINTO, R.S. (1997). Não linearidade fisica e geométrica no projeto de edifícios usuais de concreto armado. Dissertação (Mestrado) - EESC/USP.

PROENÇA, S.P.B. (1988). Sobre modelos matemáticos do comportamento não-linear do concreto. Tese de Doutorado, EESC/USP.

REDDY, J.N. (1997). On locking-free shear deformable beam finite elements. Comp. Meth. App. Mech. Eng., 149, p113-132.. 


\section{MANUAL DE UTILIZAÇÃO DO CÓDIGO COMPUTACIONAL}

Neste documento descreve-se, de maneira resumida e objetiva, a utilização do programa desenvolvido na dissertação intitulada "Análise não-linear de pórticos planos de concreto armado, considerando os efeitos do cisalhamento no cálculo de esforços e deslocamentos".

No trabalho foi desenvolvido um programa que realiza análise estática não-linear de estruturas aporticadas planas, utilizando o elemento de viga de Timoshenko para representar os efeitos da distorção, o modelo de dano escalar de Mazars para a simular a não-linearidade física do concreto e a descrição lagrangiana atualizada para a formular a análise não-linear geométrica.

No manual são apresentadas as características do programa, bem como a descrição de cada dado nos arquivos de entrada e um arquivo exemplo.

Programa - PORTNL.FOR

\section{Programa de pórtico plano - análise estática}

\section{Resumo}

Este programa, desenvolvido para micro-computadores e em linguagem FORTRAN, tem por objetivo realizar análises não-lineares estática em pórticos planas em concreto armadas. Para consideração das não-lineraridades física e geométrica utiliza-se o Princípio dos Trabalhos Virtuais nas descrições lagrangianas atualizada do equilíbrio com base no Método dos Elementos Finitos. Neste caso, empregam-se a medida de deformação de Green e a tensão de Piola-Kirchhoff de $2^{\underline{a}}$ espécie. 
A resposta não-linear física do concreto é modelada adotando-se o modelo de dano de Mazars. As discussões teóricas relativas à não-linearidade geométrica e física estão apresentadas nos capítulos 3 e 4 da dissertação, respectivamente. Utiliza-se o conceito de matriz de rigidez tangente, empregando-se a matriz aproximada, e o procedimento incremental iterativo de Newton-Raphson para obtenção da solução numérica, empregandose a carga ou o deslocamento como parâmetro controlador. Utiliza-se na integração das tensões ao longo da altura da seção transversal as quadraturas de Gauss e de Gauss-Lobatto. Nas integrações ao longo do comprimento emprega-se, também, quadraturas de Gauss e de Gauss-Lobatto. Tanto no comprimento quanto na altura pode-se utilizar um número qualquer de pontos; porém, para garantir a qualidade da resposta numérica recomenda-se um número superior a 6 no comprimento e 10 na altura. O programa permite fazer análise de cada umas da não-linearidades, separadamente ou combinadas.

Para modelar o comportamento elastoplástico, encruamento misto, da armadura utiliza-se um modelo uniaxial que apresenta um diagrama tensão-deformação bi-linear, com inclinação qualquer para o segundo trecho.

A entrada de dados é via arquivo texto com ou sem extensão. A saída dos resultados é via arquivo cujo nome deve estar contido no arquivo de entrada de dados. O programa faz alocação dinâmica, sem restrição sobre número de nós e de elementos. A matriz de rigidez da estrutura é armazenada em sua totalidade.

\section{Sistema de referência}

O sistema de referência adotado é o cartesiano.

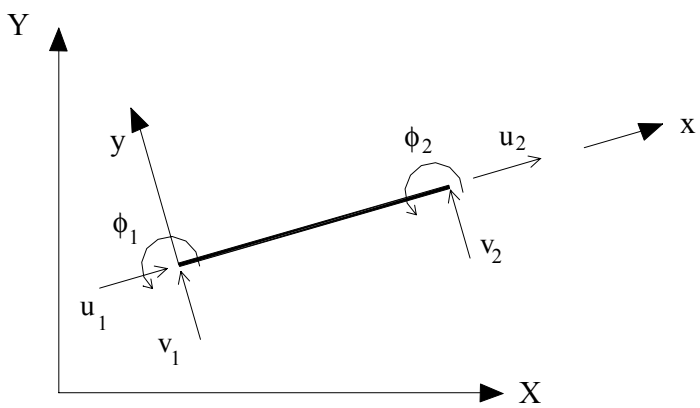

Figura (A.01): Elemento finito de pórtico plano - sistema global e local 


\section{Entrada de dados - análise estática}

info (códigos para NLG, carregamentos e método de integração) $\operatorname{cod} 1, \operatorname{cod} 3, \operatorname{cod} 4, \operatorname{cod} 5, \operatorname{cod} 6, \operatorname{cod} 7, \operatorname{cod} 8$ $\operatorname{cod} 1=1-p /$ forças aplicadas; $\operatorname{cod} 1=2-p /$ deslocamento prescrito cod3 (tipo de integração ao longo da altura), cod3=1 - Gauss; cod3=2 - Gauss-Lobatto $\operatorname{cod} 4=1-p /$ fatores incrementais iguais; $\operatorname{cod} 4=2-p /$ fatores incrementais diferentes $\operatorname{cod} 5=1-s / N L G ; \operatorname{cod} 5=2 \mathrm{c} / \mathrm{NLG}$ cod6=1 - elemento de Timoshenko; cod6=2 - elemento de Bernoulli cod7 = código para o tipo de diagrama tensão/def. para o aço linear (= 1 "linear"; = 2 "bilinear")

cod8 (tipo de integração ao longo do comprimento), cod8=1 - Gauss; cod8=2 - GaussLobatto

info (dados de convergência)

\section{npascar, nitmax}

npascar = número de incrementos; nitmax = número máximo de iterações permitido em cada incremento.

\section{errforcmax, errdeslmax}

errforcmax, errdeslmax = normas para verificação do erro em forças, deslocamento, respectivamente.

info (número de pontos de Gauss ou Gauss-Lobatto no comprimento, número de pontos de Gauss ou Gauss-Lobatto na altura).

ngausl, ngaush

info (dados sobre os nós)

n

$n=$ número de nós

info (número do nó e coordenadas $x$ e y)

no, $\mathbf{x}(\mathbf{n o}), \mathbf{y}($ no)

info (propriedades dos materiais- módulos de elasticidade e coef. Poisson do concreto)

Ec, Gt, poisson

info (módulo de elasticidade, tensão de escoamento do aço, módulo elastoplástico tangente e razão entre o módulo plástico e o módulo de encruamento cinemático; se rhk=0 => encruamento cinemático)

\section{Es, Sy, Et, rhk}

ne

ne = número de elementos

info (número do elemento, seção, armaduras (área e distância ao $C G$ da seção), incidências)

i, bs(i), hs(i), as1(i), ycg1(i), as2(i), ycg2(i), as3(i), ycg3(i), noj(i), nok(i)

info (dados da vinculação: número de nós vinculados, número do nó, vinculação em $x$, y e z) nvinc

no, vinc( $3 *$ no- 2$)$, vinc( $3 *$ no-1), $\operatorname{vinc}(3 *$ no $)$

info (Se a opção for de deslocamento prescrito: número de nós, número do nó, deslocamentos em $x, y$ e $z$ )

nd

no, desl(3*no- $), \operatorname{desl}(3 *$ no- 1$), \operatorname{desl}(3 *$ no $)$ 
info (se a opção for de carregamento: número de nós carregados, número do nó, carga em $x, y \in z)$

nf

no, $f(3 *$ no- 2$), f(3 *$ no- 1$), f(3 *$ no $)$

info (se a opção for de incrementos diferentes: valores de cada incremento)

lamb1(i), lamb2(i), lamb3(i)

info (carregamento fixo: número de nós carregados, número do nó, valor da carga em x, y e z) ncfix

no, $\operatorname{cfix}(3 *$ no- $), \operatorname{cfix}(3 *$ no-1), $\operatorname{cfix}(3 *$ no $)$

info (dados do dano - (parâmetros): $\operatorname{cod} 2=1$ (Mazars), $\operatorname{cod} 2=2$ (Sem dano))

$\operatorname{cod} 2$

Se $\operatorname{cod} 2=1$

edor, at, bt, ac, bc

info (nome dos arquivo de saída)

nomearqsai

nomearqin

\section{Exemplo - viga bi-apoiada}

A estrutura abaixo corresponde ao exemplo 4 mostrado no capítulo 6 da dissertação.
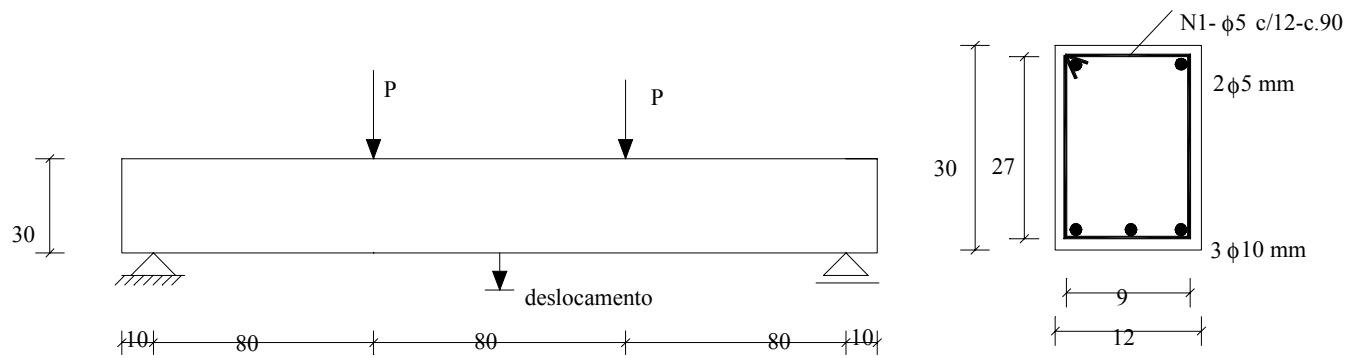

Figura (A.02): Viga bi-apoiada (dimensões em cm)

Análise estática considerando-se apenas o modelo de dano de Mazars, 6 pontos de Gauss para integração ao longo do comprimento, 20 pontos de Gauss para integração das tensões na altura, forças $\mathrm{P}=40 \mathrm{kN}$ aplicadas em 20 incrementos iguais, diagrama tensão deformação bi-linear para o aço e elemento de Bernoulli. 
Entrada de dados - análise estática

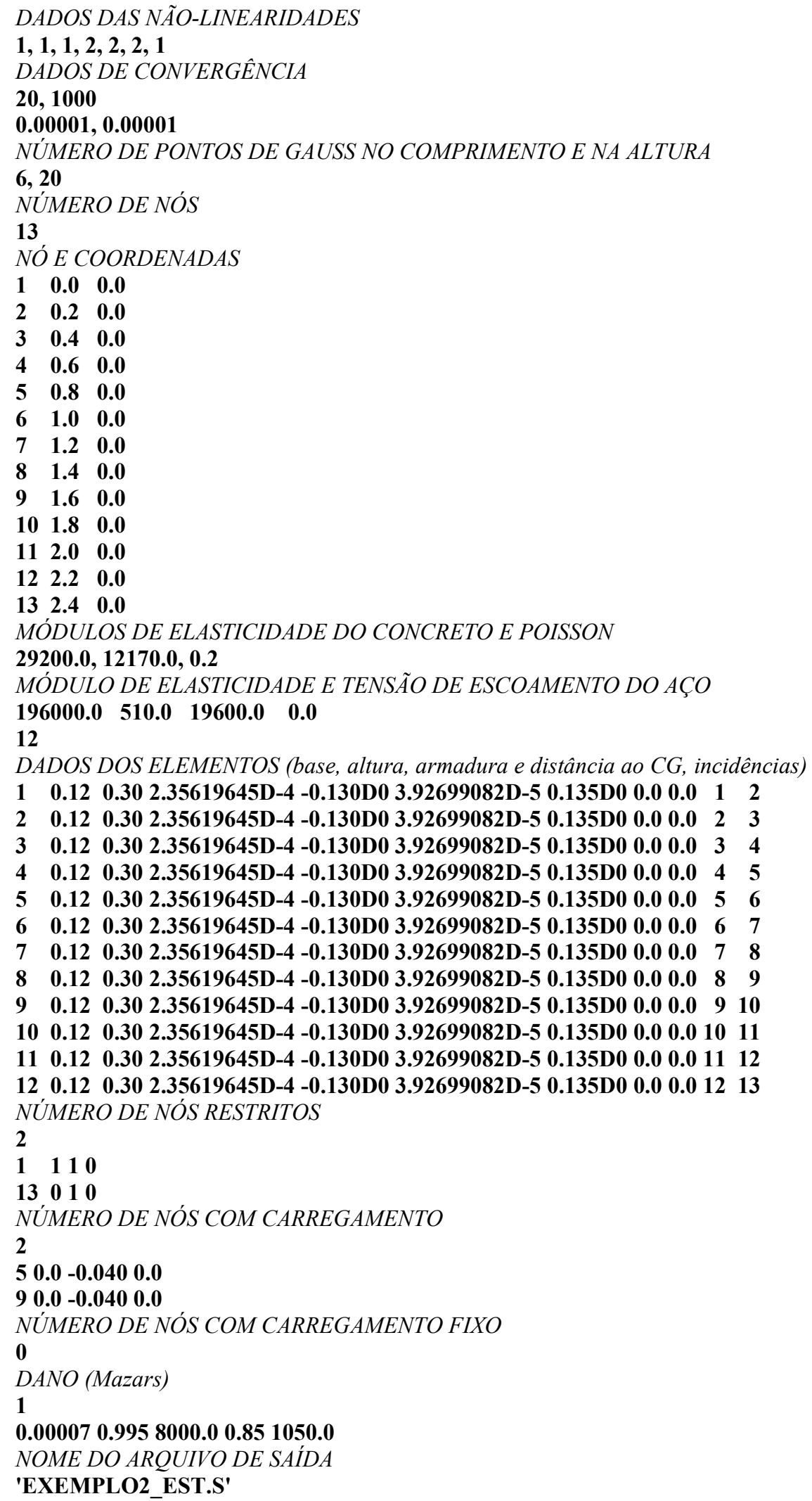


Fluxograma geral-procedimento incremental iterativo de Newton-Raphson

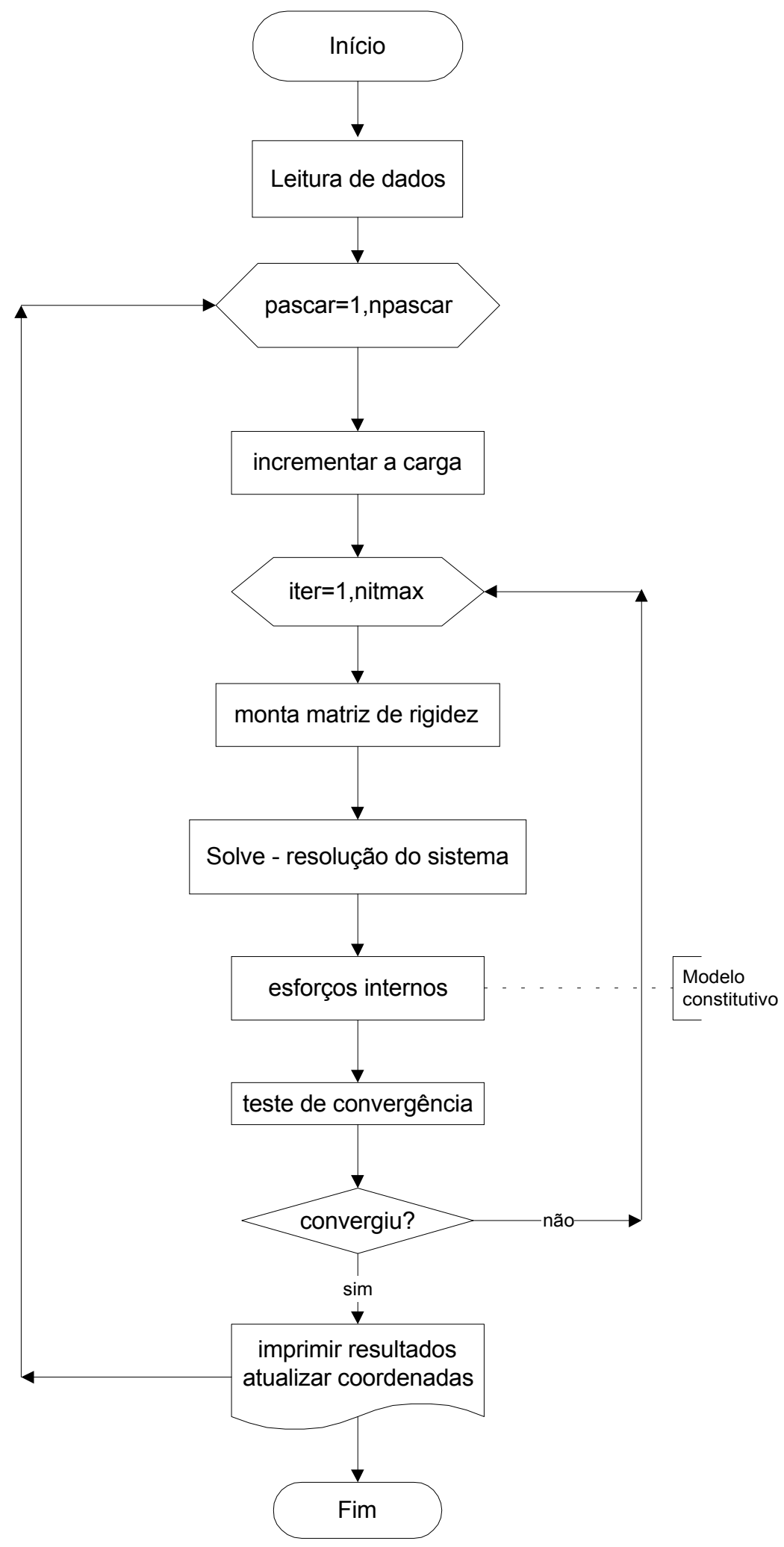

Figura (A.03): Fluxograma do método de Newthon-Raphson - adaptada de PAULA (2001) 